\title{
LA EDUCACIÓN EN DERECHOS HUMANOS DESDE LA PERSPECTIVA DE LA EDUCACIÓN EMOCIONAL PARA LOS PROFESORES DE LA BÁSICA PRIMARIA DEL COLEGIO LICEO NACIONAL ANTONIA SANTOS I.E.D.:
}

Un Estudio de Caso en el fortalecimiento de la Práctica Pedagógica

MARGARETH LUCÍA LÓPEZ ESCANDÓN

UNIVERSIDAD SANTO TOMÁS

FACULTAD DE DERECHO

BOGOTÁ, COLOMBIA

2018 


\section{LA EDUCACIÓN EN DERECHOS HUMANOS DESDE LA PERSPECTIVA DE LA EDUCACIÓN EMOCIONAL PARA LOS PROFESORES DE LA BÁSICA PRIMARIA DEL COLEGIO LICEO NACIONAL ANTONIA SANTOS I.E.D.:}

Un Estudio de Caso en el fortalecimiento de la Práctica Pedagógica

\section{MARGARETH LUCÍA LÓPEZ ESCANDÓN}

Tesis presentada como requisito parcial para optar al título de:

Magister en defensa de los derechos humanos y el Derecho Internacional Humanitario ante Organismos, Tribunales y Cortes Internacionales.

\section{DIRECTORA}

Dra. Elsa Bonilla Piratova

Línea de Investigación en Educación

UNIVERSIDAD SANTO TOMÁS

FACULTAD DE DERECHO

BOGOTÁ, COLOMBIA 


\section{CONTENIDO}

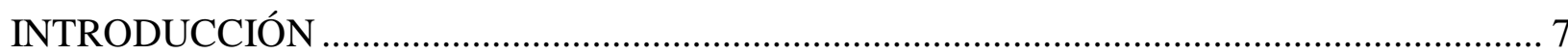

Los derechos humanos en la Básica Primaria del colegio Liceo Nacional Antonia Santos I.E.D.:

una realidad que busca un soporte emocional................................................................. 16

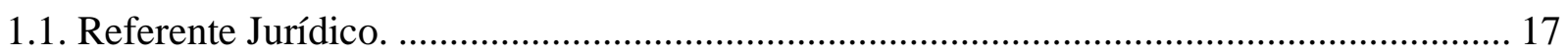

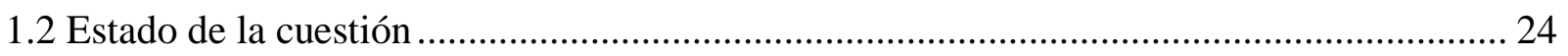

1.2.1 Educación en Derechos Humanos ........................................................................... 25

1.2.2 Educación a través de las Emociones .................................................................... 39

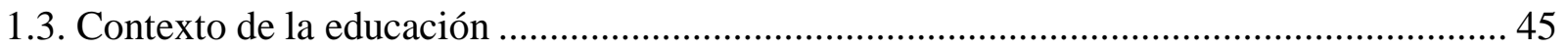

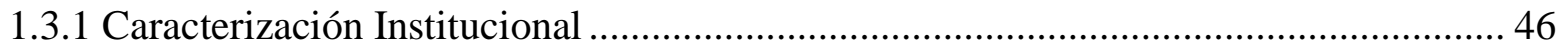

1.3.2. Caracterización y análisis de la población objeto de estudio. ................................. 49

Debates y tensiones entre la educación en derechos humanos y su relación con la pedagogía de

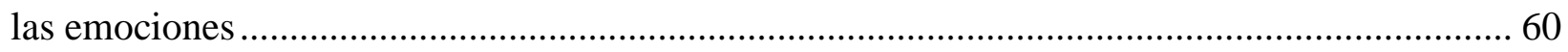

2.1 La fundamentación filosófica de los derechos humanos, una urgencia en medio de las

problemáticas sociales del mundo contemporáneo. ........................................................ 61

2.2 El debate de los derechos humanos y la educación en derechos humanos: una nueva forma

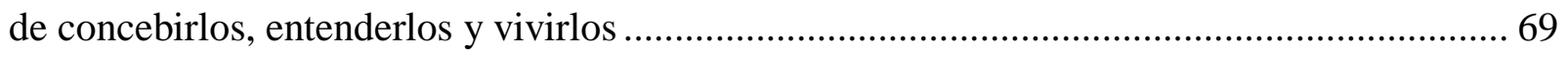

2.3 La educación emocional y su relación con la educación en derechos humanos: un vínculo

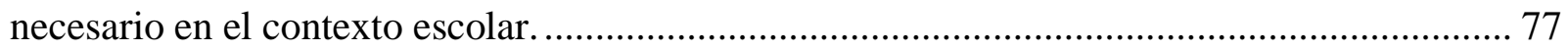

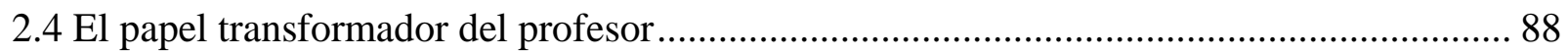


Propuesta pedagógica para los profesores del colegio Liceo Nacional Antonia Santos de Bogotá (sede B) 92

3.1 Anotaciones básicas sobre el modelo pedagógico propuesto......................................... 93

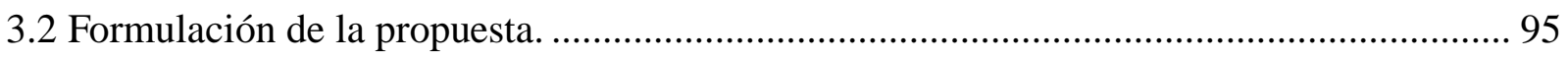

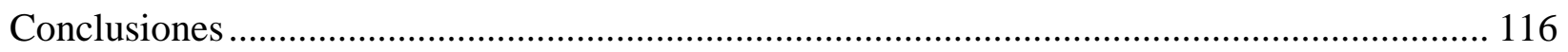

Referencias Bibliográficas ............................................................................................ 119

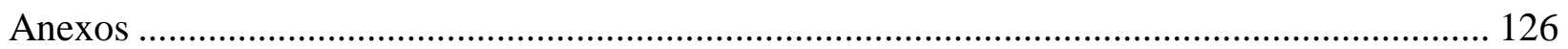

Anexo No. 1. Encuesta a los profesores de Básica Primaria del colegio Antonia Santos I.E.D. 126

Anexo No. 2. Proyecto Educativo Institucional del colegio Liceo Antonia Santos. 127 


\section{LISTA DE GRÁFICOS}

Gráfico 1. Porcentaje de participación de la Población en Edad Escolar (PEE) del Colegio Liceo Nacional Antonia Santos (5-16 años) en la localidad de los Mártires años

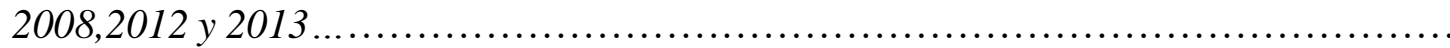

Gráfico 2. Importancia de la Educación en Derechos Humanos (EDH) en el contexto escolar

Gráfico 3. Significado que tiene para el maestro en su labor diaria contar con herramientas pedagógicas adecuadas para una Educación en Derechos Humanos........

Gráfico 4. Relevancia que tiene para los profesores del colegio Antonia Santos I.E.D. el fortalecimiento de una Educación en Derechos Humanos dentro del aula de clase .........

Gráfico 5. Importancia que tiene el que las prácticas pedagógicas de los profesores se encuentren basadas en una educación en derechos humanos con la finalidad de transformar significativamente la vida de sus estudiantes

Gráfico 6. Importancia que le adjudican los a involucrar las emociones dentro de la enseñanza de la Educación en Derechos Humanos al interior del aula de clase....

Gráfico 7. Pertinencia de vincular en el trabajo pedagógico del profesor la educación de los derechos humanos fundamentado en la educación emocional

Gráfico 8. Importancia del profesor en la transformación social de sus estudiantes.......

Gráfico 9. Pertinencia de poner en práctica una apuesta metodológica en la que se vincule la Educación en Derechos Humanos fundamentada en la Educación emocional dentro del aula de clase por parte de los profesores de primaria 


\section{LISTA DE TABLAS}

Tabla 1. Generalidades sobre la propuesta que vincula la enseñanza de la EDH y la educación emocional en la básica primaria del Liceo Antonia Santos.

Tabla 2. Distribución de las semanas de desarrollo institucional.

Tabla 3. Objetivos de la propuesta pedagógica para los profesores del Liceo Antonia Santos

Tabla 4. Plan estratégico de la propuesta pedagógica para los profesores del Liceo Antonia Santos

Tabla 5. Actividad 1. Me coloco en los zapatos del estudiante.

Tabla 6. Actividad 2. Carácter transformador del profesor en la educación emocional...

Tabla 7. Actividad 3. Un profesor asertivo que vincula la educación emocional

Tabla 8. Actividad 4. Una foto de dónde estoy, me dirá ;cómo estoy!

Tabla 9. Actividad 5. Aprendiendo derechos humanos a través de una feria de juegos tradicionales.

Tabla 10. Actividad 6. Coloquio del Antonia Santos: experiencias exitosas en EDH.......

\section{LISTA DE IMÁGENES}

Imagen 1. Ubicación del Colegio Liceo Nacional Antonia Santos sede B 


\section{INTRODUCCIÓN}

El sistema educativo colombiano en los últimos años ha mostrado una gran preocupación por adelantar políticas públicas tendientes a promover procesos de calidad académica en todas las instituciones del país, para ello, el Estado ha destinado una cantidad considerable de recursos públicos con la intención de generar dicha calidad a partir de la creación de colegios con grandes infraestructuras modernas, rutas escolares, aulas especializadas dotadas con herramientas tecnológicas adecuadas y actualizadas, comedores escolares y, para aquellas instituciones en donde aún funcionan dos jornadas, refrigerios balanceados y supervisados por las entidades de control y vigilancia y por el ojo fiscalizador de la comunidad educativa. En términos generales estas son pues, algunas de las muestras, que intentan brindar cambios significativos dentro de la estructura educativa del país a fin de cumplir con el propósito de posicionarse dentro de los mejores sistemas educativos en América Latina.

En efecto, todo este proceso modernizador con relación al aumento de la calidad educativa no termina en las mejoras visibilizadas en la infraestructura de los colegios del país, ya que dada la integralidad que representa tal fenómeno las mejoras también deben involucrar, naturalmente, a los profesores. Hablando propiamente sobre la ciudad de Bogotá, la Secretaria Distrital de Educación (SED) reconoce que la calidad educativa mejora considerablemente si los profesores continúan con sus estudios de posgrado (especialización y/o maestría) y promueven en el aula proyectos tendientes a mejorar los procesos de enseñanza y aprendizaje con los estudiantes. Es bajo esta premisa que la SED, -y en cumplimiento con la Política de formación de excelencia a los profesores y directivos docentes del sector oficial de Bogotá-, inició convenios con varias Universidades acreditadas con alta calidad para que sus profesores y directivos docentes continúen su formación académica con el propósito de apoyarlos en la profundización 
de sus estudios disciplinares y pedagógicos en aras de la mejoría en su desempeño profesional a partir de la realización de trabajos de innovación e investigación educativa que impacten los contextos específicos donde se desarrollen sus experiencias.

Es bajo el marco de estas circunstancias que se presenta esta investigación, pues como tal aquí se intenta responder a esta visión de la SED a partir de la creación de una estrategia de intervención pedagógica que impacte los escenarios educativos de la ciudad por parte de una docente del distrito comprometida con el acrecentamiento de la calidad educativa en Colombia, ya que como es bien sabido la función de los docentes es reflexionar permanentemente e innovar las prácticas desarrolladas no sólo en la escuela, sino también en las distintas sociedades. En este punto, vale la pena aclarar ante el lector las características de la mencionada propuesta pedagógica, para tales efectos dejaremos en claro que nuestro interés interpretativo se basa en dos elementos, el primero es conocido como Educación en Derechos Humanos (EDH), una práctica pedagógica concebida como un derecho fundamental y constituida el soporte de la transformación social, pues es de conocimiento general que la EDH debe estar presente en todo proceso educativo, sin interesar el nivel escolar, el área de desempeño o el perfil institucional.

Sobre esta, es importante resaltar que como herramienta de transformación social debe ir más allá de una enseñanza catedrática y a-crítica pues perdería el sentido, la eficacia y la pertinencia con la cual se ha planeado tanto por las políticas públicas nacionales, como por los instrumentos normativos internacionales que han desarrollado sus principios constitutivos. De esta manera, resulta importante e impactante que a la EDH se le agregue un componente adicional relacionado con la forma de socializarla ante los estudiantes, componente que debería ser caracterizado por el uso de las emociones pues desde nuestra perspectiva esto se constituye como un elemento innovador y enriquecedor en las dinámicas de los profesores en el aula, de ahí 
que sea la pedagogía de las emociones, nuestro segundo elemento a tener en cuenta. A saber, esta pedagogía ha sido una de las propuestas en el campo educativo más recomendada por expertos e investigadores en los últimos años, ya que a través de estudios y propuestas de intervención se ha reconocido que el involucrar las emociones, los sentimientos, los afectos y en general, todo un componte humano y psico afectivo contribuye a la promoción e impulso del aprendizaje en los estudiantes.

De esta manera, el principal objetivo de esta investigación es plantear una propuesta pedagógica de educación en derechos humanos fundamentada en la educación emocional que tenga en cuenta la realidad de los profesores inmersos en el contexto que provee nuestro estudio de caso, la Básica Primaria del Colegio Liceo Nacional Antonia Santos I.E.D de la ciudad de Bogotá. Nuestro interés en la realización de este ejercicio es contribuir al fortalecimiento de una verdadera calidad educativa que satisfaga los intereses de los niños y las niñas, que permita la aplicación de estrategias innovadoras en los profesores y que, en últimas, cumpla con las políticas públicas propuestas por las entidades educativas a nivel distrital y nacional.

Así las cosas, el problema de investigación parte de evidenciar que los profesores de Básica Primaria del colegio Liceo Nacional Antonia Santos no cuentan con estrategias asertivas para vincular la EDH y la educación emocional, situación que se asume como preocupante ya que la presencia de estas se considera como un requisito fundamental no sólo dentro de las necesidades institucionales sino también dentro de los mandatos explícitos de las políticas públicas nacionales e instrumentos normativos internacionales. En este sentido, es importante aclarar que la falta de estrategias para llevar a cabo la mencionada vinculación no sólo preocupa en términos de aquellas formalidades, sino que su inexistencia afecta de manera considerable a aquella población escolar que, posee problemas de agresividad, sufren por la falta de 
compromiso de sus padres en el proceso educativo y, además, se enfrentan a las penurias de un contexto cargado de violencia, por lo que la afectividad, las emociones y el juego resultan ser los mejores aliados.

Ciertamente, es aquí en donde nos interesa hacer hincapié pues las condiciones sociales, económicas y culturales que caracterizan a los estudiantes del colegio demandan un tratamiento especial y afectuoso por parte de sus docentes, pues son ellos con quienes comparten la mayor parte de su día. Es por ello que el interés de esta investigación se centra no sólo en resaltar la importancia que tiene la ejecución de buenas prácticas pedagógicas relacionadas con los principios constituyentes de la Educación en Derechos Humanos (por ser, en esencia, uno de los métodos más eficaces en la transformación de las realidades sociales) sino también en el cómo relacionar a las mismas con la pedagogía de las emociones, elemento a tener en cuenta en tanto se reconoce que el contexto educativo se conforma de personas cargadas con sentimientos que, en teoría, luchan día a día por influir en la construcción de espacios más democráticos, participativos e incluyentes, tal cual es dilucidado por los principios del proyecto educativo institucional (PEI) del colegio Liceo Nacional Antonia Santos (ANEXO 1), por lo que nuestro interés sea entonces proponer una herramienta que contribuya con la preocupación expuesta.

La pregunta de investigación se centra en dilucidar ¿Cómo vincular la educación en derechos humanos fundamentada en la Educación Emocional en el contexto educativo de la Básica Primaria del Colegio Liceo Nacional Antonia Santos I.E.D. de la ciudad de Bogotá?

Para ello, podríamos adelantarnos en el planteamiento de una hipótesis en los siguientes términos: "para vincular la educación en derechos humanos fundamentada en la Educación Emocional en el contexto educativo de la Básica Primaria del Colegio Liceo Nacional Antonia Santos I.E.D. es necesario plantear una Propuesta pedagógica. 
Teniendo en cuenta el problema de investigación, las preguntas y los objetivos que guían este ejercicio, la apuesta metodológica que caracteriza a esta disertación se construyó a partir de la investigación cualitativa, específicamente dentro del ámbito etnográfico. Desde esta perspectiva, se asume que un trabajo de esta naturaleza debe estar marcado no sólo por una visión crítica que permita el análisis de la realidad a partir del estudio de categorías como la educación en derechos humanos y la pedagogía de las emociones, sino también por la tenencia en cuenta de las sensaciones y los sentimientos de todos aquellos que pertenecen a la comunidad educativa objeto de estudio. En este orden de ideas, se aclara ante el lector que el desarrollo de la problemática antes expuesta implica entender al contexto educativo como un referente sociológico en tanto se interioriza la necesidad de hacer un proceso de intervención en las prácticas pedagógicas, cuestión que debe responder paralelamente a las condiciones sociales, familiares, culturales, políticas, educativas y económicas que afectan los procesos de enseñanza - aprendizaje no sólo de esta institución, sino de otras a nivel Bogotá.

Cabe señalar que el paradigma, construido a través de la postura crítica de los fenómenos sociales y del estudio sociológico, busca la transformación de prácticas que afectan la realidad. Para el caso de la educación, esa afectación se hace directamente al sistema educativo, por lo que en la aplicación del método cualitativo con un enfoque etnográfico al estudio de caso que representan los profesores de Básica Primaria del Colegio Liceo Nacional Antonia Santos I.E.D. se plantean las siguientes categorías de análisis:

- La educación en derechos humanos EDH)

- La educación basada en las emociones

- El contexto de la educación. 
Con base a lo anterior, se propone como principal técnica de recolección de datos una observación (no) participante de la realidad en el colegio Liceo Nacional Antonia Santos que permita reconocer y caracterizar las prácticas desarrolladas por los profesores con el objetivo de identificar sus falencias a fin de responder a las necesidades socio-culturales de la comunidad educativa para impulsar cambios a nivel local $\mathrm{y}$, en últimas, constituirse como un modelo digno de imitar. Para la realización de tal propósito también se utilizan otros instrumentos anexos como el trabajo de campo y el análisis documental, elementos que contribuyen al establecimiento de determinados criterios que dan forma a los debates y posteriores reflexiones sobre el papel de la Educación de los Derechos Humanos, práctica pedagógica vista desde este ejercicio a través de las emociones.

Así mismo, vale la pena aclarar que la metodología aquí planteada permite una lectura flexible e integral del fenómeno a investigar, pues a consideración se intenta realizar una revisión lo más profunda posible con relación a las vivencias y expectativas de los profesores del colegio, cuestión que implica tanto la recopilación de datos y el estudio de los mismos, como cierto cuidado y tratamiento técnico del lenguaje a la forma de estructurar una propuesta pedagógica de esta naturaleza.

Dicho lo anterior, resulta pertinente determinar la razón que justifica la presente investigación, para lo cual es preciso recordar que la Educación en Derechos Humanos ha sido un componente fundamental en el proceso formativo de los estudiantes de las instituciones educativas latinoamericanas, especialmente a partir de la década de los 80 (Magendzo, 2008) como consecuencia de las reflexiones en torno a las vulneraciones y violaciones de DDHH ocurridos tanto en el periodo de entreguerras, como en las décadas siguientes producto de las dictaduras en el continente. Este es un hecho histórico que en su momento obligó a los Estados a 
hablar sobre la implementación de esta práctica pedagógica dentro de cada uno de los sistemas educativos nacionales; adicional a ello, los instrumentos nacionales e internacionales de protección de derechos le han encomendado a los Estados el cabal cumplimiento de todos aquellos derechos que se encuentran contenidos en los instrumentos de orden universal y regional, entre ellos, el derecho a la educación, pero no una educación cualquiera, sino una educación de calidad.

Es así que existe, en términos nacionales, el imperativo constitucional y legal del derecho a la educación. Sobre ésta se sabe que una de sus características primordiales es que debe estar direccionada hacia el fomento, la garantía y el respeto de todos los derechos consagrados en las normativas internacionales a fin de construir una sociedad armónica y democrática en donde todos aceptemos las diferencias y, por tanto, podamos vivir en igualdad de condiciones sociales. Pero, puntualmente, la estructura jurídica colombiana exige la enseñanza y reproducción de una Educación en Derechos Humanos que no sólo alivie sino que prevenga el dolor que han generado para la humanidad las difíciles circunstancias de la guerra y, sobre todo, los conflictos en la vida cotidiana, especialmente en un país como este en donde la guerra interna ha sido el contexto que ha caracterizado el desarrollo de aproximadamente los últimos sesenta años.

Lo anterior es en términos legales y teóricos, pues lamentablemente en la práctica aún existe un desconocimiento generalizado por parte de algunas instituciones, directivos y profesores sobre la importancia que tiene el desarrollo de la Educación en Derechos Humanos dentro de las aulas de clase, por ello se hace necesario que, en las prácticas pedagógicas, específicamente de los docentes, se incluyan estrategias que fortalezcan a esta herramienta de transformación social. De otro lado, entendemos que la Educación en Derechos Humanos es una categoría axiológica y filosófica que no puede tener sentido si los estudiantes no la vivencian e 
interiorizan, es decir, si no la sienten, por lo que se debe tener en cuenta la necesidad de crear una estrategia eficaz y pertinente de práctica basada en las emociones, entre otras razones porque ha sido un elemento reconocido y recomendado por expertos investigadores y académicos como consecuencia de su favorable impacto dentro de la vida de los niños, niñas y adolescentes.

De ahí la necesidad de plantear una propuesta pedagógica de Educación en Derechos Humanos fundamentada en las emociones y dirigida a los profesores de Básica Primaria del Colegio Liceo Nacional Antonia Santos I.E.D. de la ciudad de Bogotá, pues el objetivo está brindar herramientas que conlleven al empoderamiento de sujetos que no sólo son estudiantes, sino que también ciudadanos que deben actuar bajo el manto de los DDHH. En este sentido se considera insuficiente que ellos sólo aprendan de memoria la lista de los derechos, pues de lo que se trata es de hacer que ellos interioricen la carga histórica y axiológica que estos tienen. Dicho lo anterior, no nos queda más sino resaltar que la propuesta pedagógica que se plantea en esta tesis responde a las necesidades evidenciadas en las aulas del colegio objeto de investigación y contiene los elementos emocionales considerados como claves para una EDH con calidad y pertinencia.

Así pues, para cumplir con el objetivo planteado en esta investigación se ha estructurado cuatro capítulos con los cuales se busca abordar de manera reflexiva, crítica y propositiva el proceso que implica tanto el reconocimiento de las condiciones en las que se desarrollan las vivencias de los estudiantes del Liceo Nacional Antonia Santos en el escenario propuesto por la EDH, como el análisis del papel que tienen los profesores en la creación de las mismas.

Hablemos entonces con un poco más de precisión al respecto. El primer capítulo se denomina Los derechos humanos en la Básica Primaria del colegio Liceo Nacional Antonia Santos I.E.D.: una realidad que busca un soporte emocional, allí se reflexiona sobre la situación 
actual de los derechos humanos (DDHH) en esta institución educativa, proceso en el que se logra demostrar que existen ciertas discrepancias entre su enseñanza y puesta en práctica como consecuencia el paradigma bajo el cual se reproduce, ya que desde la perspectiva que en el colegio se maneja la EDH se concibe como un conjunto de postulados de obligatorio cumplimiento que, por encontrarse dentro de las políticas públicas colombianas, tienden a ser reducidas a un mero tema curricular, cuestión que no problematiza los métodos de calificación dentro de los colegios por ser parte de aquel modelo estandarizado de evaluación que sólo está interesado en medir las competencias en áreas como el lenguaje y las matemáticas - y que deja de lado todo el componente humano, cultural y social que también hace parte de los procesos de enseñanza - aprendizaje en el ámbito educativo recreado por la escuela- y, a su vez, niega todo el componente emocional demandado por los niños.

Por su parte, el segundo capítulo es titulado debates y tensiones entre la educación en derechos humanos y su relación con la educación emocional, allí nuestro interés se centra en no sólo en plantear una discusión teórica con respecto a la naturaleza de nuestras dos principales categorías analíticas, sino también en visibilizar su conexión y posteriormente el papel transformador del docente.

El tercer capítulo, titulado Propuesta pedagógica para los profesores de primaria del Colegio Liceo Nacional Antonia Santos de Bogotá se propone a través de diferentes estrategias una educación en derechos humanos a través de las emociones. Igualmente, se plantea una metodología cualitativa con un enfoque crítico, que permite la lectura, el análisis de la realidad escolar de los niños en básica primaria en la relación con la EDH. En el último capítulo se recogen las conclusiones y recomendaciones finales, con las cuales se invita a implementar la propuesta en otras instituciones de la ciudad y del país. 


\section{Los derechos humanos en la Básica Primaria del colegio Liceo Nacional Antonia Santos I.E.D.: una realidad que busca un soporte emocional}

"Los derechos no son algo que exista ya dado en la naturaleza y que nosotros nos limitemos a descubrir, como los cromosomas o los continentes. Los derechos los creamos nosotros mediante nuestras convenciones. Así que la pregunta relevante no es '¿qué derechos tiene tal criatura?', sino '¿qué derechos queremos que tenga?'."

Jesús Mosterín

"Educar la mente sin educar el corazón, no es educar en absoluto"

Aristóteles

Inicialmente diremos que el propósito de este capítulo es identificar las condiciones bajo las cuales se encuentra la EDH dentro de la institución que se ha constituido en nuestro objeto de estudio, el colegio Liceo Nacional Antonia Santos I.E.D. en la ciudad de Bogotá. Para ello demostraremos que si bien existe un marco legal que fundamenta la mencionada práctica pedagógica dentro de las distintas instituciones educativas, en la realidad su impacto transformador es realmente limitado pues no responde a las diversas necesidades que expresan todos los miembros de la comunidad educativa (estudiantes, profesores, directivos, padres de familia). Además, en este apartado ha de ser resaltado el desinterés dentro del aula por impulsar, promover y empoderar un proceso formativo en los estudiantes basado en la inteligencia emocional cuestión que se constituye en el núcleo de nuestra problemática, así pues, se destacará no sólo la descripción del problema de investigación con sus objetivos y justificación, sino que también se identificará el referente jurídico y el estado de la cuestión que jerarquiza la importancia de una investigación en este tema. 


\subsection{Referente Jurídico.}

En este punto nos interesa hacer un breve recorrido con respecto al desarrollo de aquellas normas de carácter nacional e internacional que soportan y justifican la existencia y reproducción de aquella práctica pedagógica conocida como EDH, por lo que hemos de hacer una precisión inicial con relación a los principales debates en el escenario internacional, fenómeno en donde intervienen entidades como la Organización de las Naciones Unidas para la Educación, la Ciencia y la Cultura (UNESCO) a través del planteamiento, estructuración y formulación de instrumentos como el Pacto Internacional de los Derechos Económicos, Sociales y Culturales (DESC) (adoptado por la Asamblea General de las Naciones Unidas hacia diciembre de 1966 y entrado en vigor en enero del año de 1967) y el Plan Mundial de Educación en Derechos Humanos (proclamado en diciembre del año 2004 por la Asamblea General de las Naciones Unidas y puesto en marcha desde el año 2005 con caducidad para el año 2019, un proyecto que toma como base los logros que fueron alcanzados por su plan predecesor: el Decenio de las Naciones Unidas para la educación en la esfera de los derechos humanos ejecutado entre los años 1995 y 2004). En estos y otros instrumentos normativos, es de nuestro interés visibilizar como la EDH se ha consolidado no sólo como una responsabilidad el Estado, sino también como un derecho en sí mismo que garantiza la consecución de otros derechos como la mejora en la calidad educativa, el trabajo y la salud.

Sobre el tema, hemos de ser más sistemáticos y resaltar que los informes de la UNESCO (en los que se analizan las continuas y permanentes violaciones de derechos humanos a nivel mundial, pese a la existencia de normas, instrumentos y mecanismos de protección), reconocen que las violaciones a DDHH son un problema primordialmente de educación, de ahí que se sostenga que los debates que se han dado sobre los DDHH como principios pertenecientes a un 
proyecto mundial de comportamiento, necesariamente tienen una relación directa con la EDH y el marco jurídico que lo soporta. Acudimos a la afirmación anterior para entender que la EDH no sólo tiene un soporte legal, sino también histórico, axiológico y sociológico que interactúa con todas las culturas existentes en una gran parte del planeta. En este sentido, existen a nivel nacional e internacional normas que promueven una educación basada en DDHH, precisamente para evitar esa ola de violencia y vejámenes por los que ha atravesado la humanidad a lo largo de su historia, especialmente en el periodo de entreguerras que tantas vidas cobró en el mundo entero.

Ejemplo de lo anterior es la Declaración Universal de los Derechos Humanos (DUDH) creada en el año de 1948, en donde por varias décadas se ha promovido la construcción de espacios educativos basados en la EDH, pues, desde su preámbulo, se invita a todas las naciones del mundo a que realicen los esfuerzos que sean requeridos para que a través de la educación se promuevan los derechos y el respeto por las libertades, de ahí que la EDH sea entendida como una práctica inclusiva y preventiva ante fenómenos como la discriminación y/o la desigualdad, por lo que en su naturaleza pedagógica se debe prestar especial atención a los grupos vulnerables (Parra y Vásquez, 2017). El objetivo de todo aquello ha sido garantizar la consolidación de una práctica educativa basada en el respeto de la dignidad humana, cuya función sea impulsar la promoción de valores sociales que permitan una convivencia armónica a pesar de las diferencias existentes. Para el caso Colombiano, esta situación no es muy diferente pues a través de la firma y ratificación de los distintos pactos a los cuales el gobierno colombiano ha dado su visto bueno se ha intensificado la propagación de una cultura basada en los $\mathrm{DDHH}^{1}$.

\footnotetext{
${ }^{1}$ Para más información sobre los tratados internacionales que han sido firmados y ratificados por Colombia visítese el siguiente link: http://www.hchr.org.co/acnudh/EPU/A_HRC_WG.6_16_COL_1_Colombia_Annex\%20III_S.pdf
} 
Otro ejemplo a citar es el Pacto Internacional de derechos sociales, económicos y culturales, instrumento en donde se exaltan derechos como el trabajo, la salud y la educación. Sobre esta última el pacto contempla, dentro de sus artículos 13 y 14, que el derecho a la educación:

Implica orientar la educación al desarrollo de la personalidad humana, la dignidad y el respeto a los derechos humanos. Reconoce la obligatoriedad de la primaria gratuita; la generalización de la secundaria y la accesibilidad de la enseñanza superior en función de las capacidades, implementando progresivamente su gratuidad; asimismo, contempla continuar la educación de adultos; desarrollar programas de becas, y mejorar las condiciones materiales de los maestros, así como el derecho de 146802 padres y tutores de elegir la educación de sus hijos o pupilos (Comisión Nacional de los Derechos Humanos México, 2012, p. 13 - 14).

La lectura de esta afirmación nos permite entender que las Naciones Unidas han requerido con urgencia la creación de una serie de programas para apoyar a los Estados en su lucha por fortalecer el respeto de los DDHH a través de la educación, de ahí que se justifique la creación de instrumentos como la Convención sobre los Derechos del Niño en 1989, en donde no sólo se modifica la forma de intervención estatal y familiar en el desarrollo de la infancia y adolescencia con relación a sus supervivencia e integridad, sino que también asume la educación como el método fundamental en la promoción de las libertades y a la escuela como "un ámbito de socialización prioritario y (...) por tanto, fundamental para la formación de ciudadanas y ciudadanos” (Fondo de las Naciones Unidas para la Infancia-UNICEF-, 2002, p. 7), y de debates como el llevado a cabo en el Congreso Internacional sobre Educación para los Derechos Humanos y la Democracia en Montreal (Canadá) en el año1993 por la UNESCO y el Centro de 
Derechos Humanos de las Naciones Unidas en donde se aprobó el Plan de Acción Mundial sobre Educación para los Derechos Humanos y la Democracia, proyecto con el cual se impulsa a los Estados a implementar y promover la EDH tanto en el sistema escolar como en contextos externos a dicho sistema, y la Conferencia General de la UNESCO de 1988 en París, espacio donde se creó el Plan de Acción Integrado sobre la Educación para la Paz, los Derechos Humanos y la Democracia básicamente con el mismo fin.

En últimas, todos estos aparatos normativos internacionales que impulsaron la relación naturalizada entre DDHH y educación desembocaron en el surgimiento de proyectos como el Programa Mundial para la Educación en Derechos Humanos de la UNESCO en el año 2005 con fecha de finalización para el año 2019, el cual surgió en el marco de:

La Declaración de la Cuadragésima cuarta Reunión de la Conferencia Internacional de Educación que se realizó en octubre de 1994 y que se ratificó en noviembre de 1995; en esta conferencia los Ministros de Educación de los países miembros se comprometieron a crear una estrategia que fomentara permanentemente el ejercicio de los derechos humanos a través de la educación y con ello se forme a las personas en el respeto de las individualidades y de la dignidad del otro, es así como en 2005 inicia la primera etapa de éste programa de educación en derechos humanos (Parra y Vásquez, 2017, p. 10).

Ahora bien, dejando de lado el recorrido normativo de carácter global centrémonos en aquella estructura jurídica que surge a nivel nacional cuyo fundamento general se encuentra en la Constitución Política a partir de la aceptación e institucionalización de todas las responsabilidades adquiridas internacionalmente con respecto al fortalecimiento de una cultura basada en los DDHH. Siguiendo con las investigaciones de Parra y Vásquez (2017) se considera 
importante rescatar de la carta magna colombiana las generalidades establecidas por los artículos 1, 41, 67 y 93 pues en cada uno de ellos se enfatiza en no sólo en la creación de "un Estado Social de Derecho que funda sus bases en el respeto por la dignidad humana" (p.10), sino también en la educación como un elemento fundamental en el desarrollo del mencionado Estado, ya que se invita tanto a la promoción de la participación ciudadana como a la formación de los mismos a partir de los principios ya divulgados por todos los tratados internacionales sobre DDHH, paz y democracia a través de su inclusión en las directrices del sistema nacional de educación, en ello se explica la naturaleza de la Ley General de Educación, mediante la cual se señalan "las normas generales para regular el Servicio Público de la Educación que cumple una función social acorde con las necesidades e intereses de las personas, de la familia y de la sociedad” (Ley 115 de 1994, artículo 1).

Para ser más específicos en las características de la ley pueden ser citados artículos como el número 5 , en donde "se definen los fines de la educación (...) siendo estos la formación en el respeto a la vida y a los demás derechos humanos, a la paz, a los principios democráticos de convivencia, pluralismo, justicia, solidaridad y equidad” (Parra y Vásquez, 2017, p. 11), el número 13 referido a los objetivos comunes de cada uno de los niveles educativos, para lo cual dispone una orientación general referida a la formación de la personalidad, la ética, la moral y el respeto a los DDHH, la creación de una conciencia educativa hacia el esfuerzo y el trabajo, el respeto por la identidad de los distintos grupos étnicos, entre otros; y el número 104, en donde se hace referencia al educador como "el orientador en los establecimientos educativos, de un proceso de formación, enseñanza y aprendizaje de los educandos, acorde con las expectativas sociales, culturales, éticas y morales de la familia y la sociedad" (Ley 115 de 1994), afirmación que le otorga un papel fundamental en el desarrollo de todo el proceso formativo. 
De igual forma, Parra y Vásquez (2017) también nos invitan a resaltar la existencia del Plan Nacional de Educación en Derechos Humanos -PLANEDH, como una política pública existente en el país desde 2006, en la que han participado diferentes entidades del orden nacional e internacional. A nivel interno la encabeza el Ministerio de Educación Nacional, un equipo del Programa Presidencial de Derechos Humanos y Derecho Internacional Humanitario, el Defensor del Pueblo y, a nivel internacional, cuenta con el acompañamiento de la Oficina del Alto Comisionado para los derechos humanos (OACNUDH) y el programa de derechos humanos de USAID-MSD, combinación con la que se genera un gran soporte al funcionamiento y puesta en escena de la EDH en el país, entre otras cosas, porque brinda las directrices acerca de cómo se debe impartir la educación en derechos humanos en el territorio nacional pues, en últimas, lo que se busca es que la educación se centre en la formación de sujetos que ejerzan de forma activa sus derechos, cuestión que inevitablemente conlleva a la consolidación del Estado Social de Derecho en Colombia (p.12).

Siguiendo con los planteamientos de ambas autoras se reconoce la expedición de la Ley 1620 de 2013, por la cual se crea el sistema nacional de convivencia escolar y formación para el ejercicio de los derechos humanos, la educación para la sexualidad y la prevención y mitigación de la violencia escolar, cuyo objetivo es:

Contribuir a la formación de ciudadanos activos que aporten a la construcción de una sociedad democrática, participativa, pluralista e intercultural, en concordancia con el mandato constitucional y la Ley General de Educación -Ley 115 de 1994- mediante la creación del sistema nacional de convivencia escolar y formación para los derechos humanos, la educación para la sexualidad y la prevención y mitigación de la violencia escolar, que promueva y fortalezca la formación ciudadana y el ejercicio de los derechos 
humanos, sexuales y reproductivos de los estudiantes, de los niveles educativos de preescolar, básica y media y prevenga y mitigue la violencia escolar y el embarazo en la adolescencia (Ley 1620 de 2013, Artículo 1).

Hecho este breve recorrido con relación a la estructura jurídica tanto nacional como internacional no nos queda más sino insistir en que la justificación del extenso desarrollo de la mencionada normatividad tiene que ver con la capacidad que tienen cada una de estas entidades en la creación de las distintas experiencias que los estudiantes vivirán en los establecimientos educativos, pues se le considera como definitivas para el desarrollo de la personalidad de los mismos al ser las responsables de definir sus formas de desarrollar y construir su proyecto de vida. Además, es importante entender este fenómeno en sus dimensiones globales pues no sólo se trata de la formación individual de cada niño y joven en el país, sino el cómo cada una de sus personalidades va a influir en el bienestar y prosperidad colectiva, razón por la cual el gobierno colombiano aún hoy se esfuerza por solidificar los fundamentos normativos educativos tendientes a garantizar el respeto por los DDHH, materializados en la EDH, práctica basada en los dictámenes de las voluntades internacionales sobre todo este tema.

En conclusión, las condiciones legales en torno a la formación de la EDH dentro del contexto nacional e internacional constituyen un referente jurídico que va más allá de un cuerpo jurídico-normativo cristalizado en instrumentos nacionales e internacionales de protección, pues cada uno de ellos invita a los Estados, Organizaciones e Instituciones a promover la paz y la democracia para dar fin a las continuas y permanentes violaciones de los DDHH a través de la educación para, de esta manera, entender a los DDHH como la mejor forma de construir una convivencia armónica en el país. 


\subsection{Estado de la cuestión}

El objetivo de este acápite es evidenciar lo trabajado por expertos y autoridades en el tema de la educación en derechos humanos desde la perspectiva de la educación emocional con el propósito de identificar, desde diferentes posturas conceptuales, el papel del profesor en la formación de los DDHH mediante la educación de las emociones. Para ello, son revisadas algunas tesis de maestría, investigaciones y libros, cuyo contenido se focaliza en el escenario de la educación en derechos humanos a través de las emociones con énfasis en la educación inicial y básica, proceso que posibilita la exploración de ideas provenientes de quienes han abordado las emociones, los sentimientos y la afectividad como una estrategia de formación en el aula. En la lectura de cada uno de ellos se tendrán en cuenta las posturas teóricas que más se consideren acordes con el objetivo de esta investigación y los tipos de metodología que se desarrollan en cada uno de los casos.

Como una salvedad inicial, se hace manifiesta la tendencia a la investigación cualitativa en este tema, sin embargo las diferencias de cada investigación recaen en el enfoque trabajado por cada experiencia y, claro está, los objetivos de las mismas. En mente lo anterior, se presenta una mirada global de los aportes teóricos y conceptuales de los investigadores y la influencia de aspectos sociales, culturales, económicos y jurídicos que han incidido en la clase de enseñanza que se imparte en las instituciones educativas. Para ello, se aborda el estado de la cuestión a partir de dos grandes componentes o subcapítulos, el primero de ellos tiene que ver con el desarrollo conceptual que se le ha dado a la Educación en Derechos Humanos, mientras que el segundo hace referencia al tratamiento ya dado a lo definido como educación emocional, elementos que constituirán las bases fundamentales para la estructuración del tema de investigación en esta oportunidad. 


\subsubsection{Educación en Derechos Humanos}

Como afirmamos anteriormente, en las siguientes páginas serán retomadas algunas investigaciones relacionadas con el estudio de la educación en derechos humanos a nivel global, tal ejercicio se hará desde una visión crítica que permita conceptualizar y analizar ciertos debates que han caracterizado el abordaje de este tema hasta la actualidad. Para tal objetivo, iniciemos este recorrido con los planteamientos del profesor Francisco Antonio Arias Murillo en el marco de su tesis doctoral La emergencia del hombre en la formación de maestros en Colombia: segunda mitad del siglo XX, presentada en el año 2010 ante el Centro de Estudios Avanzados En Niñez y Juventud de la Universidad de Manizales (CINDE), allí el autor tiene como objetivo indagar sobre "las formas hombre que 'aparecen' en los programas de formación de maestros, servidos por la Universidad Santo Tomás” (Arias, 2010, p. 20) desde los 1965 hasta finales del siglo XX, para cumplir con este propósito se vale del método foucaultiano denominado como arqueología, entendido como un instrumento que contribuye a la comprensión de los discursos a partir del estudio de su producción y de las condiciones contextuales bajo las cuales se da la misma.

En términos generales, las preocupaciones analíticas de este autor implican un estudio sobre el carácter situacional del hombre, es decir, de aquellas características externas que forman a la concepción de hombre, o más bien, del profesor, dentro de las instituciones educativas durante un periodo particular de la historia. De esta forma, Arias posibilita un camino hacia el abordaje y discusión conceptual sobre la multidimensionalidad de la pedagogía al mostrar y hacer visibles las características que constituyen la "enseñanza" sobre el hombre, las formas como éstas se hacen presentes, se instalan y se desarrollan en programas de formación de profesores en Colombia, específicamente dentro de la Universidad Santo Tomás. Los aportes 
conceptuales de este autor resultan relevantes para esta investigación en tanto perfila el tipo de profesores que se proyectan desde las universidades públicas y privadas en Colombia, con ello es posible identificar las características específicas de los profesores que se encuentran vinculados con las instituciones educativas del orden estatal o privado y, a partir de ello, reconocer el tipo de estrategias que se llevan a las aulas y sobre todo el tipo de procesos de enseñanza y aprendizaje que se acogen.

Como segundo referente tenemos a Abraham Magendzo, autor del texto Ideas-fuerza y pensamiento de la educación en derechos humanos en Iberoamérica publicado para el año 2008 en el marco dado por la Cátedra para la paz de la UNESCO EDH/UAHC. En palabras del autor se reconoce que la EDH en la región Iberoamericana tiene una historia propia que se remonta a la década de los ochenta del siglo pasado, periodo en el que se considera que han emergido una serie de ideas-fuerza caracterizadas por los cambios políticos, sociales, culturales y económicos de esta región del mundo y que han tenido un impacto considerable en la formulación de esta práctica educativa (Magendzo, 2008). Dichas ideas-fuerza han surgido esencialmente del trabajo en campo realizado por una serie de instituciones y un conjunto de educadores en derechos humanos inspirados especialmente en la vida y obra de Paulo Freire ${ }^{2}$, precursor de la pedagogía crítica y el pensamiento complejo en la educación, una situación que en últimas permite abrir un amplio espectro sobre los retos que se están generando en las sociedades contemporáneas resultado de cada una de las demandas que hoy en día son visibilizadas, muchas de ellas

\footnotetext{
${ }^{2}$ Para aquellas personas que deseen indagar más acerca de la vida de este personaje, se recomienda la lectura del documento escrito por Heinz-Peter Gerhardt en 1993 titulado Paulo Freire $(1921$ - 1997). Texto disponible en el siguiente enlace: http://www.ibe.unesco.org/sites/default/files/freires.pdf
} 
contradictorias y conflictivas consecuencia de las distintas concepciones políticas y éticas que existen en el mundo.

Sobre el tema, cabe señalar que el punto de enaltecer lo que Magendzo denomina como ideas-fuerza está en el hecho de resaltar la presencia de múltiples y diversas corrientes tanto de pensamiento como prácticas que se asocian al tema de la EDH, un fenómeno que claramente es dependiente de las condiciones en las que se encuentren los territorios. Es de esta forma como el texto en mención recoge 11 de las experiencias más representativas en este campo, entre las cuales se encuentran propuestas desde Chile, Colombia, Brasil, Costa Rica, España, México, Perú, Portugal, Puerto Rico, República Dominicana y Uruguay, delimitación que en términos metodológicos no desconoce la existencia de otras experiencias de igual importancia, pero que para este caso no son consideradas funcionales para los objetivos del texto publicado por Magendzo. El diálogo de dichas vivencias demuestra que no sólo existen una gran cantidad de pensamientos, sino que muchos de ellos concuerdan y son convergentes sin la necesidad de catalogarse como homogéneos, de ahí que el autor afirme que estas ideas-fuerza "no son una colección de nociones, ni la noción de una estructura preestablecida, sino que [son] un producto de las interacciones de las personas involucradas en la EDH y de momentos que generan configuraciones relacionadas" (p. 5) que pueden cambiar total o parcialmente, o se pueden conservar.

Con el ánimo de ser mucho más puntuales al respecto, diremos que entre las ideas-fuerza seleccionadas por el autor pueden ser encontrados los siguientes denominadores: (1) La educación en derechos humanos es, en esencia, una educación política, (2) La educación en derechos humanos debe estar comprometida con la justicia social, (3) La educación en derechos humanos trabaja en aras del reconocimiento de la diversidad social y cultural, (4) La educación 
en derechos humanos hace referencia a una educación contextualizada en donde se tienen en cuenta las particularidades históricas de cada territorio, (5)La educación en derechos humanos no se acaba en las concepciones normativo-jurídicas, por lo que requiere avances hacia interpretaciones holísticas e integrales, (6) La educación en derechos humanos contribuye a la consolidación de las democracias participativas, (7) La educación en derechos humanos tiene fuertes componentes ético - valóricos en su interior producto del enaltecimiento de principios como la dignidad y la libertad, (8) La educación en derechos humanos es por antonomasia una herramienta constructora de paz en tanto incentiva la creación de una cultura basada en los DDHH y, finalmente, (9), La educación en derechos humanos propone la consolidación de sujetos de derechos, es decir, de un sujeto que piensa, siente, reflexiona e interviene en su realidad.

En mente lo anterior, no nos queda más sino resaltar que los aportes de Magendzo a través de este texto resultan útiles al tema de investigación aquí propuesto no sólo porque estructura, sistematiza y perfila las grandes ideas que se gestan en Iberoamérica sobre la Educación en Derechos Humanos (fenómeno que nos permite hacer una lectura comparativa sobre las distintas experiencias), sino que también nos ofrece un trabajo particular para el caso que nos compete (Colombia) por medio del documento de Manuel Restrepo Yusti (antioqueño, sociólogo y doctor en Ciencias Políticas quien en la actualidad es representante de la Oficina del Alto Comisionado de los Derechos Humanos de la ONU y tiene en su recorrido académico resaltable) titulado Apuntes para una reflexión sobre pedagogía de los derechos humanos en Colombia, allí se hace un recorrido histórico por las tres últimas décadas con el propósito de reconstruir el camino que tuvo que recorrer el discurso de los DDHH en un país caracterizado 
por la violencia y la desigualdad, un trabajo imposible de desconocer en el marco de esta investigación.

Leído lo anterior no cabe duda que Abraham Magendzo se posiciona como uno de los autores más importantes en el escenario de la EDH, de ahí que se considere necesario citar otro de sus trabajos. A saber, uno de los textos más relevantes de este autor se titula Educación en Derechos Humanos: Curriculum, historia y ciencias sociales del $2^{\circ}$ año de enseñanza media. Subunidad "régimen militar y transición a la democracia”, investigación realizada en compañía de María Isabel Toledo Jofré en el año 2009. En él, los autores realizan un estudio exploratorio sobre lo imperativo que resulta la enseñanza tanto de las particularidades históricas que tuvo contexto chileno durante la existencia de un régimen militar que finalizó en el año de 1973, como de la democratización y el retorno de los derechos dentro del mismo en el marco de la reforma curricular chilena ocurrida a mediados de la década de los 70's. Respecto al tema Magendzo y Toledo (2009) mencionan que:

Aproximar a los estudiantes a los Derechos Humanos desde la enseñanza de la historia reciente y las violaciones de estos derechos no es, por cierto, la única forma posible de abordar la educación en Derechos Humanos. Sin embargo, constituye una manera ética que tiene como intención primordial perpetuar la memoria y contribuir al 'Nunca Más' (...) Así, la educación en Derechos Humanos se convierte en un vigilante del recuerdo para que nunca más se repitan sucesos tan deleznables y terribles como los vividos. Su rol no es ni de control ni de censura, sino que de acogida, de hacer del aprendizaje de la memoria histórica un acontecimiento ético existencial, un acto de apertura hacia la historia de los 'Otros/Otras' en sus penas y sufrimientos (Magendzo 2004). (p. 6). 
Siguiendo este recorrido hemos de citar las reflexiones de un tercer autor, Guillermo Hoyos Vásquez, profesor de la Universidad Nacional de Colombia quien se ha convertido en uno de los mayores filósofos de la educación en el país y, por tanto, en un referente internacional sobre la materia. Él, un gran educador por la democracia y la democratización de la educación, ha centrado sus aportes en lo concerniente a la ética kantiana y a la teoría habermasiana sobre la acción comunicativa, elementos que estallaron la emoción entre los educadores al promover un ámbito educativo ligado a la enseñanza de la libertad a partir del dialogo entre ciudadanos conscientes de sus derechos y deberes. Dejando de lado esta breve presentación, diremos que el texto de nuestro interés se titula Formación ética, valores y democracia publicado en el año 2001 (este es un breve apartado que compone la totalidad del libro Estados del Arte de la Investigación en Educación y Pedagogía en Colombia, Tomo I), allí el autor se cuestiona sobre el papel de la educación en la conformación de la sociedad colombiana y, por tanto, del ejercicio de la ciudadanía.

En aras de lo anterior, Hoyos (2001) plantea una discusión filosófica sobre la naturaleza ética y moral de la educación y de la escuela utilizando otros referentes que profundizan notablemente su discusión. Más allá de centrarnos en este punto, diremos muy brevemente que nuestro interés en el texto se basa en el acogimiento de elementos como las injusticias materiales, la participación ciudadana y el interés por el bienestar del otro para desarrollar su concepto de cultura cívica, "un conjunto de ideas y creencias que, unidas a aquel ideal cívico normativo del buen gobierno y al desarrollo histórico de sus cometidos pedagógicos, incorporan elementos esenciales" (p. 9) tales como el pluralismo, la diversidad cultural, la tolerancia, la libertad, entre otros, un presupuesto que en últimas intenta posicionar a la escuela como un espacio que debe estar caracterizado por propagar un sentido social y crítico, que ineludiblemente debe tomar 
como un punto de referencia la EDH. Como una breve anotación, nos interesa destacar a este trabajo no sólo por los aportes propiamente dichos del profesor Hoyos, sino porque el documento también nos presenta un estado del arte en donde se sistematizan otras investigaciones que pueden contribuir a la visibilización de metodologías alternativas y propuestas novedosas en este campo de estudio.

Por otro lado, se considera pertinente tomar como referencia en la investigación los trabajos de Germán Vargas Guillén (Educación para la democracia y educación ciudadana de adultos en América Latina de 1995), y el de Marco Raúl Mejía y Gabriel Restrepo (Formación y educación para la democracia en Colombia de 1997), ambos caracterizador por la implementación y el desarrollo de entrevistas a profundidad y la revisión de archivo.

De igual forma encontramos el texto de Adolfo Álvarez titulado Democracia y conflicto en la escuela publicado en el año de 1999 en el marco del grupo investigativo denominado “educación y democracia”. Allí, Álvarez propone el desarrollo de su trabajo a partir de la coyuntura provocada por la creación de los gobiernos escolares (ley de educación, artículos 142 a 145) con el objetivo de fortalecer dichos espacios en aras de consolidar la democracia dentro del aula y generar una transformación de las prácticas de poder inmersas en los ámbitos escolares. De acuerdo con las observaciones hechas por Delgado y Luque (s.f.) sobre este documento, se sabe que el autor da forma a su propuesta en el ámbito organizacional de la escuela a partir de trabajos previos del grupo investigativo, caso del texto Los derechos humanos en la escuela formal ${ }^{3}$ en donde se realiza el estudio de la cultura escolar frente a los DDHH en tres instituciones educativas de Santiago de Cali, allí se toman como categorías de estudio la

\footnotetext{
${ }^{3}$ Sin referencias sobre este documento.
} 
estructura de los manuales de convivencia, los procedimientos para su garantía y los procesos para ejecutar una sanción. Adicional a lo anterior, ambos autores reconocen que Adolfo Álvarez propone en su estudio de la cultura democrática en la escuela un enfoque metodológico ubicado “en la línea de la investigación evaluativa de los procesos y dinámicas de la organización escolar, al igual que en la línea de la descripción evaluativa y la $\operatorname{IAP}^{4}$ ( $($ p. 90), cuestión que aporta a la investigación al incluir y considerar las relaciones de poder que se estructuran en la comunidad escolar como método para aplicar una propuesta pedagógica de EDH a través de la educación emocional.

Por su parte, Alma Delia Torquemada González nos proporciona un estudio ligado a la enseñanza de los DDHH dentro de la educación básica mexicana mediante programas curriculares que se encuentra sistematizado en su texto La práctica educativa de derechos humanos en educación primaria, publicado en el año 2007 en Eikasia, revista de filosofía mexicana. Allí la autora traza una serie de objetivos para el abordaje de tal problemática:

1. Analizar si se plantean curricularmente los derechos humanos como contenidos educativos en cada uno de los seis grados de educación primaria.

2. Conocer si en los planes y programas de primaria se sugieren planteamientos apropiados para la enseñanza de derechos humanos.

\footnotetext{
${ }^{4}$ Investigación - acción participativa (IAP), de acuerdo con lo dicho por Rojas (s.f.) la IAP es un enfoque investigativo y una metodología de investigación, aplicada a estudios sobre realidades humanas. Como enfoque se refiere a una orientación teórica (filosofía, marco teórico) en torno a cómo investigar. Como metodología hace referencia a procedimientos específicos para llevar adelante una investigación - estudio científico diferente a la investigación tradicional; es una manera concreta de llevar adelante los pasos de la investigación científica de acuerdo con su enfoque. La novedad puede ubicarse en el sentido e implicación de las dos palabras que acompañan la primera (investigación): Acción - Participación. No es solo investigación, ni solo investigación participativa, ni solo investigación -Acción; implica la presencia real, concreta y en interrelación de la Investigación, de la Acción, y de la Participación. (p. 1.) Rojas, J. (s.f.). Investigación - Acción Participativa. Recuperado de http://tie.inspvirtual.mx/recursos/temas/etv/OAParticipacionSocialWeb/material/La\%20investigaci\%C3\%B3n\%20a cci\%C3\%B3n\%20participativa.pdf
} 
3. Analizar si los profesores de primero a sexto de una escuela primaria pública diseñan actividades específicas para el dominio de los derechos humanos.

4. Indagar y analizar en los niños de los diferentes grados de una escuela primaria pública su conceptualización en torno a los derechos humanos y los derechos de los niños.

5. Analizar si en las clases cotidianas en los diversos grados de primaria, se transmiten implícitamente los derechos humanos como valores sociales.

6. Contrastar las concepciones pedagógicas de los profesores sobre la formación de derechos humanos con lo que realizan dentro de sus salones de clase. (Torquemada, 2007, p. 188)

Aunque la investigación, por la cantidad de objetivos planteados, puede parecer pretensiosa, resulta de gran valor para este trabajo investigativo ya que sus objetivo sirven como indicadores para la realización de un diagnóstico acerca de la situación de los derechos humanos en las instituciones públicas de básica primaria.

De otro lado, encontramos la investigación llevada a cabo en Argentina por Mercedes Virginia Peluffo y Paula Pérez Roig durante el año 2005 titulada Los Derechos Humanos y la enseñanza de una lengua: experiencia áulica en escuela secundaria, en este documento las autoras proponen la construcción de un plan de estudio "para los alumnos de sexto año del Colegio Nacional Rafael Hernández a fin de incentivar en aquellos estudiantes el desarrollo de una conciencia crítica con relación a los derechos humanos" (Peluffo y Roig, 2005, p. 4); en él se propone un método de aprendizaje a través del uso de una lengua extranjera, el inglés, con el propósito de poner al alumno en "contacto con otros mundos" y otras formas de interpretación de la realidad en diferentes contextos. Este trabajo en una segunda lengua, tiene un carácter 
interdisciplinar con el objetivo de responder tanto a los lineamientos propuestos curricularmente frente al aprendizaje del inglés, como a los requerimientos tanto educativos como sociales de afianzar desde la escuela una cultura basada en los DDHH. El hacerlo de esta manera permite que el estudiante pueda interiorizar aún más los contenidos sin que sea tedioso el proceso pues la idea es que él ni siquiera note que aprende tantas cosas a la vez. Toda la metodología de esta investigación es bastante interesante pues vemos la sinergia entre los distintos contenidos, fenómeno que hace de esta propuesta algo bastante creativo y original.

Igualmente, es preciso referenciar al texto de Christoph Menke y Arnd Pollman llamado Filosofía de los Derechos Humanos publicado por Herder Editorial en el año 2010. Dentro del mismo los autores exponen de forma sistemática el concepto de los derechos humanos con sus diferentes variables conceptuales dentro de los campos jurídico, moral y político para después dar una fundamentación a través conceptos como el contrato social y la razón a fin de aterrizar en el análisis de postulados éticos, epistemológicos y ontológicos como la dignidad humana.

Añádase a esta lista las experiencias y estrategias metodológicas expuestas por Yurany Andrea Malagón Aldana en Problemas, contenidos y acciones relacionados con los derechos humanos en la escuela. El caso de cinco instituciones educativas y una fundación social, un artículo publicada en la Revista de Desarrollo Humano, Educativo y Social Contemporáneo (Aletheia) en el 2015. Dentro de este documento se revisan los planes de estudio y proyectos transversales sobre derechos humanos de obligatorio cumplimiento en las instituciones educativas tanto públicas como privadas en Colombia, con lo que la autora se centra en explicar los contenidos y las acciones de enseñanza relacionadas con este tema a fin de "identificar y analizar los procesos de formación docente y las prácticas pedagógicas que se llevan a cabo en la escuela y en las organizaciones sociales, así como el sentido y alcance de la formación del sujeto 
de derechos" en el marco de la EDH (Malagón, 2015. p. 72). Este estudio proporciona facilidades para identificar problemas frente a la EDH y las experiencias de éxito de algunas prácticas anexas.

Llegados a este punto es pertinente hacer mención de un documento institucional que alimenta considerablemente a este trabajo, se trata de una publicación del Ministerio de Educación Nacional (MEN) en coordinación con el Fondo de Población de las Naciones Unidas (UNFPA) llamada Programa de Educación para el Ejercicio de los Derechos Humanos EDUDERECHOS -, La educación para e l ejercicio de los derechos humanos en la escuela: un compromiso de todos. Módulo 1. Este documento del año 2009 muestra el cómo incorporar la enseñanza de los DDHH se vuelve un elemento fundamental en la formación de la ciudadanía, un reto que exige el desarrollo de ciertas competencias a partir de la construcción de programas transversales en concordancia con los parámetros establecidos por la Constitución Colombiana y la Ley General de Educación, normas en donde se establece que la educación tiene como objetivo "la formación para el respeto a los derechos humanos, en especial la vida, la paz, la democracia, la convivencia, el pluralismo y el ejercicio de la tolerancia y la libertad" (Ministerio de Educación Nacional República de Colombia - MEN -, 2009, p. 5).

Siguiendo con las afirmaciones del MEN, el trabajo que representa EDUDERECHOS es el resultado del proceso de reflexión que enmarcó la construcción del Plan Decenal de Educación 2006-2016, política pública en la que:

A través de una consulta y un debate público, cerca del $42 \%$ de los participantes, plantearon la educación en y para la paz, la convivencia y la ciudadanía, como uno de los mayores desafíos del país en los próximos diez años. En concordancia con ello y en el 
marco del Plan Sectorial y la política de mejoramiento de la calidad, el Programa de Educación para el Ejercicio de los Derechos Humanos -Eduderechos- se estructuró a partir de un piloto que permitió construir y validar una propuesta para la implementación de proyectos pedagógicos de educación para el ejercicio de los derechos humanos orientados al desarrollo de competencias ciudadanas y básicas en función de la formación de sujetos activos de derechos, como una razón fundamental del quehacer de la escuela. (MEN, 2009, p. 5).

Este texto resulta de gran aporte para el trabajo aquí propuesto en tanto evalúa toda experiencia pedagógica por medio de:

(i) Procesos de innovación pedagógica para el ejercicio y práctica de los derechos humanos en la escuela, (ii) procesos de formación permanente de profesores y agentes educativos en derechos humanos y competencias ciudadanas y (iii) construcción de redes de soporte institucional para la educación en derechos humanos. [Además porque conforman] Equipos Técnicos Institucionales (en cada uno de los establecimientos educativos), Equipos Técnicos Territoriales, liderados por 11 secretarías de educación y acompañados por Universidades Regionales con la asistencia del Equipo Técnico Nacional del Ministerio de Educación Nacional. (MEN, 2009, p. 5).

Adicional a la información anterior, el documento explica que:

El pilotaje se realizó entre el 2006-2009 con 77 establecimientos educativos de 7 regiones del país, del cual hicieron parte las acciones de articulación con la experiencia Maleta Pedagógica en Caquetá y Florencia, el currículo Juegos de Paz en Norte de Santander y la estrategia de formación de formadores Congenia en Tunja, Neiva, Huila y Norte de 
Santander. Las lecciones aprendidas en desarrollo del Proyecto Piloto nos permiten contar hoy en el Programa con una serie de módulos que integran principios y orientaciones para que la educación para el ejercicio de los derechos humanos sea una realidad en la cotidianeidad escolar. Los módulos iniciales son tres. El primero expone el marco general del Programa de Educación para el Ejercicio de los Derechos Humanos en la escuela, precisa los referentes normativos y conceptuales y presenta la estructura del programa. El segundo módulo enfatiza en la ruta para implementar la educación para el ejercicio de derechos humanos en la escuela, para ello aborda los enfoques y modelos educativos que facilitan la incorporación de los proyectos pedagógicos en la escuela y define los momentos para la construcción e implementación de esa ruta, así como también las prácticas que facilitan la construcción de ambientes democráticos en la escuela. El tercer módulo, es de profundización y da herramientas para abordar la lectura de contextos educativos con enfoque de derechos humanos. Estas orientaciones establecen los referentes conceptuales, metodológicos y operativos, es decir los mínimos comunes que orientan la acción del Programa en la escuela, pero esa acción debe adelantarse atendiendo a las particularidades y necesidades de las instituciones educativas y del contexto del cual ellas hacen parte (MEN, 2009, p. 5 - 6).

El último texto que fundamenta el estado de la cuestión en esta investigación es Tres experiencias para pensar la educación en derechos humanos en Colombia la tesis de grado de Douglas Rodríguez presentada el año de 2015 para optar al título de Magister en Estudios Sociales de la Universidad del Rosario. En ella, son comparadas las experiencias de la Escuela 
de Derechos Humanos del CINEP $^{5}$ (organización no gubernamental), la IED Eduardo Umaña Mendoza (colegio oficial de la ciudad de Bogotá), y la del Movimiento Nacional de Víctimas de Crímenes de Estado, todas ellas identificadas con la práctica pedagógica conocida como

Educación en Derechos Humanos. Básicamente allí se analizan cómo se construyen cada uno de los escenarios a partir de un estudio antropológico y pedagógico que:

Implica, por una parte, una aproximación etnográfica alrededor de los discursos, las prácticas y los sentidos que los protagonistas movilizan en cada escenario con respecto a lo educativo, a los Derechos Humanos y a los sentidos de la Educación en Derechos Humanos, y por otra, la distinción entre la diversidad de redes de significado que precedieron su proceso de institucionalización, a lo cual denominaré campo simbólico, y su cohesión como un campo de saber dotado de claves analíticas propias. Campo simbólico y campo de saber operan como dos momentos analíticos diferenciables. A través del primero, se hacen evidentes las representaciones políticas, sociales y culturales heredadas del "mundo bipolar" y de la guerra fría que en términos generales exponen una defensa a ultranza de los valores y principios de la democracia liberal y de la lucha anticomunista (Rodríguez, 2015, p. 5).

Este texto es importante en la investigación dado que permite esbozar las trayectorias que le han permitido a la Educación en Derechos Humanos recrear nociones como la de sujeto de

\footnotetext{
${ }^{5}$ Centro de investigación y educación popular (CINEP), es una institución fundada por la Compañía de Jesús desde hace más de cuatro décadas. En 1972 se crea el CINEP como una fundación sin ánimo de lucro, con la tarea de trabajar por la edificación de una sociedad más justa y equitativa, mediante la promoción del desarrollo humano integral y sostenible. En 1987, nace el Programa por la Paz como una propuesta cuyo objetivo central es aportar a la construcción de una paz justa y duradera en el país. Y en 1988 el CINEP en alianza con la Comisión

Intercongregacional de Justicia y Paz de la Conferencia de Religiosos de Colombia crean el Banco de Derechos Humanos y Violencia Política cómo un servicio que hace visible la memoria de las víctimas y denuncia las graves violaciones que ellas sufren. Información disponible en: CINEP (s.f.). Nosotros. Recuperado de: http://www.cinep.org.co/Home2/institucion/nosotros.html
} 
derechos, además de la trazabilidad de lo que el autor define como "tres rutas de emergencia e institucionalización de la Educación en Derechos Humanos que (...) no trascurren paralelamente sino en medio de superposiciones, intersticios y desplazamientos” (Rodríguez, 2015, p. 6), una cuestión que posibilita entender la manera cómo funciona en los escenarios educativos la EDH.

En conclusión, frente al tema la educación de los derechos humanos existe una generosa literatura que permite conocer diferentes estrategias sugeridas por investigadores y estudiosos de este campo y de fácil aplicación en el contexto escolar. Todos los autores coinciden en la necesidad de involucrar los derechos humanos de manera transversal en las aulas, planes de estudio y en las prácticas pedagógicas de los profesores.

\subsubsection{Educación a través de las Emociones}

De acuerdo con lo dicho páginas atrás es fundamental hacer referencia a otra de nuestras principales categoría de análisis, la educación a través de las emociones. Para ello haremos un breve recorrido por las ideas de algunas de las publicaciones más representativas frente al tema, iniciando con el texto La inteligencia emocional: por qué es más importante que el consciente intelectual (2017) del psicólogo y redactor científico del periódico estadounidense New York times Daniel Goleman, una autoridad en el escenario de la pedagogía de las emociones. Olguín (s.f.) en su blog inteligencia emocional, hace algunos comentarios sobre la obra de Goleman, allí expone que este autor entiende a la inteligencia emocional como:

Una forma de interactuar con el mundo que tiene muy en cuenta los sentimientos, y engloba habilidades tales como el control de los impulsos, la autoconciencia, la motivación, el entusiasmo, la perseverancia, la empatía, la agilidad mental, etc. Ellas 
configuran rasgos de carácter como la autodisciplina, la compasión o el altruismo, que resultan indispensables para una buena y creativa adaptación social (p.1.).

Teniendo en cuenta lo anterior, es comprensible que desde la perspectiva de Goleman las condiciones en las que se desarrolle y/o encuentra la inteligencia emocional de un sujeto tiene una notable influencia en todos los aspectos de la vida cotidiana; en el caso específico de los niños y el contexto escolar, su déficit puede conducir a la depresión, trastornos alimentarios, agresividad y delincuencia (United States InterAmerican Community Affairs, s.f.), un fenómeno que desde la experiencia de la autora de esta investigación indudablemente afecta al proceso de aprendizaje y rendimiento escolar. En este orden de ideas, se puede afirmar que lo importante para Goleman es que todos podamos fortalecer nuestra inteligencia emocional pues este es un proceso fundamental en la construcción de la plenitud del ser, una afirmación que evade todo pensamiento determinista sobre la inteligencia emocional. Por estos y otros aportes, Goleman es referente central de esta investigación, pues contribuye a establecer en un principio relacional entre la pedagogía de las emociones y la EDH, de ahí que reconozcamos la pertinencia de sus reflexiones en el campo educativo y su contribución a las reflexiones que demanda el rol del profesor, referente de la investigación.

Ahora bien, al revisar la bibliografía de los últimos diez años en torno a la EDH desde la perspectiva dada por las emociones, consideramos que los estudios existentes presentan un común denominador: los valores, es por ello que quisimos recoger algunos antecedentes al respecto. Empecemos citando el trabajo de Rosa María Mujica, quien en el año 2007 escribe un artículo titulado ¿Qué es educar en Derechos Humanos?, un texto que traza una importante ruta de trabajo considerada, posiblemente, como la columna vertebral de la propuesta pedagógica de esta investigación, ya que al lograr llevar a cabo una propuesta educativa alternativa como la 
"Pedagogía de la Ternura" en el aula aumenta las posibilidades de abordar temas como los DDHH desde el "arte de educar y enseñar con cariño, con sensibilidad, que evita herir, que intenta tratar a cada uno como persona, como ser valioso, único, individual e irrepetible" (Mujica, 2007, p. 26). Detallando un poco más el documento, resaltaremos que Mujica retoma los postulados de Abraham Magendzo y Alejandro Cussianovich, para invitarnos a crear una cultura de valores en las escuelas, por lo que nos plantea la importancia de crear principalmente en los profesores credibilidad en lo que se transmite, además de impulsar el establecimiento de una dinámica organizativa horizontal en la clase.

Para complementar lo dicho, la autora sostiene que es desenvolver cada método de aprendizaje y enseñanza con la certeza de que el estudiante sea reconocido como un ser valioso, que no está sólo para recibir una serie de conocimientos sistematizados sino que, al contrario, él debe sentirse como el centro del proceso de construcción de saberes colectivos. Adicional a esto, cabe señalar que para Mujica la EDH debe transmitir conocimientos desde el sentir el niño (a) los jóvenes que están siendo participes de este aprendizaje, por lo que se sobreentiende que la educación no busca un fin individual, pues es más bien una propuesta colectiva, altruista y liberadora donde los educandos pueden replicar, compartir, socializar su mundo de entender la vida, de ahí que se comprenda que para la autora:

El rol del educador es crear las condiciones propicias para que la persona 'aprenda a aprender'. Se debe promover que las personas pasen de la acción dirigida y programada por el educador a la acción libre, aprendiendo a asumir las consecuencias de sus actos. Sólo actuando con libertad y decisión propia frente a situaciones diferentes, y autoevaluando sus acciones, las personas ejercitan su capacidad para tomar decisiones (Mujica, 2002, p. 12). 
Finalmente, sería importante señalar que la autora más que desarrollar una metodología sugiere varias metodologías para desempeñar la labor de educadores en torno a la EDH, pues ella parte de vivenciar y experimentar las cosas y luego teorizarlas, desde el juego, realizando un impacto terapéutico del afecto. Es con base a lo anterior que consideramos que Mujica va muy acorde con los últimos postulados del profesor Hoyos en lo que se refiere con "humanizar la educación”, algo que sonaría redundante, pero no es así, ya que el eros y el logos son traspasados por lo comercial, convirtiendo a la educación en un producto, lo que desdibuja su potencial emancipador. Esta última afirmación era necesaria en tanto hemos de aclarar ante el lector que la escogencia de cada uno de los textos aquí brevemente reseñados está basada en una concepción afectiva y humanística de la educación, punto central que puede ser encontrado en otros textos, como por ejemplo en Educación emocional en la escuela publicado en el año 2013 por Monserrat Deulofeu, Lidía Morillas, Irene Pellicer, Violant Quer, Josep Toll, y María Antonia Tusell, una colección de cuatro (4) Tomos, cada uno dirigido a unas edades específicas dividido de la siguiente manera: tomo 1, actividades del aula dirigidas a niños de 3 a 5 años; tomo 2, actividades del aula dirigidas a niños de 6 a 7 años; tomo 3, actividades del aula dirigidas a niños de 8 a 9 años, y tomo 4, actividades del aula dirigidas a niños de 10 a 11 años.

Es oportuno ahora seguir este recorrido refiriéndonos al libro de las autoras Graciela Guzmán y Libia Oviedo de Reyes titulado Inteligencia emocional y procesos pedagógicos, publicado en el año 2009. Este texto es producto de una intervención pedagógica en dos escuelas de primaria de la ciudad de Ibagué (Tolima) con el propósito de evidenciar la relación existente entre ambos factores. El proyecto se desarrolló en tres fases. En la primera, se recolectó cierta información para llevar a cabo un diagnóstico en colaboración con las practicantes de quinto semestre de licenciatura, quienes aplicaron diferentes instrumentos de investigación. En la 
segunda fase se propició un espacio formativo con profesores en aspectos relativos a la inteligencia emocional con el objetivo de sensibilizarlos frente al tema y, en la tercera fase, se retomaron los resultados de las dos anteriores para generar un proyecto de aula que ejecutara prácticas pedagógicas asertivas y eficaces en la enseñanza de la inteligencia emocional. Este trabajo es de gran utilidad para la formulación de la propuesta pedagógica en EDH a través de las emociones pues, desde el esfuerzo metodológico de las autoras, son puestas a disposición algunas formaciones prácticas que para ese contexto fueron exitosas y que, por tanto, consideramos dignas de replicar.

Otro de los trabajos a tener en consideración es el libro de Daniel Chabot y Michael Chabot Pedagogía emocional. Sentir para aprender. Integración de la inteligencia emocional en el aprendizaje del año 2009, allí los autores proponen explorar el proceso enseñanza aprendizaje ya no desde sus contenidos propiamente, sino desde las emociones y, en asociación con ello, las partes del cerebro que intervienen en la producción de tales emociones. Así pues, para estos autores muchos indicios, tanto científicos como inductivos, llevan a creer que las competencias emocionales explican en gran parte las dificultades de aprendizaje, por lo que uno de los objetivos propuestos en su libro se centra en establecer las primeras bases teóricas de una nueva visión de la pedagogía y del aprendizaje vinculando tanto la parte cognoscitiva como la biológica. En adición con este objetivo, ambos autores intentan proponer aplicaciones concretas e integradas de la inteligencia en las estrategias pedagógicas, por lo que en términos generales esta obra resulta de gran valor para la investigación debido a la apertura de sus argumentos entorno a la integralidad que plantea la acción de educar a los seres humanos, una cuestión que le brinda mayor riguridad científica a este tema. 
Para finalizar con estas breves referencias, hemos de citar al libro de Miguel De Zubiría Samper La afectividad humana. Sus remotos orígenes, sus instrumentos y operaciones, cómo medirla en niños y jóvenes mediante afectogramas (2007), en donde se destaca por parte del autor la necesidad que tiene el hombre, o más bien, el niño, de reconocer y valorar la interacción con su entorno social a fin de hacerla más cálida, fenómeno que también incentiva el flujo de la afectividad dirigida sobre sí mismo. Sobre el tema, Zubiría investiga acerca del rol que tiene la afectividad en el desarrollo de la vida, por lo que evidencia la inmensa necesidad de evaluar el desarrollo afectivo desde la más temprana edad. Esta propuesta va dirigida a los profesores que día a día se enfrentan a la trascendental tarea de formar a aquellos niños, por lo que se considera un excelente texto a la hora de pensar las funciones y los objetivos de los profesores dentro de las aula, ya que es precisamente en ese espacio en donde se deben gestar todas las propuestas de enseñanza a partir de la afectividad y las emociones. Tomar en consideración lo anterior resulta de gran valor para el trabajo aquí propuesto pues en últimas nuestro interés es situar al profesor en el epicentro del cambio, pues ente tantos males necesitamos insistir en volver a mirar la felicidad, intentar entenderla, repensarla, estudiarla con los poderosos métodos de la psicología y de las neurociencias.

En conclusión las propuestas pedagógicas basadas en las emociones han tenido gran acogida durante los últimos diez años, tal cual lo hemos documentado. Basándose en esta afirmación, podemos decir que los investigadores y estudiosos de la pedagogía se han preocupado por mejorar las dinámicas escolares a través de estrategias que involucran no sólo la parte cognitiva de los estudiantes, sino también sus emociones, pues desde la integralidad de ambos aspectos se pueden lograr grandes avances en todos los demás campos y competencias. A saber, el mayor referente de esta investigación con respecto al tema de las emociones es David 
Goleman y es bajo sus postulados que se estructura la visión de la educación en derechos humanos desde la perspectiva de la educación emocional en el aula pues, en la experiencia de la autora de esta investigación, Goleman es un referente esencial en el proceso de proponer cambios dentro de aquellos escenarios de nuestra sociedad que requieren de una atención especial en aras de fortalecer la garantía, protección y respeto por los derechos humanos, tal cual es el caso del escenario educativo, es decir, el contexto escolar, y la vida en comunidad

\subsection{Contexto de la educación}

Es de conocimiento general que los niños, niñas y adolescentes conviven la mayor parte de su tiempo dentro de las instituciones educativas, por lo que la escuela es -después del hogar- el espacio donde inician sus primeros pasos hacia la construcción de identidad, saberes, conocimientos y formación personal, de ahí que se posicione como el núcleo de generación de pautas mínimas de convivencia en sociedad a partir del reconocimiento y aceptación de los demás como seres humanos en tanto se entiende que los mismos son caracterizados por diferentes pensamientos, credos o religiones, maneras de percibir el mundo y una multiplicidad de personalidades que constituyen los espacios de diversidad cultural. Es así como se sostiene que la escuela permite a los educandos la construcción de relaciones interpersonales basadas en lazos de amistad y fraternidad, o por lo menos eso es lo que se afirma desde un punto ideal; no obstante, en el contexto institucional de nuestro estudio de caso se identifican una serie de circunstancias problema de carácter formativo y de convivencia que se generan en el interior del mismo, razón por la cual en las siguientes páginas nuestro interés será ahondar mucho más sobre las especificidades de aquellas circunstancias y, por supuesto, los impactos que estas generan. 


\subsubsection{Caracterización Institucional}

Para dar desarrollo a este apartado, hemos de especificar las condiciones que caracterizan el contexto bajo el cual se lleva a cabo este ejercicio investigativo con el propósito de describir el espacio que se constituye como nuestro objeto de estudio a partir de la puesta en escena de la información provista por fuentes de carácter institucional. Iniciemos diciendo que el Colegio Liceo Nacional Antonia Santos sede B se encuentra ubicado en Calle 12 No. 21-14 de la localidad de los Mártires en Bogotá en medio de edificaciones cuyos primeros pisos están dedicados al comercio, restaurantes, talleres de mecánica y fábricas. Hacia el oriente encontramos la llamada Calle Cinco Huecos, conocida por ser un lugar de indigencia y drogadicción. En el costado occidental encontramos la Estación de Policía de la Localidad Los Mártires y hacia el sur se ubica el sector comercial conocido como San Andresito "San José". Con respecto a su estructura física, resaltaremos que ha sido reestructurada recientemente y que en la actualidad posee tres pisos. Frente a la sede principal se encuentra la sección primaria, separada por la carrera 22 .

\section{Imagen 1}

\section{Ubicación del Colegio Liceo Nacional Antonia Santos sede B.}

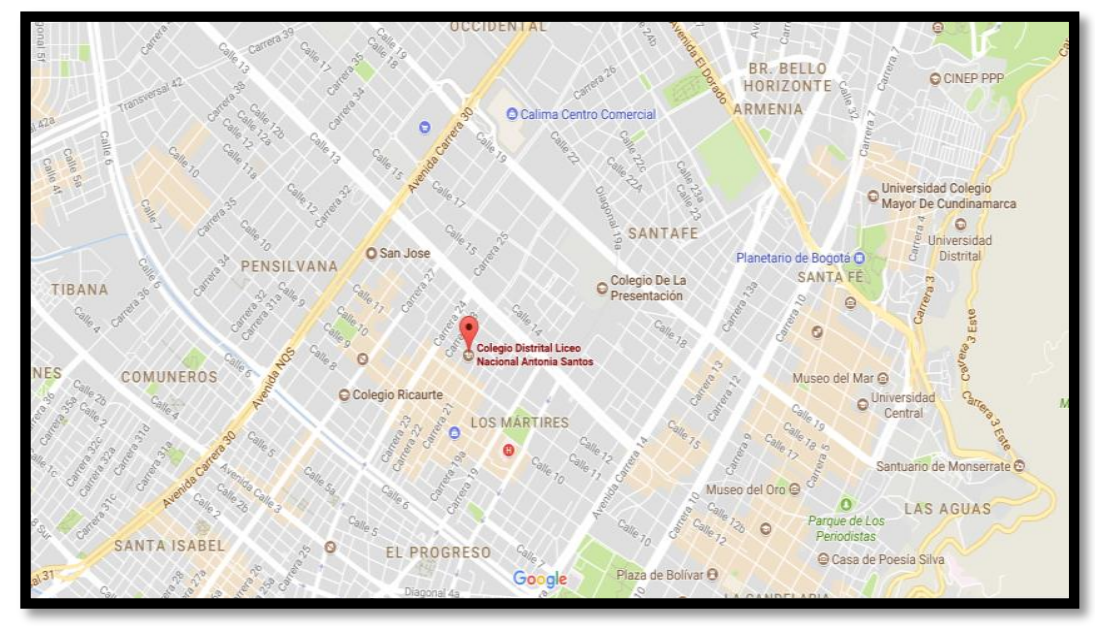


Fuente: Google Maps (s.f.). Colegio distrital Liceo Nacional Antonia Santos. Recuperado de:

https://www.google.com.co/maps/place/Colegio+Distrital+Liceo+Nacional+Antonia+Santos/@4.6106926,-

74.0844904,15z/data=!4m5!3m4!1s0x0:0x1d6c745f89558f8c!8m2!3d4.6078266!4d-74.0880095

A manera histórica citaremos la información provista por la página institucional del Colegio Liceo Nacional Antonia Santos:

Fundado el 1937 en el Municipio de Chía durante el gobierno del presidente Eduardo Santos con el nombre de "Liceo Nacional Femenino", por iniciativa del ministro de Educación Dr. Alfonso Araujo.

En el año de 1939 se construyó el edificio situado en la Cra 22 № 12-49, de Bogotá, Con el propósito de trasladar esta institución al lugar en donde funciona actualmente.

En 1940 se iniciaron labores con 45 alumnas, y en 1944 se abre el internado para facilitar la educación a las alumnas de provincia. En 1945, la institución proclama la primera promoción de bachilleres. En 1948 se creó el grado quinto $\left(5^{\circ}\right)$ de primaria.

Mediante resolución Nº 6829 de 1948, el ministerio de Educación Nacional le dio el nombre de "Liceo Nacional Femenino Antonia Santos".

En 1967 se creó la jornada tarde con el fin de ampliar la cobertura de servicio educativo. En 1969 se cierra el internado y continúa funcionando como bachillerato académico de primero a sexto de bachillerato con 20 grupos en cada jornada diurna. En 1972 se proclama la primera promoción de bachilleres de la jornada de la tarde.

Durante el lapso comprendido entre el año 1973 y 1996 el colegio proclamo aproximadamente a 2.500 bachilleres y muchas de ellas han seguido estudios superiores y se han destacado en el campo laboral. 
En 1997 se crearon los grados cuarto $\left(4^{\circ}\right)$ y quinto $\left(5^{\circ}\right)$ de primaria y el 11 de Agosto del mismo año la Secretaria de Educación del Distrito Capital, promulgo la Resolución N ${ }^{\circ}$ 5581 mediante la cual se le otorgo a la institución el nombre de "Liceo Nacional de Educación Básica Y Media Antonia Santos”, lo cual permitió la creación de la educación básica primaria del grado cero (o) a quinto (5). Así, sé amplio la cobertura y se dio cumplimiento a lo dispuesto en la ley General de Educación (Liceo Nacional Antonia Santos, s.f., p. 1).

Ya hablando propiamente de las condiciones actuales del colegio, anotaremos que la misión del mismo (aprobada por el Consejo Académico en su última actualización en 2013) establece que:

La I.E.D. Liceo Nacional Antonia Santos brinda educación a los estudiantes en los niveles de Transición, Educación Básica Primaria, Básica Secundaria y Educación Media. La acción participativa de todos y cada uno de los miembros de los diferentes estamentos de la Comunidad Educativa en la planeación, complementación y evaluación del Proyecto Educativo Institucional (P.E.I) garantiza la educación integral del educando para asegurar así los procesos de desarrollo biofísico, competencia comunicativa, valorativa o ética y cognitiva, de manera tal que se garantice el crecimiento y desarrollo social adecuado, para posibilitarle su vinculación a la educación superior, dentro del marco de la dignificación humana (Proyecto Educativo Distrital -PEI-, 2013).

Mientras que como visión establece que:

La I.E.D. Liceo Nacional Antonia Santos llegará a ser una Institución donde primen la dignificación de la persona, los procesos de personalización, el avance tecnológico y 
científico, el sentido comunitario y democrático que requiere la sociedad colombiana del mañana mediante el compromiso social, con una adecuada gestión administrativa y la continua capacitación de los profesores (Proyecto Educativo Distrital -PEI-, 2013).

\subsubsection{Caracterización y análisis de la población objeto de estudio.}

Siguiendo en esta línea de ideas hemos llegado a la sección en donde se hará una caracterización de la población objeto de estudio propiamente dicha, para tales efectos se tendrá en cuenta la información recolectada por los instrumentos dispuestos para esta tarea (encuestas y entrevistas). Empecemos por señalar que durante el periodo 2008-2012 las proyecciones de población contempladas por la Dirección de Educación de los Mártires indican que la Población en Edad Escolar (PEE) del Colegio Liceo Nacional Antonia Santos, es decir, aquella que se encuentra entre los 5 y los 16 años de edad ha venido decreciendo exponencialmente.

\section{Gráfico 1}

Porcentaje de participación de la Población en Edad Escolar (PEE) del Colegio Liceo

Nacional Antonia Santos (5-16 años) en la localidad de los Mártires años 2008, 2012 y

2013.

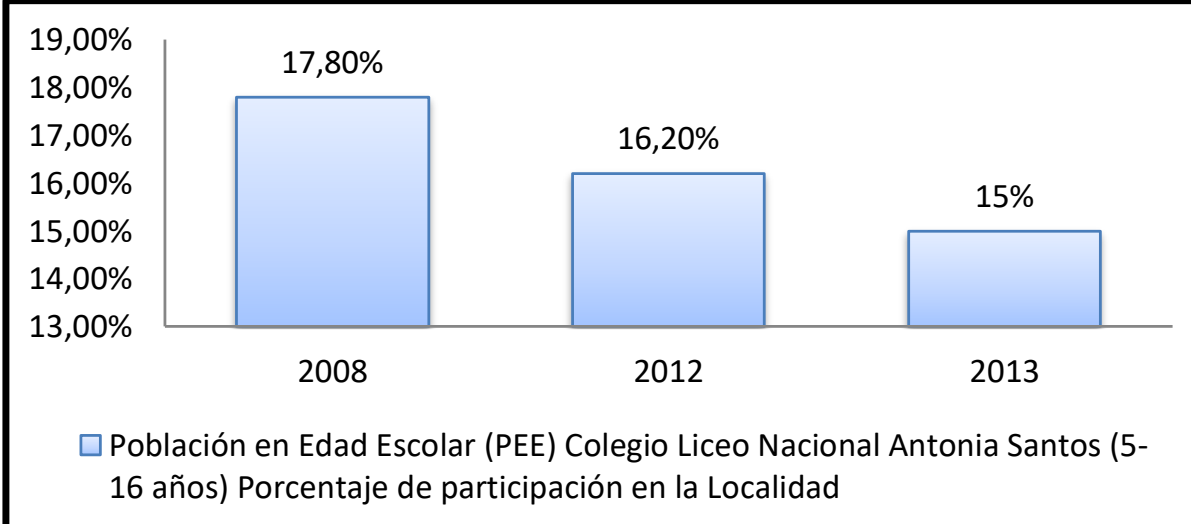

Fuente: Dirección de Educación de los Mártires. 
Con respecto a los padres de familia se ha logrado establecer que, en términos generales, no tienen una participación activa en los procesos formativos de sus hijos pues, en la mayoría de los casos, se evidencia abandono, desinterés y falta de afecto hacia ellos o, paradójicamente, mucha preocupación por mandarlos a la escuela no por lo que puedan aprender sino por los subsidios económicos que pueden obtener, siendo esto su principal motivación. Por otro lado, según directrices del colegio, los niños (as) y adolecentes de esta localidad no pueden ingresar a la institución fácilmente dado que es una población con problemas de índole económica y social, por lo que su acceso se convierte en un tema de restricción. Sumado a ello, el sector representa un alto grado de peligrosidad -queda cerca del llamado Bronx ${ }^{6}$-, y hay un gran porcentaje de habitantes de calle. La intervención del Bronx ${ }^{7}$, trajo consigo, entre muchas consecuencias para la ciudad, el desplazamiento de los habitantes de calle hacia diferentes sectores, entre ellos los alrededores del colegio Liceo Nacional Antonia Santos. Es común que en medio del ingreso o salida de los estudiantes transiten habitantes de calle y se entremezclen con ellos.

También hay niños que tienen procesos legales por custodia o abandono, por lo que no es extraño encontrar a menores siendo el centro de seguimientos por parte del Instituto Colombiano de Bienestar Familiar. Pero más allá de centrarnos en este punto, es fundamental resaltar la

\footnotetext{
${ }^{6} \mathrm{El}$ informe Las revelaciones del Bronx Intervención de zonas de alta complejidad: desafios y alternativas publicado por la Fundación Ideas Para la Paz en el año 2017 define que el Bronx es esa zona ubicada en el centro de Bogotá cercana al Batallón Militar de la ciudad que se caracteriza por "débil presencia institucional, el fuerte control por parte de estructuras criminales y la crítica situación de vulneración de derechos de menores de edad y habitantes de calle" (p. 15). Para más información visítese en siguiente link: http://cdn.ideaspaz.org/media/website/document/58b41dfce9773.pdf

${ }^{7}$ Nos referimos a la intervención del Bronx como ese proceso llevado a cabo el 28 de mayo del año 2016 por parte de la alcaldía de Bogotá al mando de Enrique Peñalosa (alcalde de la ciudad para ese periodo). El informe Las revelaciones del Bronx Intervención de zonas de alta complejidad: desafíos y alternativas publicado por la Fundación Ideas Para la Paz en el año 2017, señala lo siguiente: "reiteradamente las autoridades calificaron al Bronx como el principal centro de tráfico de estupefacientes de la ciudad y uno de los mayores focos de criminalidad, [de ahí que el propósito de tal intervención haya sido la creación de] un territorio libre de ilegalidad y recuperado por la institucionalidad. Para más información visítese en siguiente link: http://cdn.ideaspaz.org/media/website/document/58b41dfce9773.pdf
} 
existencia de diversas variables que pueden incidir de forma negativa en el desarrollo de los niños (as) tales como la situación económica de sus familias, el nivel educativo de los padres, la actividad laboral de sus acudientes y problemas familiares de todo tipo. Sin embargo, se considera que todas estas circunstancias negativas tienen un factor común, la falta de afectividad que sufren los niños y las niñas, cuestión que se traduce en un bajo rendimiento académico, desinterés por el estudio y carencia de valores éticos, elementos cristalizados, de una parte, en comportamientos agresivos y/o violentos de manera constante $\mathrm{y}$, de otra parte en ensimismamiento, tristeza o apatía por todo lo que se les propone.

Ahora bien, en este punto es imperativo resaltar que la educación en la familia incide notoriamente en los procesos formativos que se llevan a cabo dentro de la institución educativa, pero lo que se evidencia no es únicamente desidia o negligencia hacia los niños por parte de los padres que tienen un menor nivel educativo, sino que se comprende que estos padres son también individuos que hacen parte de un sistema mediado por la violencia y la ley de la supervivencia pues ellos, en su gran mayoría, poseen escasos recursos, condición que los obliga a vivir en medio de fuertes luchas sociales para poder sostenerse en un mundo cada día más complicado. Hacía diez años atrás, los padres de los estudiantes eran los comerciantes o los dueños de los locales comerciales de San Andresito, pero con el tiempo esta población se ha ido transformando. En la actualidad la mayoría de los padres de familia son recicladores de la zona, o se dedican al trabajo informal, como a transportar en bici- taxi en la zona comercial de san Andresito.

Adicional al fenómeno anterior, se considera que la población estudiantil en la institución educativa Antonia Santos es constantemente cambiante ya que se encuentran estudiantes de tránsito que vienen de diferentes sectores de la ciudad o de fuera de ella, permanecen por un 
tiempo y luego se van, por lo que es poco frecuente empezar con un número determinado de estudiantes al inicio del año escolar y finalizarlo con los mismos, ello hace que se pierda la identidad escolar y, por ende, los propios intereses de la comunidad educativa. Es, en este sentido, que son reflejadas y denunciadas las diferentes preocupaciones por parte de todos los actores que confluyen en las realidades de la mencionada institución (padres preocupados por recibir subsidios, desmotivación dentro del contexto escolar, niños desorientados y/o pidiendo auxilio a gritos la no repetición de sus contextos de violencia, etc.), situación que merece el enaltecimiento del papel de los profesores en la resolución de estas problemáticas, pues desde la postura de este trabajo investigativo se les asume como los responsables de diseñar y ejecutar prácticas pedagógicas enfocadas a fortalecer una educación encaminada al respeto y garantía de los DDHH a partir de estrategias novedosas, impactantes y pertinentes, estrategias que involucren las emociones, los sentimientos y el afecto de los niños y niñas que tanto lo necesitan.

Hablando sobre los docentes, es preciso hacer una descripción mucho más detallada sobre su presencia en el colegio, para ello hemos de señalar que el Liceo Nacional Antonia Santos I.E.D. cuenta actualmente con 95 profesores, 65 de ellos en bachillerato y los otros 30 en primaria, siendo todos licenciados. 62 de los profesores cuentan con especializaciones en el área de educación y 18 con maestría también del área de la educación. Para efectos de lo que se quiere establecer se realizó una observación estructurada por parte de la investigadora a inicio del año 2016 con el propósito de indagar sobre la percepción que tienen los maestros con respecto a los DDHH, por lo que en este contexto se aplicó una encuesta a 30 profesores con el objetivo puntual de conocer algunas de sus apreciaciones con el tema de la Educación en Derechos Humanos fundamentada en la educación emocional y el papel transformador del profesor en esta labor, los resultados obtenidos fueron importantísimos, primero, para reconocer 
el problema de investigación planteado en esta investigación y, segundo, para proponer una propuesta pedagógica enfocada en este tema. A continuación se destacan, a través de gráficas y esquemas, los resultados obtenidos.

Frente a la pregunta acerca de la importancia que tiene una educación en derechos humanos $(\mathrm{EDH})$ en el contexto escolar, el $99 \%$ de los profesores refirieron una relevancia significativa de la EDH en las aulas, mientras que el 1\% restante consideró el tema algo insignificante.

\section{Gráfico 2}

Importancia de la Educación en Derechos Humanos (EDH) en el contexto escolar.

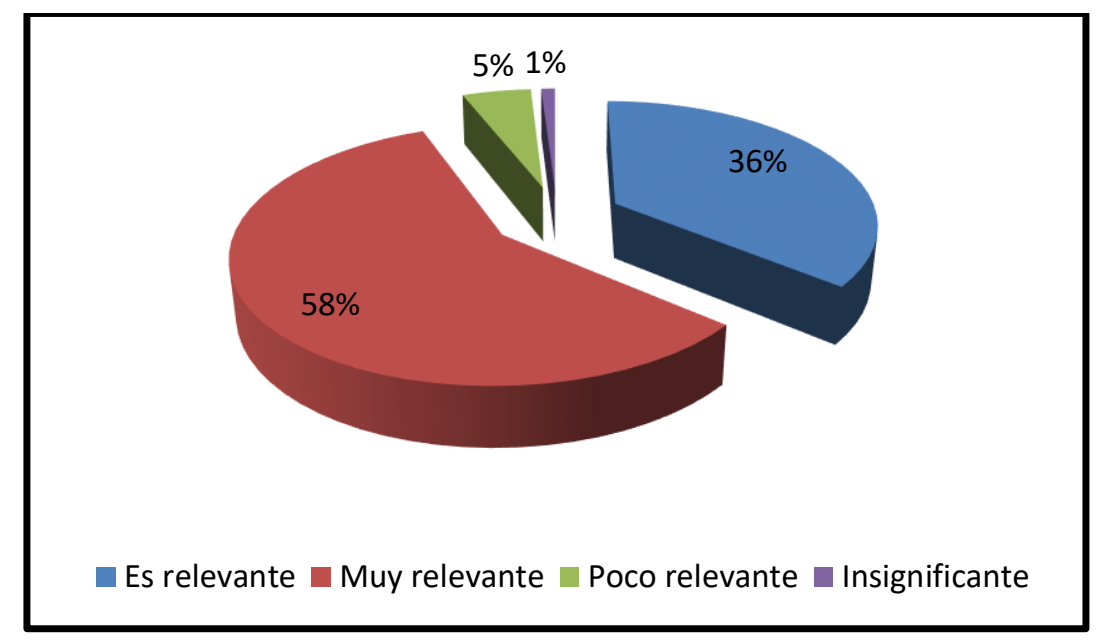

Fuente: Gráfico realizado por la investigadora con base a la información recolectada en las encuestas.

De igual forma se indagó sobre del significado que tiene para el maestro en su labor diaria contar con herramientas pedagógicas adecuadas para una EDH. El 18\% reconoció a este factor como muy relevante, mientras que un $70 \%$ lo catalogó de relevante. El porcentaje restante (12\%), asumió la tenencia de estas herramientas como poco relevante y/o insignificante. 


\section{Gráfico 3}

Significado que tiene para el maestro en su labor diaria contar con herramientas pedagógicas adecuadas para una Educación en Derechos Humanos.

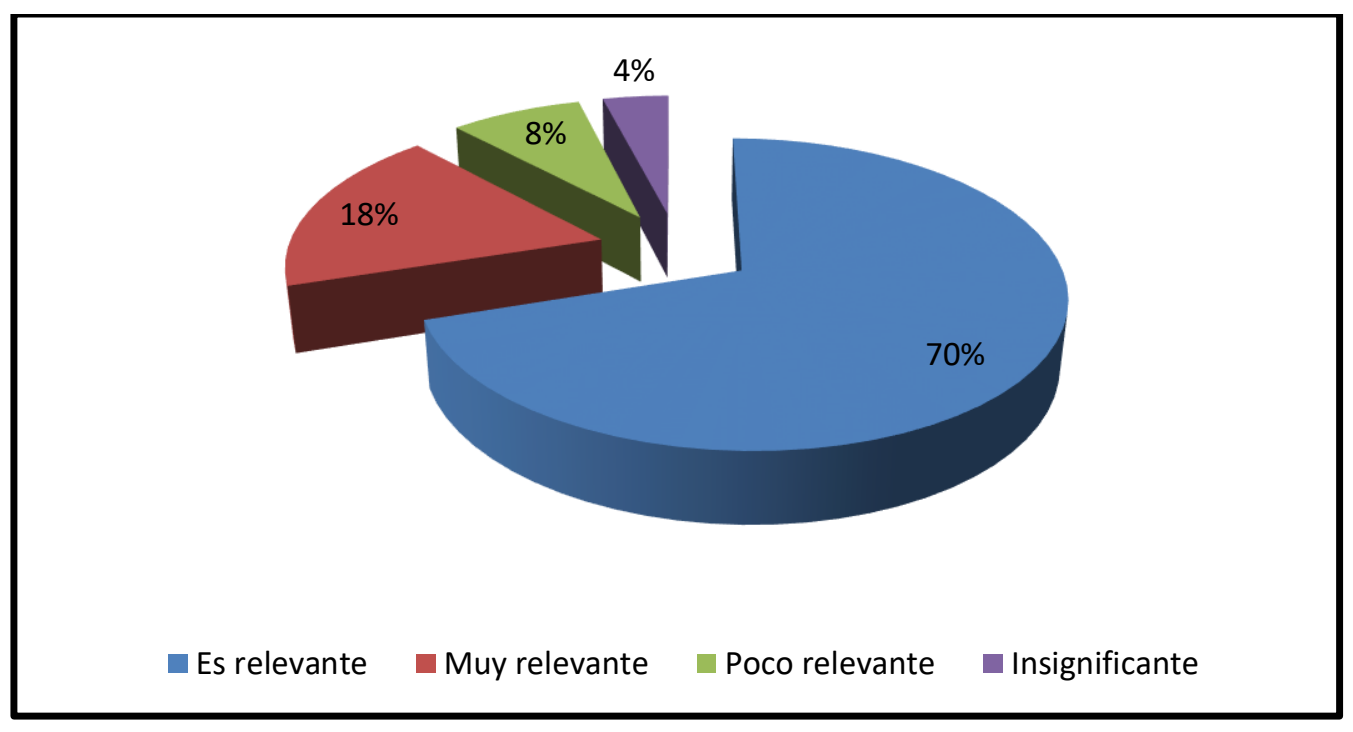

Fuente: Gráfico realizado por la investigadora con base a la información recolectada en las encuestas.

La tercera pregunta tiene que ver con la importancia que los profesores le adjudican al fortalecimiento de la EDH dentro del aula de clase, a lo que un $88 \%$ respondió entre relevante y muy relevante, mientras que un $8 \%$ del total contestó poco relevante y sólo un $4 \%$ de los profesores consideró el progreso de esta práctica pedagógica dentro del colegio algo totalmente insignificante.

\section{Gráfico 4}

Relevancia que tiene para los profesores del colegio Antonia Santos I.E.D. el fortalecimiento de una Educación en Derechos Humanos dentro del aula de clase. 


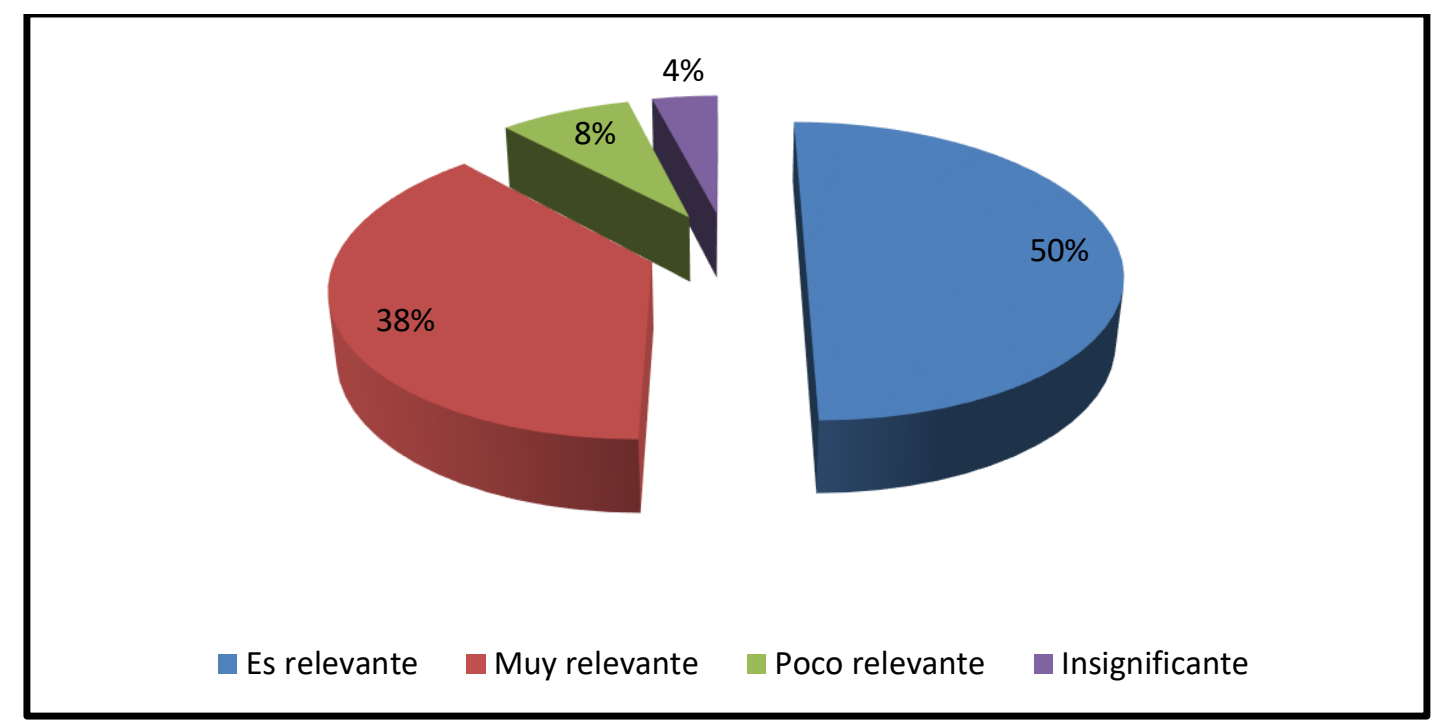

Fuente: Gráfico realizado por la investigadora con base a la información recolectada en las encuestas.

Las cuarta pregunta se enfocó más en obtener información sobre aquellas prácticas pedagógicas que se consideran como transformadoras dentro de la vida de los estudiantes y, por tanto, de la sociedad. Así pues, se quiso evidenciar cuál era la percepción de los profesores no sólo sobre las mencionadas prácticas sino también sobre la asociación que se plantea entre estas y la Educación en Derechos Humanos. Los resultados aclararon que para el menos el 56\% de los encuestados estás prácticas transformadoras basadas en la EDH son relevantes, pero sólo un $28 \%$ los considero mucho más que relevantes. En últimas, sólo un 10\% las consideró poco relevantes, mientras que un $6 \%$ de los profesores las consideró insignificantes tal vez como consecuencia de no considerarles útiles a la hora de llevar a cabo verdaderos cambios.

\section{Gráfico 5}

Importancia que tiene el que las prácticas pedagógicas de los profesores se encuentren basadas en una educación en derechos humanos con la finalidad de transformar significativamente la vida de sus estudiantes. 


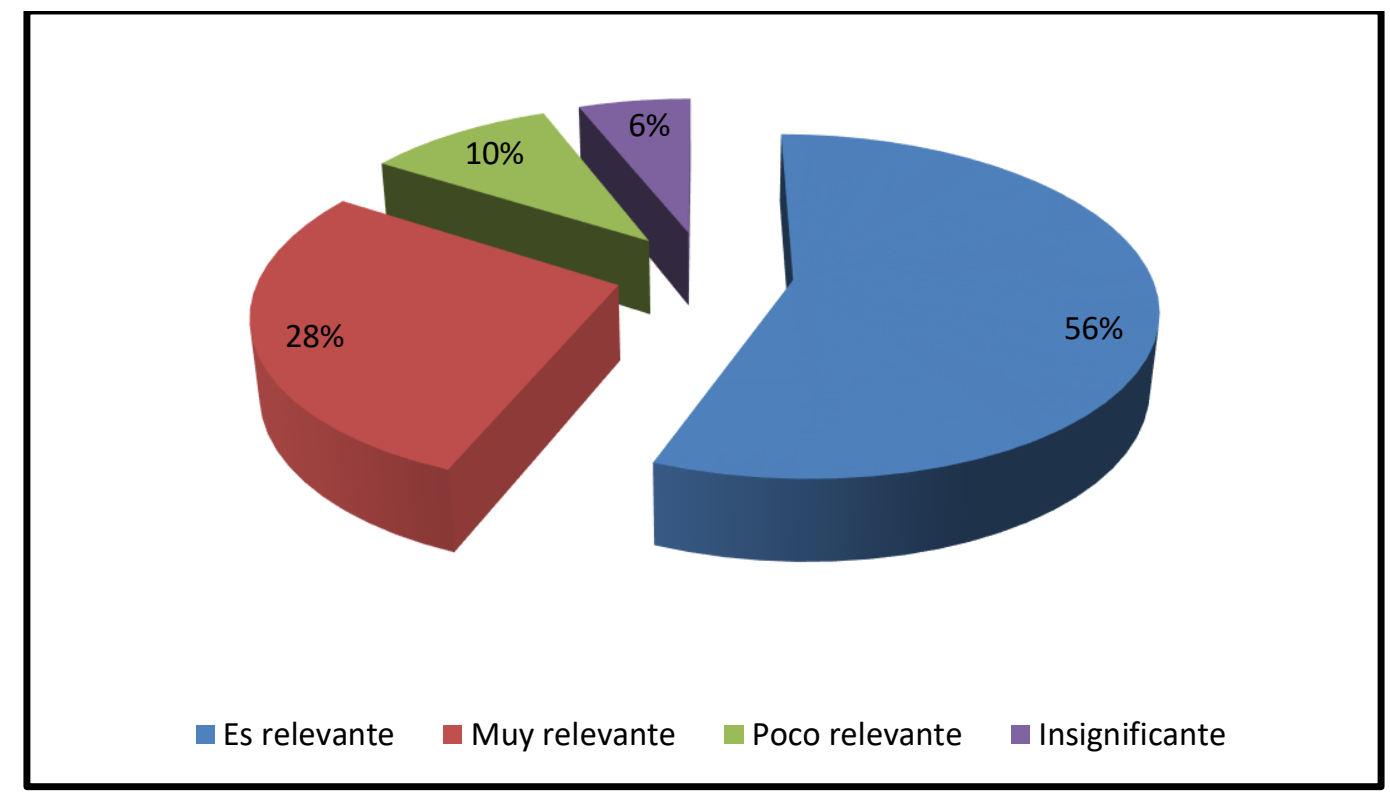

Fuente: Gráfico realizado por la investigadora con base a la información recolectada en las encuestas.

La quinta pregunta tiene que ver con la evaluación de la relevancia que tiene para los profesores el vincular la Educación en Derechos Humanos y la Educación Emocional en el contexto dado por el proceso de enseñanza - aprendizaje en las diferentes aulas, los resultados frente a esta pregunta reiteraron que existe un $86 \%$ del total del profesorado que considera muy relevante y relevante la relación entre estos dos modelos pedagógicos, mientras que un significativo $14 \%$ consideró muy poco relevante o insignificante la mezcla entre ambas prácticas.

\section{Gráfico 6}

Importancia que le adjudican los profesores a involucrar las emociones dentro de la enseñanza de la Educación en Derechos Humanos al interior del aula de clase 


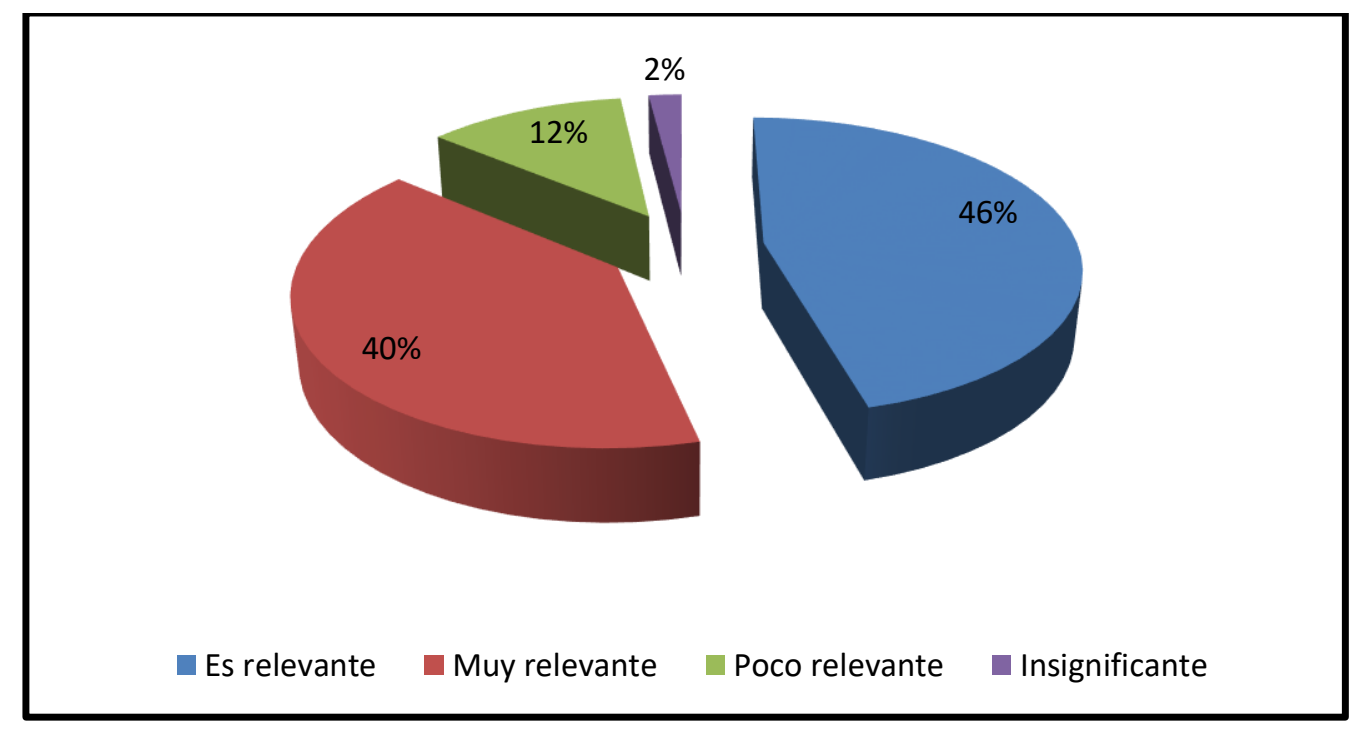

Fuente: Gráfico realizado por la investigadora con base a la información recolectada en las encuestas.

La sexta pregunta intenta identificar si en efecto existe una necesidad latente entre los profesores por vincular su trabajo pedagógico la enseñanza de la Educación en Derechos Humanos fundamentada en las emociones de los estudiantes a quienes va dirigida aquel modelo pedagógico. Las respuestas en este punto fueron bastante positivas pues el $100 \%$ de los encuestados considero relevante y muy relevante esta vinculación.

\section{Gráfico 7}

Pertinencia de vincular en el trabajo pedagógico del profesor la educación de los derechos humanos fundamentado en la educación emocional 

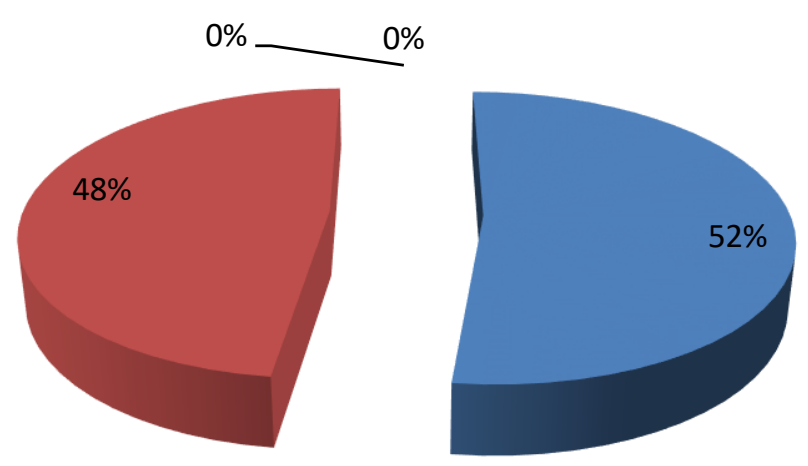

$\square$ Es relevante $\square$ Muy relevante $\square$ Poco relevante $\square$ Ingignificante

Fuente: Gráfico realizado por la investigadora con base a la información recolectada en las encuestas.

Con las respuestas de la séptima pregunta se demostró que los profesores se consideran como fundamentales en el proceso de transformación social del entorno en el que viven sus estudiantes, de ahí que sea la totalidad de los encuestados quienes revelan tal importancia.

\section{Gráfico 8}

Importancia del profesor en la transformación social de sus estudiantes

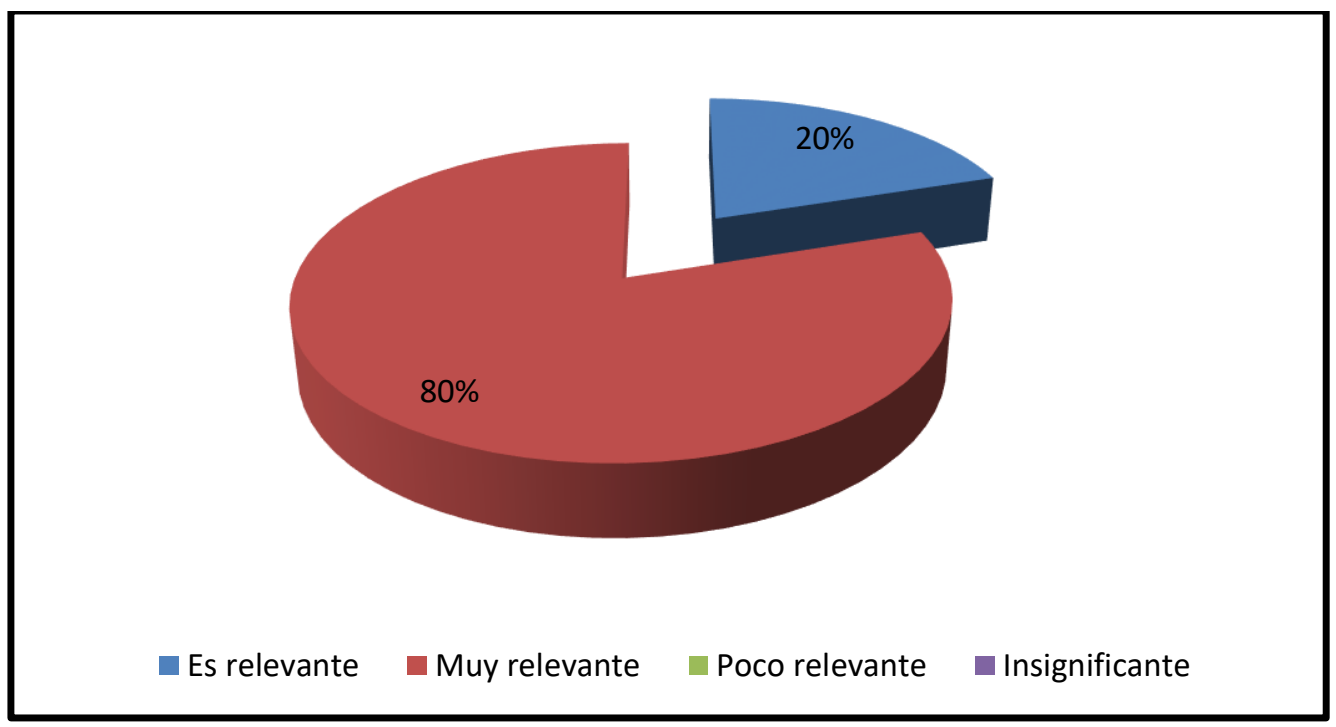


Fuente: Gráfico realizado por la investigadora con base a la información recolectada en las encuestas.

Finalmente, y con la intención de proponer una intervención pedagógica que involucre la EDH con la educación emocional, se preguntó si los profesores de primeria del Colegio Liceo Nacional Antonia Santos consideraban pertinente poner en práctica una apuesta pedagógica en la que se vinculen ambos pedagogías dentro de su aula de clase, cuestionamiento a la que el 100\% del profesorado encuestado respondió positivamente.

\section{Gráfico 9}

Pertinencia de poner en práctica una apuesta metodológica en la que se vincule la

Educación en Derechos Humanos fundamentada en la Educación emocional dentro del aula de clase por parte de los profesores de primaria.

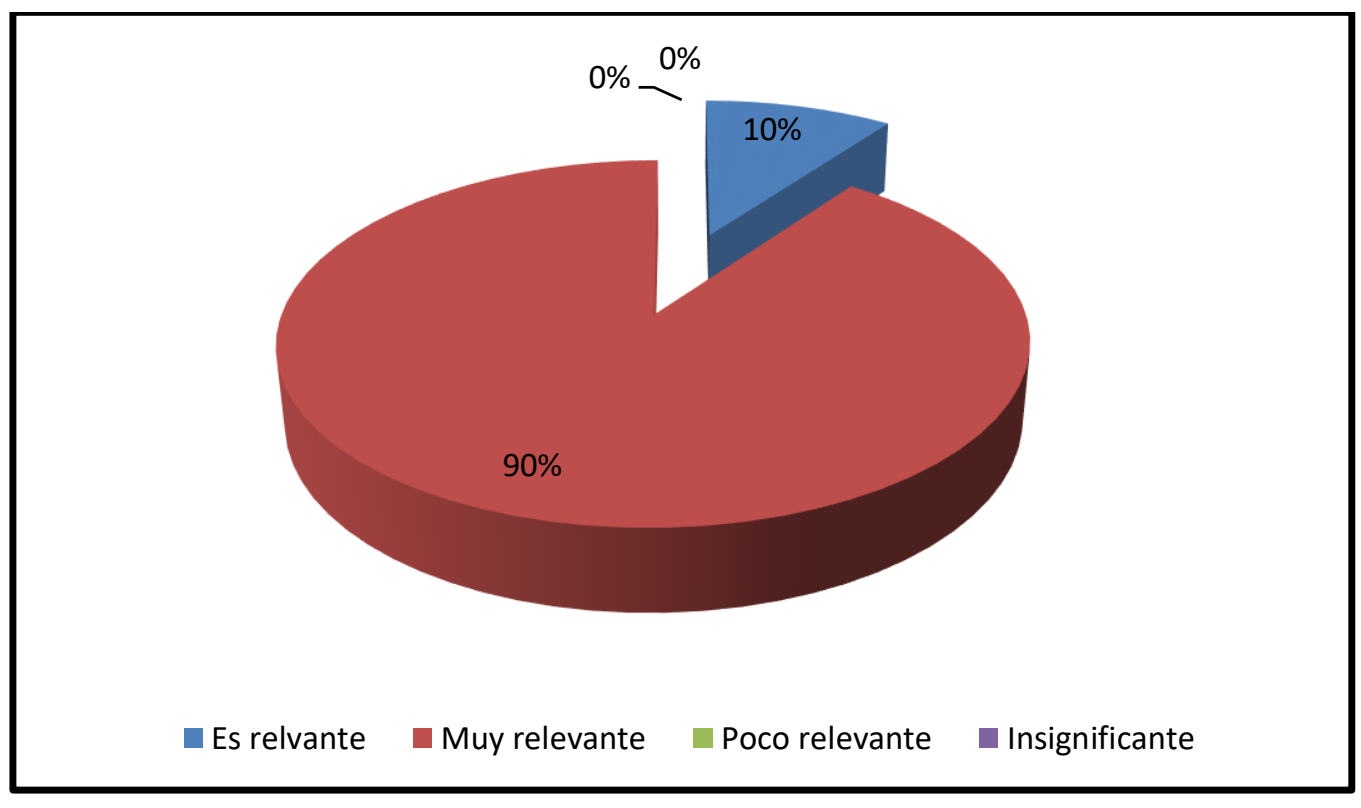

Fuente: Gráfico realizado por la investigadora con base a la información recolectada en las encuestas. 


\section{Debates y tensiones entre la educación en derechos humanos y su relación con la pedagogía} de las emociones

"Ya Freud decía que hay tres misiones imposibles: gobernar, educar y curar y tal vez la más difícil es educar, como decía Luis Pérez Aguirre, porque educar implica estar educado de tal manera que por el hecho de estar uno frente a alguien ese otro pueda sentirse afectado y modificado como persona. Es lo que decía Paulo Freire, que "nadie se educa solo" y más aún que "nadie educa a nadie”, que los seres humanos nos educamos en comunión".

Mujica (2007)

Hechas las aclaraciones pertinentes sobre la naturaleza y propósitos de esta investigación, el objetivo de este segundo capítulo se centra en la fundamentación teórica de las categorías analíticas que constituyen la preocupación conceptual de este trabajo, aquí se enaltecen principalmente dos fenómenos, el primero de ellos tiene que ver con la Educación en Derechos Humanos y las prácticas que su desarrollo implica (el discurso de los derechos humanos y lo imperativo que resulta el rol del profesor dentro de los procesos transformadores que requieren la vida del estudiante, la escuela y la sociedad en general), mientras que el segundo hace referencia a la educación emocional, una estrategia pedagógica que - desde nuestra perspectiva - puede ser acogida y puesta en marcha por los profesores dentro del aula con la finalidad de vehiculizar la enseñanza de la Educación en Derechos Humanos. Sobre este ejercicio, vale la pena resaltar que su importancia radica en la apertura reflexiva que merecen ambos conceptos, pues su abordaje permitirá la comprensión de la multidimensionalidad del proceso de aprendizaje - enseñanza y, 
por ende, la integralidad que debe caracterizar a la propuesta pedagógica que será construida dentro de los planteamientos del tercer capítulo.

Sin ahondar más en lo anterior, hemos de decir que para cumplir con el objetivo propuesto este capítulo ha de ser dividido en cuatro partes, la primera de ellas se caracterizará por el planteamiento de un debate frente al componente filosófico, estructural, jurídico y moral de los derechos humanos desde las ideas de autores como Christoph Menke, Arnd Pollmann y Thomas Pogge, figuras que conceptualizan sobre nociones como la dignidad, la justicia, la igualdad, entre otras. En la segunda parte se analizarán las tensiones que constituyen la relación entre el discurso de los derechos humanos y el desenvolvimiento del contexto escolar a partir de las declaraciones de Abraham Madgenzo y Ana María Bruccetti, personajes que aportan considerablemente a las discusiones respecto a la necesidad de generar modelos curriculares dedicados a la democracia, la libertad y a la convivencia armónica. La tercera parte, estará dedicada al estudio de la educación emocional y el vínculo que se establece con la Educación en Derechos Humanos a partir de autoridades en el tema como Daniel Goleman, Rafael Bisquerra y María Mujica, para finalmente tener una última parte dedicada a la reflexión que merece el papel del docente dentro de la construcción de propuestas pedagógicas desde la educación emocional para socializar la Educación en Derechos Humanos retomando los planteamientos de Rafael Flórez y Mireya Vivas.

\subsection{La fundamentación filosófica de los derechos humanos, una urgencia en medio de las problemáticas sociales del mundo contemporáneo.}

Para iniciar, es pertinente mencionar que el debate filosófico entablado por incontables autores sobre los derechos humanos implica un análisis de los debates que acompañan la comprensión ética, moral y jurídica de estos principios consolidados como imperativos en la 
edificación tanto del accionar institucional nacional e internacional como en la cotidianidad de las personas dentro de sus propios territorios. Así pues, debe ser traída a colación la tensión protagonizada entre la visión tradicional de los derechos humanos, cuyo planteamiento se basa en que la naturaleza humana es equiparable con la obligación que tienen los hombres de respetar a los demás por su condición de iguales sin distinción alguna, y las complejas realidades que son evidenciadas hoy en día a lo largo y ancho del mundo y que contradicen lo anterior, en otras palabras, en esta primera parte resaltaremos el hecho de que aquella visión tradicional que defiende que el hombre, por ser hombre, respeta naturalmente los derechos de los otros seres humanos, no es consecuente con la crisis humanitaria que actualmente se vive en el mundo, un fenómeno negativo en el que se envuelve toda una crisis de valores dentro del tejido social global Menke y Pollmann (2010).

Así las cosas, nos interesa dejar en claro que lo planteado desde la postura más tradicional es inconsistente con las problemáticas y los desafíos que son evidenciados en las realidades del momento, pues es de conocimiento general que el modelo económico y social que hoy impera en las distintas comunidades nacionales está caracterizado por el egoísmo, la codicia, la intolerancia y la búsqueda del beneficio personal. Cada una de estas deficiencias es fácilmente comprobable en casos como el colombiano, en donde no es un secreto para nadie que una de las dificultades más profundas del país se relaciona con la corrupción de la clase dirigente, es decir, con el provecho que cada político de turno quiere obtener de su periodo en el poder sin tener en consideración el grado de afectación que su avaricia genere en la sociedad. Es, precisamente, en consideración de la situación anterior que los docentes, actores fundamentales en el proceso de construcción de la cultura, deben cuestionar los planteamientos que tienen los autores que defienden esta clase de posturas ya que desde la visión crítica que se acoge en esta investigación 
se afirma que lo planteado teóricamente no tiene gran relación con lo evidenciado en las realidades prácticas, de ahí que se proponga una lectura de los derechos humanos alejada de esa concepción teórica sin fundamentos. Así pues, para este trabajo, los derechos humanos ya no se deben interpretar a partir de la supuesta "naturaleza respetuosa del hombre" ya que como se ha mencionado la crisis de valores y/o principios humanistas justifica actos inaceptables como la corrupción, discriminación y desigualdad para lograr los propósitos de quienes los promueven.

Aclarado lo anterior, es necesario profundizar un poco en este debate con respecto al tratamiento de los derechos humanos desde la perspectiva teórica tradicional, para ello serán retomados las ideas de Menke y Pollmann (2010), quienes nos introducen en lo conflictivo que resulta la adopción de tres modelos asociados tanto a aquella visión debatible, como a su aplicabilidad en el marco proporcionado por políticas totalitarias en la contemporaneidad. El primero de aquellos modelos de postura tradicional tiene su origen en los planteamientos filosóficos de Jean Jacques Rousseau ${ }^{8}$ y la construcción del concepto de contrato social, allí los hombres en su totalidad son considerados en igualdad de derechos como consecuencia de un contrato que así lo define. El segundo modelo tradicional se constituye a partir de la razón, teniendo en cuenta los postulados de Immanuel $\operatorname{Kant}^{9} \mathrm{y}$, el tercer modelo, hace referencia a un esquema que define a los derechos humanos a partir de sentimientos como la compasión, la simpatía y el amor al prójimo, fenómeno que hace referencia a la capacidad que tiene un hombre

\footnotetext{
${ }^{8}$ Jean Jacques Rousseau, uno de los pensadores del liberalismo político más representativos del siglo XVIII y cuya filosofía se caracteriza por considerar al ser humano en esencia bueno pero corrompido por la sociedad a través de su contacto con la misma. Para más información se recomienda la lectura del texto de Michel Soëtard titulado Jean Jacques Rousseau (1712 - 1778), disponible en el siguiente link: http://www.ibe.unesco.org/sites/default/files/rousseaus.PDF

${ }^{9}$ Immanuel Kant, filósofo alemán pionero de la ilustración por medio de sus conceptualizaciones sobre la importancia de la razón dentro del desarrollo de la vida humana. Para más información sobre la vida de este personaje léase el texto de Heinrich Kanz titulado IMMANUEL KANT (1724-1804). Disponible en el siguiente link http://www.ibe.unesco.org/sites/default/files/kants.pdf
} 
de ponerse en la posición del otro. Dicho esto, es necesario resaltar que esta última perspectiva es la más pertinente, ya que se considera que la sociedad necesita con urgencia que los hombres comprendan a los derechos humanos a partir de sentimientos que le permitan entender y compartir la posición de otros seres humanos que, aunque diferentes, deben ser tratados con toda la importancia requerida.

Precisamente, esta investigación se encamina a destacar el papel fundamental de los profesores en la aplicación de una propuesta pedagógica que vincule una educación en derechos humanos fundamentada en la educación emocional, para ello y tal como lo proponen los autores, sólo en la medida en que la educación es el principio básico de tales derechos se debe permitir una continua revisión de los mismos, lo que genera una tensión constante que permanece al interior de los derechos humanos, entre la declaración de un sistema de derechos y el reconocimiento de cada uno de los demás derechos que son esencialmente pre legales y que por ello, tal reconocimiento, es y será siempre no legal (Pollmann y Menke, 2010).

Para esta investigación resulta significativo ubicarse en la visión contemporánea de los derechos humanos, debido a que promueve su fundamentación a partir los derechos humanos basados en determinadas emociones, comprendiendo los sentimientos del amor al prójimo de un modo parecido a la capacidad de y a la predisposición a ponerse en lugar del ser querido, y eso es lo que precisamente requieren los profesores para aplicar en sus estudiantes la estrategia pedagógica que vincule las emociones y todo tipo de sentimientos en los niños y niñas que vivan de cerca los derechos humanos más allá de una concepción meramente teórica, histórica o conceptual. 
Frente a esta postura filosófica en la fundamentación filosófica de los derechos humanos en voces de Pollmann y Menke, tenemos el debate dado por Pogge (2005), con respecto a la postura jurídica y moral de los derechos humanos. Partiendo de la idea según la cual los derechos deben entenderse como exigencias que cada hombre puede hacer valer frente a todos los demás; "se trata entonces de aquellas exigencias que tienen la fuerza de comprometer a todos los hombres solamente porque se trata de exigencias de un hombre, de un miembro de la comunidad humana” (Pogge, 2005). Por esta razón, este autor considera que:

Las normas de la moral sostienen que cada hombre debe respetar a todos los demás hombres como iguales y el Derecho Moral consiste en que cada hombre debe ser considerado por todos los demás como igual, por ello es claro que al ser los hombres iguales e independientes, nadie debe dañar a otro en su vida, salud, libertad o posesiones (Pogge, 2005, p. 56).

Es precisamente bajo esta perspectiva que se plantea en esta investigación la propuesta pedagógica para los profesores del colegio Antonia Santos I.E.D. en la cual se pretende desarrollar la EDH desde la educación emocional, teniendo como fundamento la postura filosófica de los DDHH de Pogge, según la cual, todos debemos respetarnos como iguales y por lo tanto, la educación emocional resulta ser el medio idóneo para una adecuada y pertinente EDH. A este debate planteado por Pogge se contrapone una tensión acerca de los DDHH planteada por Pollmann y Menke, (2010), afirman que los Derechos Humanos no son Derechos Morales (de compromiso), ni son Derechos Jurídicos (de situación legal), en tanto las obligaciones tienen destinatarios diferentes y no solamente los iguales ante nosotros, ejemplifican que, "en el caso de que un hombre lesione a otro no se llama vulneración de su 
Derecho Humano a su integridad física, sino que se refiere a la vulneración de un Derecho Moral o de un Derecho Jurídico" (Pollmann y Menke, 2010).

Para esta investigación resulta importante reconocer el carácter moral de los Derechos Humanos, consistente en el reconocimiento de los profesores de los derechos morales que tiene los unos con los otros, entonces bajo esta postura teórica, todos los hombres están comprometidos moralmente a respetarse mutuamente como iguales, de la misma manera el orden público debe estar comprometido a respetar a cada hombre como igual. Los derechos morales y lo que Pollmann y Menke denominan, el derecho cosmopolita, "reconocer como igual no sólo a cada uno de los miembros de un Estado, sino a cada hombre como ciudadano del mismo mundo", posibilita que los profesores a partir de sus prácticas pedagógicas puedan hacer comprender a sus estudiantes que son ciudadanos del mundo y no limitarlos con fronteras que más que físicas son mentales.

$\mathrm{Al}$ respecto y de acuerdo con el planteamiento del problema planteado en esta investigación, acerca del contexto de violencia, falta de tolerancia y afecto en que se encuentra nuestro contexto educativo, requiere de manera urgente una transformación social y pedagógico que aporte a un cambio de mentalidad en cada uno de los contextos institucionales, partiendo de los mimos profesores; transformación que promueva y permita una educación en derechos humanos y que además se haga teniendo en cuenta la educación emocional, los sentimientos y lazos de afecto que día a día se entrelazan y cruzan en los diferentes miembros de la comunidad educativa del colegio Antonia Santos I.E.D.

Otra de las tensiones acerca de la fundamentación de los DDHH, según el debate y tensión dada en los autores puestos en discusión, es su postura universalista y relativista. Esta 
tensión expone que la visión universalista actualmente quiere mantener un derecho igual para todos y un estatuto jurídico-moral igual para cada individuo. Entonces surge el problema del universalismo, cuestionado últimamente en el tema de los derechos humanos, éstos se quieren dirigir a todos los hombres de forma general, idéntica, igualitaria, indivisible y categórica, pero la consideración universal de todos los hombres es que sólo es aceptada y practicada en ciertas culturas, no en todas (Pollmann y Menke, 2010).

De otra parte, los relativistas consideran que los derechos humanos no pueden adecuarse de igual manera en todas partes y para todos, plantean que los derechos humanos son un invento occidental, europeo y norteamericano, en este sentido proponen que los hombres se distinguen unos de otros básicamente por sus prácticas: “el ámbito de la praxis humana es esencialmente plural. Por lo tanto si el fundamento de los derechos humanos es una praxis (conclusión relativista) entonces ya no se puede reclamar más la validez universal para los derechos humanos" (Pollmann y Menke, 2010).

Aplicando estos planteamientos al contexto escolar, las ideas del universalismo y el relativismo de los derechos humanos no deben ser vistas de manera aislada, unívoca e independiente, dado que las dos aportan desde perspectivas diferentes a la comprensión y vivencia de los derechos humanos en la vida práctica; por un lado, el universalismo en la medida en que propone unos mínimos universales de igual respeto hacia toda la humanidad, el que cada individuo tenga autodeterminación, la oportunidad de pensar y elegir por sí mismo, y por otro lado el relativismo, en tanto no se homogenice políticas que atenten contra el respeto y el reconocimiento a la diversidad y todos los derechos humanos en general. 
En la comunidad educativa se trata de no imponer de manera arbitraria normas y leyes que aparentan ser principios orientadores de convivencia, sino de entrar en un diálogo diverso e incluyente entre profesores, estudiantes, padres de familia y demás miembros de la comunidad que abarquen posibilidades y retos de poder ser y estar en este mundo de manera armónica planteando propuestas que permitan enriquecer prácticas pedagógicas desde el ámbito escolar.

Finalmente hay un debate interesante en la fundamentación de los derechos humanos y tiene que ver con el concepto de dignidad humana, reconocer si existe o no una relación entre dignidad humana y derechos humanos, si ésta se da antes de ellos, si es independiente o si necesariamente están conectados. Esta tensión, analizada por Pogge (2005), encuentra su génesis en el mismo concepto, para este filósofo, la dignidad humana es entendida como el florecimiento humano, refiriéndose a ello no sólo con el concepto de calidad de vida, sino que lo enriquece con otros componentes que hacen parte del placer y la satisfacción, resaltando que entre estos componentes se ubican los conceptos de bienestar, prosperidad, virtud, además de la excelencia y los logros diversos, inclusive llevando a que se tenga en cuenta el criterio que tienen los demás para definir su propio florecimiento. Sin embargo, Pollmann y Menke (2010), cuestionan si los derechos humanos pueden concebirse sin tener en cuenta el concepto de dignidad humana o si por el contrario existe una relación indisoluble entre ellos, toda vez que cada uno de los derechos humanos solamente despliega lo que el concepto de dignidad humana ya contiene en sí mismo.

En conclusión, los conceptos de dignidad y derechos humanos se encuentran estrechamente relacionados; ya que la dignidad humana se perfila desde las pretensiones morales y la subjetividad antes que desde la misma norma, además la dignidad humana, lleva a que las personas se sientan satisfechas desde su autopercepción, autodeterminación y reconocimiento; es así como el florecimiento que propone Pogge (2005) se refiere a la idea de complemento 
fundante que le permite al ser humano a través de su bagaje histórico, cultural, social y pragmático, diseñar y construir su proyecto de vida, el cual es dinámico y va acorde con sus intereses, sentimientos y necesidades. Finalmente las tensiones y debates presentados por autoridades como Pollmann y Menke con respecto a Pogge, posibilitan una adecuada fundamentación filosófica de los derechos humanos como herramienta necesaria para que los profesores reconozcan y valoren su importancia en las prácticas pedagógicas y sobre todo, que se pueda cumplir a cabalidad con la propuesta pedagógica en el colegio Antonia Santos I.E.D. para ello es fundamental entender la esencia de los DDHH y sólo el desarrollo histórico que es a lo que más recurrimos los profesores a la hora de fundamentar una propuesta pedagógica.

\subsection{El debate de los derechos humanos y la educación en derechos humanos: una nueva}

\section{forma de concebirlos, entenderlos y vivirlos}

Con el objetivo de plantear una propuesta pedagógica a los profesores en el escenario de la $\mathrm{EDH}$, en esta investigación se hace necesario reflexionar sobre el debate actual entorno a la concepción de la educación en derechos humanos dado que la misma ha tenido diversas formas de concebirse dependiendo de la época y de la postura teórica defendida por distintos autores expertos en el tema. Por ello, se parte de las nuevas formas de concebirlos, entenderlos y vivenciarlos en el escenario educativo a partir de los planteamientos hechos por Magendzo (2006), quien considera que la EDH implica el "reconocimiento, la defensa, el respeto y la promoción de los Derechos Humanos y su objeto es desarrollar en los individuos y los pueblos sus máximas capacidades como sujetos de derechos y brindarles las herramientas y elementos para hacerlos efectivos" (p. 23).

Para profundizar más en el tema, diremos que resulta evidente que para Magendzo los profesores están llamados a promover la formación de valores teniendo como eje central la 
dignidad humana, en tanto la formación de sujetos de derechos significa que el individuo reconozca sus derechos y los del otro, además los exija y coloque en práctica en cada rol que cumple en la sociedad. Para esta investigación, la educación en derechos humanos ha de concebirse como un derecho humano en sí mismo, es decir, como un principio con el cual cada persona se reconozca como sujeto de derechos, (los ejerza y los exija), pero también los reconozca y los respete en los demás. Bajo esta misma perspectiva, también nos valdremos de las ideas Mujica (2007) quien también considera que la educación en derechos humanos no significa un ejercicio intelectual, sino que pertenece a los sentimientos, porque "supone trascender la palabra y pasar a la acción. Es el desafío de ser más humanos. Educar sería en este sentido el intento de transmitir y adquirir actitudes que encarnan la utopía de los derechos humanos" (p. 23).

Para complementar esto, se dirá que la EDH tiene unas características especiales entre las cuales se destaca su centralidad en la persona, en el aprendizaje significativo y la búsqueda de una enseñanza integradora, por lo que se sostiene que desde la EDH los profesores buscan humanizar la práctica educativa en la que los estudiantes vivencien los valores, los principios y los sentimientos con ellos y con sus semejantes (Mujica, 2007). Además, los derechos humanos se conciben como aspiraciones morales, por tanto la EDH va más allá de la transmisión de derechos reconocidos internacionalmente, la cual debe convertirse en una práctica diaria del ser humano, que implica "una cultura de derechos humanos que inspire y abarque las relaciones humanas" (Espinel, 2010, p. 42), es por ello que en el contexto educativo no es válido plantear que los derechos humanos se enseñan como cátedras en el aula de clase ya que no se trata de una transmisión de un saber o un conocimiento para su memorización sino de su respeto y ejercicio. (Esa ha sido una de las dificultades encontradas en las encuestas que se practicaron a los 
profesores del colegio Antonia Santos I.E.D. en la cual algunos profesores señalaron que enseñar derechos humanos equivalía a transmitirlos en una clase a los estudiantes).

Así las cosas, hemos de recalcar nuevamente que la tarea como profesores en las instituciones educativas es formar sujetos de derechos capaces de transformar la sociedad, por lo que se exige que los individuos:

a. Conozcan las normas e instituciones a las cuales pueden recurrir frente a una situación en la que se le haya violado alguno de sus derechos.

b. Tenga la capacidad de defender sus derechos por medio de un lenguaje apropiado y que revele su empoderamiento frente al tema.

c. Haga valer sus derechos pero a la vez reconozca al otro y de manera recíproca espera a que ese otro también lo identifique y trate como sujeto de derechos.

d. Sea capaz de tener en cuenta al otro sin el ánimo de juzgarlo, mostrando una actitud comprensiva frente a su historia de vida (Magendzo, 2008).

Para ello, también es importante generar en los estudiantes un pensamiento crítico como en su momento lo propuso Paulo Freire, un pensamiento que permita aprendizajes significativos y que por lo tanto implique cambios a nivel social pero, para ello, es fundamental la formación de la persona a partir de la cual percibe y comprende el contexto en el que se encuentra. En mente lo anterior, cabe señalar que otros autores como Stephen Kemmis (citado por Magendzo, 2008) han destacado a la EDH desde la noción de comunidades críticas, lo cual implica la formación de valores y la participación de profesores, padres de familia, estudiantes, etc., en una adecuada y pertinente EDH. Sin embargo, para este autor no es suficiente lo que se logre desde las aulas de clase, ya que debe generarse desde los diversos ámbitos que influyen en el ser humano, entre ellos el Estado representado por sus servidores públicos quienes, en el desempeño de sus 
funciones, deberían promover el reconocimiento y el respeto por los derechos propios y de los demás.

Ahora bien, analizando el devenir histórico de la EDH, vemos que esta tuvo su génesis en las décadas de los 70 a los 90 en América Latina, en medio de dictaduras militares y guerras civiles pero se fue fortaleciendo a través del surgimiento de organizaciones no gubernamentales, movimientos sociales, actividades y programas educativos, de esta manera nace ligada al movimiento de la educación popular, de una educación liberadora, anti opresora (Paulo Freire citado por Magendzo, 1998) “una educación formadora de una moral y una conciencia capaz de transformar la sociedad para hacerla más justa y solidaria”.

Así los profesores van a cumplir un papel trascendental en este proceso de construcción de la EDH a través de diversas acciones tales como la multiplicaron de talleres, además las organizaciones civiles promotoras de DDHH se expandieron rápida y vertiginosamente en todos los países, se realizaron experiencias pedagógicas, se aumenta la producción escrita en este tema, se promueven encuentros académicos y nace el Instituto Interamericano de DDHH (IIDH) ubicado en Costa Rica y el Departamento de Educación, la EDH se incorporó a las políticas públicas (Magendzo, 2008).

La EDH en América Latina ha tenido un desarrollo muy importante, partiendo de un reconocimiento en el que los DDHH han pasado a formar parte de las políticas públicas en educación en todos los países de la región; pero ello no ha sido fácil ni mucho menos rápido, se ha logrado a través de muchas luchas sociales de los profesores, de paros, manifestaciones y protestas en las que se ha reclamado una mejor calidad educativa, ha sido un avance lleno de múltiples y variadas tensiones y dificultades, cada una de las décadas ha tenido su propia lucha y su propio aporte en esta construcción de modelo educativo vinculado a los derechos humanos. 
Aunque ha de reconocerse que la tarea aún esta inacabada, todavía requiere de más trabajo y puesta en práctica en los escenarios educativos, un ejemplo de ello se evidenció directamente con los profesores al momento de identificar las necesidades institucionales en materia de educación en derechos humanos en el colegio Antonia Santos I.E.D., parece ser que se encuentra fortalecido desde el documento, desde la teoría, pero en la práctica, falta mucha puesta en escena, los profesores tienen que ser más asertivos, propositivos, y prácticos para llevar a cabo esta tarea, entre otras razones porque la EDH exige un trabajo constante y no tan silencioso. En la sociedad falta bastante trabajar en el tema de los valoras, los derechos la justicia social, la equidad, erradicar las discriminaciones, "promoviendo nuevas formas de interacción social disminuyendo las brechas que clasifican, estratifican y estimulan el abuso de poder" (Magendzo, 2008).

En la presente investigación es muy relevante entender de manera global los aspectos propios de la EDH en Colombia y Latinoamérica. Colombia ha aportado a este proceso de construcción a pesar de la situación difícil de violencia de más de cincuenta, décadas de violación de los DDHH, y desigualdad social. Así, dentro de los aspectos de la EDH en esta sociedad, expuestas por Magendzo (2008), tenemos en primer lugar los entornos, es decir, debe ser una educación contextualizada, que vincule las formas variadas del medio, las características políticas, sociales, culturales y económicas propias de cada país. En segundo lugar, debe ser una educación constructora de democracia, que respete los derechos fundamentales de los ciudadanos; y tercero, debe ser una educación política y transformadora:

La relación entre la política, el Estado y la EDH es un tema recurrente en esta sociedad y ello es porque ésta es educación política pues uno de sus objetivos es formar personas 
comprometidas con la transformación de la sociedad, en una más justa e igualitaria, en donde los DDHH sean parte integral de la cultura ciudadana (Magendzo, 2008, p.9).

Desafortunadamente, se proponen políticas públicas en relación a la EDH, hay planes, programas bien estructurados en cada país, incluso los Estados firman tratados y compromisos internacionales al respecto, sin embargo, y como le he mencionado anteriormente, en la práctica ello no se evidencia en la comunidad educativa y mucho menos en la sociedad en general.

Magendzo (2008), también propone que la EDH debe ser una educación ético-valórica, dada la característica universal de todos los hombres que nacen libres e iguales en dignidad y derechos; debe ser una educación integral-holística, que no se limite al suministro de información, sino permita la construcción de un proceso integral que sea para toda la vida; debe ser una educación para la paz, pues la violencia genera es el espacio propicio para la vulneración de los DDHH; y finalmente, debe ser una educación que vincule decisiones curriculares y pedagógicas, que tenga en cuenta tanto el currículum explícito como del oculto, de esta manera todos estos elementos característicos deben verse reflejados en la forma en la que opera la escuela.

Por otro lado, Magendzo (2008) identifica las principales Tensiones de la educación en derechos humanos en esta sociedad, las cuales se describen a continuación:

Primero, la tensión que se presenta entre el autoritarismo y la autonomía, hace referencia a que las propuestas educativas, se ven influenciadas por posturas políticas con las que se imponen ideologías homogenizantes. 
Segundo, la tensión entre el entorno y el sujeto; se presenta una confrontación entre el entorno (lo de afuera) y la expresión del sujeto de conocimiento (el adentro), representado en los pensamientos o sentimientos de la persona y lo que manifiesta su entorno social represivo.

Tercero, la tensión de construcción de confianza - desconfianza y los miedos, toda vez que es difícil construir confianza únicamente a partir de la memoria histórica, así mismo la desconfianza logra que la EDH politice la escuela, obstaculice la reconciliación y la transición hacia la democracia; además los miedos tienen la característica de silenciar la memoria permitiendo que los poderes que participaron en la vulneración generalizada de los DDHH sigan operando (Magendzo, 2008).

Cuarto, la tensión entre neutralidad y el compromiso político-ideológico y el cambio y la transformación social; la EDH no puede ser neutra, sino que tiene compromisos ineludibles con la justicia social, el entorno político, social, cultural, económico y con los problemas que la sociedad confronta.

Quinto, la tensión entre Estado y sociedad civil, ésta cuestiona sobre quiénes deben ser los responsables de educar en DDHH a la ciudadanía, si el Estado o las ONG y la sociedad civil, ambas partes tienen una responsabilidad compartida en estos procesos formativos.

Por último, Magendzo (2008) menciona la tensión derivada de la polisemia de términos; existe una variedad de conceptos para definir la EDH, entre los cuales se encuentran, educación ciudadana, cívica, en DDHH, para la democracia, en valores, para los DDHH, para la tolerancia, no sexista, no violenta, y en el caso de Colombia también se encuentra la cátedra para la paz, educación multicultural y contra la violencia, entre otras. Esta polisemia lleva a una 
incomprensión de los mismos, generando confusiones, y hasta posturas en las cuales ni siquiera se adopte ninguna de ellas y por el contrario se dé la espalda a esta importante acción escolar.

En Colombia, durante la década de los 80 sobresalen dos ideas en el tema de la EDH: la paz y la vida, con la finalidad del fin del conflicto armado interno y el surgimiento de otros actores diferentes a la guerrilla (Restrepo, citado por Magendzo, 2008). En esta década, se señalaba que a la grave situación de violencia en el país se sumaban dos actores más, el paramilitarismo y las autodefensas, apoyados inclusive por miembros del Estado con intereses particulares, especialmente en el agro, de multinacionales que se preparaban para explorar sectores de la agricultura y la minería, de políticos, miembros del ejército y de la policía sin escrúpulos, y el fortalecimiento del narcotráfico (Restrepo, 2008).

Esta problemática se ha visto reflejada en la actualidad, por un lado, es de conocimiento público el apoyo del Estado al paramilitarismo y la grave violación a los derechos humanos que estos generaron, en el campo, en las ciudades y por supuesto en el contexto educativo pues las realidades escolares de nuestros estudiantes estuvieron permeadas por la afectaciones psico sociales y los impactos que ello les generaron; por otro lado, en lo que tiene que ver con la imposición e invasión de las multinacionales, hoy por hoy, son cada vez más los municipios que le dicen no a la minería, realmente la consulta popular se ha convertido en una gran herramienta jurídica para proteger los recursos de la nación. Por supuesto todos estos elementos, tiene una gran incidencia en la EDH, dado que en las escuelas no podemos hablar de derechos humanos si evidenciamos una sociedad con múltiples problemáticas como las hemos tenido y la seguimos teniendo. 
Otro aspecto importante que destaca Restrepo (citado por Magendzo, 2008), dentro del marco de la evolución de la EDH en Colombia tiene que ver con el reconocimiento de la existencia de una multiculturalidad y plurietnicidad, es así como se abre un lugar en el campo de los DDHH para los pueblos indígenas, afrodescendientes y grupos campesinos en la actualidad. De cualquier modo, el derecho a la inclusión en el escenario educativo ha permitido vincular en los procesos pedagógicos de la comunidad educativa no sólo a estos grupos étnicos, sino a todo tipo de grupos poblacionales que por alguna u otra razón se consideren con características especiales, tales como aquellos estudiantes con trastornos del aprendizaje, deficiencias psicológicas y/o psiquiátricas, entre otras.

Finalmente, Magendzo (2005) sintetiza que la educación en derechos humanos "tiene por objeto desarrollar en los individuos y los pueblos sus máximas capacidades como sujetos de derechos y brindarles las herramientas y elementos para hacerlos efectivos" (p.23). Teniendo en mente lo anterior, apuntaremos que para esta investigación es importante que la EDH debe direccionarse al desarrollo de un pensamiento crítico entre los profesores, es decir, al desarrollo de la capacidad que tienen los mismos de transformar las realidades de los estudiantes y analizar sus dificultades para ayudar a la formación de un ser humano libre, capaz de construir su proyecto de vida con corresponsabilidad, sin temor a las batallas que tenga que afrontar en la búsqueda y exigibilidad de sus derechos humanos.

\subsection{La educación emocional y su relación con la educación en derechos humanos: un vínculo necesario en el contexto escolar.}

Llegados a este punto es necesario hablar con más profundidad sobre la educación emocional, para ello serán tomados los planteamientos de autoridades como David Goleman, Rafael Bisquera, Rosa María Mujica, entre otros, con la finalidad de proponer una discusión 
sobre algunos de los aportes más significativos en este ámbito y, por supuesto, su vínculo con la educación en derechos humanos. Empecemos entonces por definir el concepto de emoción. Según la definición de la Real Academia Española de la Lengua (s.f.), se refiere a una “alteración del ánimo intensa y pasajera, agradable o penosa, que va acompañada de cierta conmoción somática”. En el contexto escolar, este elemento es muy importante porque es precisamente lo que caracteriza a los estudiantes ya que los entendemos como seres cargados de emociones que transitan entre la felicidad y el disgusto, cuestión que si bien hace aún más complejo el trato con ellos es imposible de excluir de las dinámicas propias del aula de clase.

Además de lo anterior, cabe señalar que la emoción y, en consecuencia, la educación emocional parten de los postulados de la inteligencia emocional. De acuerdo con los postulados de Fernández (2009) la inteligencia emocional es aquella:

Habilidad para percibir, comprender, asimilar y regular las emociones propias y la de los demás, aparece como una destreza crítica que ayudaría a los adolescentes a guiar sus pensamientos y a reflexionar sobre sus emociones ayudándoles a mejorar sus niveles de bienestar (p. 85).

Teniendo como referencia lo anterior, se afirma que las emociones cumplen un papel fundamental en el proceso de aprendizaje. No obstante, para autoridades en este campo como Daniel Goleman la inteligencia emocional no es concebida únicamente como una "habilidad", sino que se reconoce como:

Una forma de interactuar con el mundo que tiene muy en cuenta los sentimientos y engloba habilidades tales como el control de los impulsos, la autoconciencia, la motivación, el entusiasmo, la perseverancia, la empatía, la agilidad mental, etc. que 
configuran rasgos de carácter como la autodisciplina, la compasión o el altruismo, indispensables para una buena y creativa adaptación social (Domínguez et al., 2009, p. 4476).

Para esta investigación, el postulado de Goleman sobre la educación emocional resulta más que fundamental en tanto se tiene en cuenta que el escenario educativo no es sólo un espacio donde los estudiantes interactúan con el mundo, sino que además se constituye como un ámbito cargado de emociones (ya que los niños todo el tiempo están exteriorizando sus sentimientos, si están alegres, tristes, confundidos, los aciertos o desaciertos en las relaciones intrafamiliares las manifiestan en el aula el aula de clase y es allí donde todo ese entramado emocional se hace visible y perceptible entre unos y otros), razón por la cual su tratamiento e inclusión dentro de este estudio es más que necesario. Ahora bien, respecto a esta definición cabe señalar que Goleman también identifica los componentes de la inteligencia emocional: el autoconocimiento, el autocontrol, la automotivación, la empatía y el buen desarrollo de las relaciones interpersonales (Pico, s.f. p. 1), cada uno de estos elementos hace posible tomar las riendas de nuestros impulsos emocionales y, a su vez, comprender los sentimientos de nuestros semejantes.

Hablando más detalladamente, diremos que el autoconocimiento emocional se refiere a la capacidad de reconocer los propios sentimientos, estados internos e intuiciones, una cuestión que se convierte en un elemento fundamental en la personalidad de cualquier profesor, pues este no sólo debe ayudar a sus estudiantes a descubrir los sentimientos que cada uno de ellos posee, sino que inclusive también debe ayudase a sí descubrirse a sí mismo, en otras palabras, desde esta perspectiva el profesor es el quien tiene que descubrir su propia emocionalidad primero para de esta manera contribuir al descubrimiento de la emocionalidad de sus estudiantes. Por su parte, el autocontrol emocional se refiere a la actitud de asumir la responsabilidad por los propios actos, 
una cualidad que debe ser bastante recalcada por los profesores dentro de las aulas ya que se tiene conocimiento de que la afectación en el autocontrol emocional tiente tanto implicaciones físicas como implicaciones de carácter psicológico, de ahí que el bienestar de los niños en muy buena medida se base en el autocontrol.

En el caso de la automotivación como componente de la inteligencia emocional, se sostiene que debe ser entendida como la capacidad para motivarse a sí mismo canalizando todo el potencial del que se dispone en aras del cumplimiento de una meta u objetivo. En el aula de clase, la automotivación posibilita promover la paciencia y la creatividad pero, además, dominar la impulsividad de algunos estudiantes. Es así como se cree que ayudar a desarrollar la automotivación aumenta la productividad y eficacia del niño y/o niña. También, el reconocimiento de las emociones ajenas, más conocido como empatía, hace referencia a la capacidad de apreciar las emociones propias y las de los demás, es decir, reconocerlas y percibir los deseos y necesidades que tienen las otras personas. Este es un factor determinante para el contexto escolar ya que entre más los estudiantes sean educados no sólo con valores sino con afecto, serán capaces de comprender los sentimientos de otros; por ello la empatía se reconoce como ponerse en el lugar de los demás, aceptar otros puntos de vista y escuchar sin imponer ningún tipo de ideas.

Finalmente, entendemos al desarrollo de buenas relaciones interpersonales como aquellas habilidades sociales necesarias en la vida del ser humano que contribuyen a la cordialidad, determinan la capacidad de liderazgo y aumenta la eficiencia en los procesos comunicativos. Como es evidente, estos cinco componentes de la inteligencia emocional propuestos por Goleman se enmarcan en lo que a diario se vivencia en el contexto escolar, son elementos con los que recurrentemente se enfrentan los profesores para entablar con sus estudiantes un proceso 
de aprendizaje que va más allá de la transmisión y memorización de simples conceptos. Se sabe que hoy en día la educación tiene un gran reto, y es superar la forma tradicional de entender el proceso de enseñanza por ello, es necesario plantear soluciones que respondan a las realidades no sólo de los estudiantes, sino además de su contexto familiar, social, y hasta mediático.

Basados en estas aclaraciones es oportuno ahora resaltar que la definición de cada uno de estos componentes asociados a la inteligencia emocional nos ayuda a entender que la educación también debe ser pensada en función de las emociones, es decir, es necesario pensar en una educación emocional. Para ello, Goleman plantea que la escuela debe ir más allá de la misión encomendada, por lo que convoca a la integración y compromiso de la comunidad con el mundo escolar ya que no se trata únicamente de llenar en conocimientos, sino de vivenciar todo aquello que se enseña y, también, vincular a toda la comunidad educativa (padres, profesores y directivos) para que los estudiantes signifiquen el saber con su entorno. Es en virtud de esta afirmación que la educación emocional debe implicar el desarrollo de currículos que permitan la vivencia de valores morales y cívicos. En el contexto escolar, para una educación en derechos humanos, es fundamental la vivencia de los valores más que su enseñanza teórica.

Ahora bien, otro debate importante sobre la educación emocional ha sido protagonizado por las ideas del pedagogo y catedrático Español Rafael Bisquerra quien, compartiendo el postulado de Goleman acerca de que el desarrollo de las competencias emocionales, da lugar a la educación emocional, un elemento definido como un:

Proceso educativo, continuo y permanente, que pretende potenciar el desarrollo de las competencias emocionales como elemento esencial del desarrollo integral de la persona, 
con objeto de capacitarle para la vida. Todo ello tiene como finalidad aumentar el bienestar personal y social (Bisquerra, 2003, p. 27).

Basándonos en la lectura del fragmento anterior, reconocemos que en efecto la educación emocional es un proceso continuo y permanente que está presente a en el currículo escolar y que va a permanecer a lo largo de toda la vida del estudiante, de ahí que la educación emocional resulte ser un elemento fundamental en el proceso educativo ya que a largo plazo posibilitará el desarrollo social e individual del niño. Al respecto, conviene decir que el autor no se limita a conceptuar la educación emocional, sino que también se adentra en la delimitación de algunos de sus propósitos generales, tal cual es demostrado en el siguiente fragmento:

Adquirir un mejor conocimiento de las propias emociones; identificar las emociones de los demás; desarrollar la habilidad para regular las propias emociones; prevenir los efectos nocivos de las emociones negativas; desarrollar la habilidad para generar emociones positivas; desarrollar la habilidad de automotivarse; adoptar una actitud positiva ante la vida; aprender a fluir, etc. (Bisquerra, 2003, p. 28).

Estos objetivos son muy similares a los componentes de la inteligencia emocional planteados por Goleman, casi que los dos coinciden en un fortalecimiento interno que debe tener un impacto externo. El siguiente esquema permite hacer un paralelo entre los planteamientos de ambos autores: 


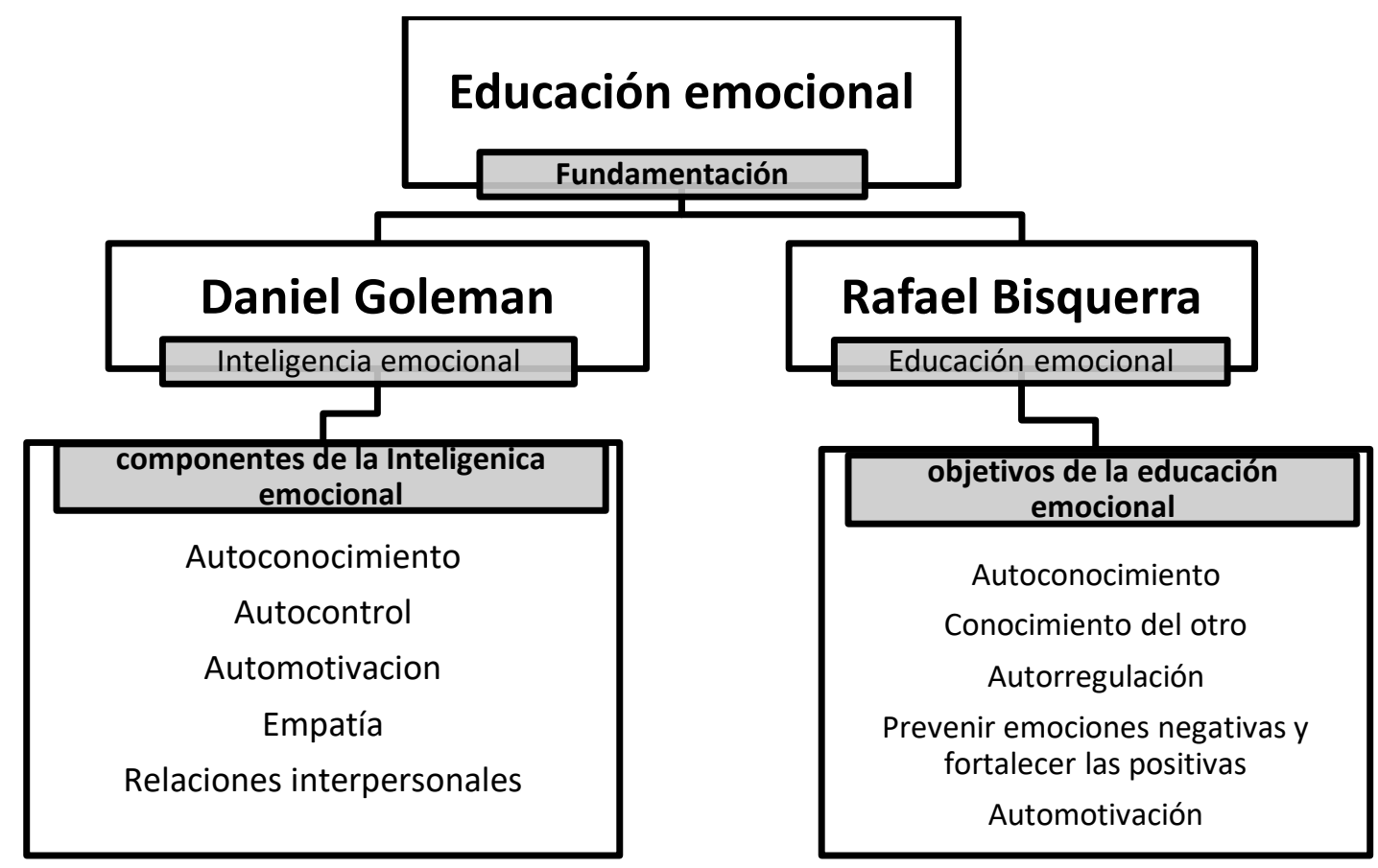

Figura 1. Fundamentación de la Educación emocional, ideas de David Goleman y Rafael Bisquerra.

Fuente: Elaboración propia.

Siguiendo con algunos de los debates dados en el campo educativo por Bisquerra, es hora de hablar sobre los contenidos de la educación emocional. Según este autor, los mencionados contenidos pueden variar según los destinatarios y sus características más básicas (nivel educativo, conocimientos previos, madurez personal, etc.), de esta manera podemos distinguir entre un programa de formación de profesores y un programa dirigido a los estudiantes, no obstante los contenidos tienen unas generalidades que se relacionan principalmente con el dominio de un:

Marco conceptual de las emociones, que incluiría el concepto de emoción, los fenómenos afectivos (emoción, sentimiento, afecto, estado de ánimo, perturbaciones emocionales, etc.), tipos de emociones (emociones positivas y negativas, emociones básicas y derivadas, emociones ambiguas, emociones estéticas, etc.). Conocer las características 
(causas, predisposición a la acción, estrategias de regulación, competencias de afrontamiento, etc.) de las emociones principales: miedo, ira, ansiedad, tristeza, vergüenza, aversión, alegría, amor, humor, felicidad, etc. La naturaleza de la inteligencia emocional es un aspecto importante, con múltiples aplicaciones para la práctica (Bisquerra, 2003, p. 30).

Visto lo anterior, no queda más sino decir sobre este punto que la educación emocional implica un sinnúmero de sentimientos, estados y acciones que en el escenario educativo juegan un papel importante, con mayor razón dentro de la básica primaria en donde los niños y niñas exteriorizan todo el tiempo sus emociones. Continuando con este recorrido, tenemos las ideas de Mujica (2007) quien en aras de responder a la pregunta ¿Qué es educar en Derechos Humanos? nos permite vislumbrar algunos elementos articulatorios entre la educación emocional y los derechos humanos, para ello se vale de los postulados de Abraham Magendzo y de la pedagogía de Alejandro Cussianovich, e invita a crear una cultura de valores en el aula al plantear la importancia de crear en los profesores credibilidad en el proceso de enseñanza-aprendizaje y establecer una dinámica organizativa horizontal en la clase. En relación con lo anterior, sería pertinente comentar que para Mujica (2007) el abordar este tema no es nada fácil pues considera que:

Ya Freud decía que hay tres misiones imposibles: gobernar, educar y curar y tal vez la más difícil es educar, como decía Luis Pérez Aguirre, porque educar implica estar educado de tal manera que por el hecho de estar uno frente a alguien ese otro pueda sentirse afectado y modificado como persona. Es lo que decía Paulo Freire, que "nadie se educa solo" y más aún que "nadie educa a nadie", que los seres humanos nos educamos en comunión (p. 23). 
En este sentido, el educador en EDH no debe entenderse sólo como un transmisor de contenidos y/o elaborador de conceptos y percepciones, sino que debe entenderse como el encargado de impactar corazones, algo que, aunque suene romántico, va más allá de un simple postulado sensible, ya que se remite a la complejidad que significan el amor y el afecto dentro del campo educativo. Siendo más puntuales al respecto, de lo que se trata es que los niños entiendan el significado o concepto de todos los artículos de la declaración universal de los derechos humanos o de cualquiera de los derechos reconocidos en el ordenamiento nacional o internacional, ya que el solo hecho de dar a conocer ciertos conceptos entre los adultos llega a ser bastante complejo. Ejemplo de lo anterior lo constituye el concepto de la otredad y la alteridad, dos fenómenos bastante relevantes pero que son bastante desconocidos entre las personas. A saber, por un lado se define a la otredad como ese término que me permite identificar lo que no es mío o nuestro si se habla de un grupo (Buganza, 2006), mientras que la alteridad va más allá, pues no sólo hace al reconocimiento de la existencia del otro sino que, además, va ligado con la empatía y el respeto por la diferencia.

Algo más que añadir sobre el tema en general, Mujica señala que en la EDH es importante transmitir no sólo este tipo de conocimientos al niño (a) y los jóvenes que están siendo participes del proceso de aprendizaje, sino que también se debe transmitir, al mismo tiempo, emocionalidad ya que los alumnos deben creer que son tratados de manera afectiva. En actualidad estas condiciones son bastante complicadas, sobre todo en un mundo que cada vez es más individualista y en donde la construcción de la dignidad y de valores pasa a un segundo plano. Este es un fenómeno bastante preocupante para autores como la misma Mujica (2007), quien al pensar en el tema se refiere de la siguiente manera: 
Pérez Aguirre escribía que "la trampa en la que cayó esta cultura globalizada es la de haber cedido la primacía al LOGOS sobre el EROS, desembocando en mil cercenamientos de la creatividad y gestando mil formas represivas de vida. Y la consecuencia de esto es que se sospecha profundamente del placer y del sentimiento, de las razones del corazón”. Y entonces ya nada nos conmueve, sólo campea la frialdad de la lógica, la falta de entusiasmo por cultivar y defender la vida, campea la muerte de la ternura. Esto, para el acto educativo transformador y liberador que debería ser siempre profundamente erótico es letal (p. 26).

Leída la apreciación anterior, es fácil entender que la educación no busca un fin individual, sino que más bien busca una propuesta colectiva, altruista y liberadora en donde los educandos pueden replicar, compartir, socializar y emancipar su mundo de vida, de ahí que Mujica (2007) asegure que "el rol del educador es crear las condiciones propicias para que la persona "aprenda a aprender. Se debe promover que las personas pasen de la acción dirigida y programada por el educador a la acción libre” (p. 29). En adición con lo anterior, es pertinente mencionar que la autora más que desarrollar una metodología como tal sugiere varias de ellas para desempeñar la labor de educadores en EDH. Se parte de vivenciar las cosas y luego teorizarlas (desde el juego), realizando un impacto terapéutico del afecto, es por ello que se sostiene que Mujica va muy acorde con los últimos postulados del profesor Hoyos en lo que se refiere con "Humanizar la educación”, algo que sonaría redundante, pero no es así pues en la actualidad la educación tiende a ser un producto con carácter comercial cuestión que la hace perder su fundamento social.

Para finalizar Mujica (2007) invita a "mirarse a sí mismo" revisar los propios pensamientos, sentimientos y actitudes de manera crítica, cambiar la individualidad, egoísmo y fomentar la fe en cada uno de nosotros y en los demás (p. 26), cuestiones que son la utopía constante de la "Pedagogía de la ternura". Vale la pena aclarar que esta pedagogía no significa 
ser blandos, al contrario es con autoridad y disciplina que se necesita trabajar, pues de lo que se trata es de escudriñar en nuestros errores y auto reflexionar. Con todo y lo anterior, es valioso anotar que desde la perspectiva de Fernández, M. R., Palomero, J.E. y Teruel, M. (2009) se reconoce que en la actualidad continúa primando una educación tradicional basada en el conocimiento y desconociendo la riqueza de las emociones y con ella, de la afectividad:

La Escuela, sin embargo, no cumple aún las exigencias para una educación socioafectiva porque tradicionalmente ha primado el conocimiento por encima de las emociones, sin tener en cuenta que ambos aspectos no se pueden desvincular. La dimensión afectivoemocional debe ser planteada como eje vertebrador del desarrollo integral de las personas (p. 3).

Bajo esta misma mirada, Teruel (200) considera que en la escuela se hace necesario (además del aprendizaje de las habilidades académicas, que naturalmente son importantes) “el ofrecer una visión de la educación que no se base únicamente en contenidos intelectuales, sino que considere también el aprendizaje de las habilidades sociales, el control emocional, el autoconocimiento o la resolución de conflictos" (p. 145). Debe haber entonces, un equilibrio entre lo académico y lo afectivo, de tal manera que pueda generarse una educación integral. Por ello es necesario generar transformaciones pedagógicas en la escuela, tal es el propósito de este trabajo investigativo pues como se mencionó en un principio el fenómeno de la violencia y los déficits evidenciados en contextos académicos como el de nuestro estudio de caso requieren lo más pronto posible un cambio, por ello:

Es fundamental que desde edades tempranas se dé a conocer la necesidad de la no violencia para crecer en un ambiente psicológico y afectivamente sano que desencadene procesos de 
convivencia en paz que conlleve a generar una nueva cultura en la que se rescate la necesidad e importancia de ser emocionalmente competentes (Arias, 2003, p. 1).

Visualizado lo anterior, no queda más sino decir que la propuesta pedagógica planteada en esta investigación resulta ser el camino para fortalecer las prácticas pedagógicas de quienes son los principales transformadores de vida, es decir, de los profesores, dándole la posibilidad de sentirse reconocidos como sujetos de derechos, fenómeno que en últimas contribuirá a los tan anhelados cambios sociales en las comunidades educativas. Así mismo, para esta investigación el concepto de educación emocional implica la puesta en escena, dentro del contexto educativo, de todos los elementos correspondientes al fuero interno de la persona (tanto del estudiante, como del profesor), de manera que se pongan a disposición del aprendizaje, por lo que en otras palabras la educación emocional debe permitir a estos sujetos una interacción mediada por la sensibilidad más que por la intención de llenar de contenidos o de saberes.

\subsection{El papel transformador del profesor}

Teniendo en cuenta que el profesor es el sujeto a quien va dirigida la propuesta pedagógica de este proceso investigativo resulta importante reflexionar sobre su papel en la vida de los estudiantes, la escuela y la sociedad. Para ello, se tendrán en cuenta las ideas recreadas por Rafael Flórez y Mireya Vivas en su texto La formación como principio y fin de la acción pedagógica, así como las de Catalina Rodríguez en su tesis de Maestría La constitución de sujetos profesores en las tensiones escolares. Estos dos textos formarán la base teórica de este acápite, cuyo propósito es dar cuenta del rol transformador que tiene el docente en las distintas esferas de la realidad social. Para introducir este tema, anotaremos que el deber ser del docente ha de estar centrado en enseñar para la vida, es decir, enseñar a ser y respetar los derechos 
humanos, de ahí que los valores se conviertan en un elemento clave para poner en práctica los componentes de la inteligencia emocional referidos anteriormente. Si los profesores no consiguen que los niños logren ser sí mismos (con todo y sus implicaciones) y, además, respeten al otro, difícilmente se puede avanzar en la conquista de logros mayores.

En este sentido, se afirma que el profesor debe lograr intervenir en todos y cada uno de los momentos de la vida escolar con pertinencia, incluso en medio del conflicto escolar, entendiendo que el conflicto es natural en la sociedad y que éste se puede resolver por vías pacíficas (una afirmación que trata de hacer entender ante el lector que el conflicto es el resultado de las diferencias existentes entre las personas, sin embargo no tiene que constituirse como algo negativo, sino más bien como algo inherente a las relaciones sociales). Lo anterior debe servir como una condición que ayuda al docente a ser reconocido como transformador, ya que son ellos quienes tienen que impulsar la creación de formas pacíficas de resolver los conflictos a través de la creatividad, el ingenio y el amor que caracteriza su labor.

Ahora bien, dejando de lado las anotaciones anteriores es preciso decir que el hablar sobre la naturaleza del profesor realmente no es una tarea fácil. Sobre este tema Rodríguez (2012) reconoce que:

Existen muy pocas referencias de la categoría sujetos profesores en las investigaciones que abordan la complejidad del oficio de profesor, por esto, es necesario tener en cuenta las tendencias discursivas que están presentes cuando se habla de profesores, docentes, profesores, enseñantes, etc. $\mathrm{Al}$ respecto se encuentra un gran número de estudios que pretenden dar cuenta de estos sujetos, tales como las investigaciones de corte factorial, las investigaciones desde la psicología social, las que se preguntan por la condición social del 
maestro, las que siguen el debate inacabado sobre su enunciación como intelectual, técnico, artesano etc. (p.18).

A partir de este planteamiento, la autora establece las imágenes que se han configurado sobre las maneras de "ser profesor" en Colombia, entre ellas encontramos: el profesor apóstol, el sindicalista asalariado, el artesano, el funcionario, el administrador de procesos, los "quemados", los sujetos de saber, los sujetos políticos y, finalmente, la figura de los profesores en tensión (Rodríguez, 2012). Por otro lado, Flórez y Vivas (2007) analizan los principios pedagógicos que han sido probados por los profesores tanto en la práctica como en las validaciones conceptuales, además de aquellos que han sido asumidos por los principales teóricos de la pedagogía, tales principios hacen referencia al afecto, la experiencia natural, el entorno de aprendizaje, la actividad, el desarrollo progresivo, el buen profesor, la enseñanza lúdica, la individualización de la enseñanza, el antiautoritarismo y el desarrollo grupal. Uno de los más importantes es el principio del buen maestro pues se sostiene que influye decisivamente en el factor de desarrollo y crecimiento para el estudiante, de ahí que se afirme lo siguiente:

Al lado del maestro, el alumno eleva su potencial de desarrollo, en la medida en que el maestro lo inspira y le permite posibilidades de realización, horizontes de interrogación y de soluciones hipotéticas. El maestro, como ejemplo digno para sus alumnos, basa su preeminencia y su autoridad no sólo en su sabiduría, sino en su compromiso con la enseñanza y con el mejoramiento de aquellos, aun a costa de su propio sacrificio (Flórez y Vivas, 2007, p. 171).

Basados en estas declaraciones es evidentemente que el profesor tiene un papel transformador e inspirador en sus estudiantes, quienes en un futuro serán padres de familia y 
ciudadanos, por lo que a través de su práctica pedagógica contribuyen al mejoramiento tanto de la escuela como de la sociedad en general. En conclusión, el profesor es la figura clave en el proceso de enseñanza - aprendizaje en la escuela, pues motiva, transforma e inspira, por ello la propuesta pedagógica va dirigida a ellos, para que optimicen aún más su potencial creativo y puedan hacer de la EDH una práctica enriquecedora a partir de la educación emocional.

Finalmente, el recorrido teórico de este capítulo posibilitó fundamentar las categorías de análisis como fueron los derechos humanos, la educación en derechos humanos, la educación emocional y el papel transformador del profesor, elementos que constituyen el soporte estructural para la formulación de la propuesta pedagógica planteada en el capítulo final. 


\section{Propuesta pedagógica para los profesores del colegio Liceo Nacional Antonia Santos de Bogotá (sede B)}

Ahora bien, habiendo dejado en claro las discusiones teóricas sobre la naturaleza de la Educación en Derechos Humanos y la educación emocional es momento de acercarnos a la práctica y dar forma a aquella propuesta pedagógica que permite la vinculación de ambos discursos en el que hacer de los profesores de primaria del colegio Liceo Nacional Antonia Santos. Sobre esta, es necesario decir que su progreso es el resultado de una revisión minuciosa llevada a cabo por parte de la autora de la presente investigación cuyo objetivo fue responder a las necesidades detectadas tanto en los profesores de la institución educativa frente al tema de la enseñanza de los derechos humanos como, por supuesto, en la recepción, acogimiento y ejecución de los mismos a través de los pensamientos, sentimientos y emociones de los estudiantes.

En adición con lo anterior, no sólo es de resaltar que este modelo pedagógico que será expuesto a continuación se basa en experiencias concretas que pueden ser ubicadas espacial y temporalmente dentro del colegio en mención, sino que, al mismo tiempo, deben ser debidamente reconocidos los aportes hechos por la doctora Elsa Bonilla Piratova, docente que posee una vasta experiencia en este campo y de quien, en gran parte, ha sido tomada la estructura para el desarrollo de la propuesta aquí presentada. En mente lo anterior, este capítulo tiene como propósito desarrollar una propuesta pedagógica digna de poner en práctica dentro del colegio de nuestro interés, para ello serán anotadas algunas especificaciones sobre la naturaleza de su funcionamiento y, por supuesto, se hablará sobre la forma en la que se estructura. 


\subsection{Anotaciones básicas sobre el modelo pedagógico propuesto.}

Antes de dar inicio al grueso de la propuesta recordemos brevemente dos cosas, la primera es que la institución educativa a la cual va dirigida la propuesta pedagógica es el colegio Liceo Antonia Santos sede B ubicado en Calle 12 No. 21-14 de la localidad de los Mártires en la ciudad de Bogotá, tal cual fue mencionado en páginas anteriores, y la segunda es que el grupo poblacional al cual está enfocada esta propuesta está constituido por los 30 profesores que hay en la básica primaria. Además de lo anterior, también es necesario aclarar los niveles de la aplicación de la propuesta, la temática, las áreas curriculares para las cuales aplica y otra información básica condensada en la siguiente tabla:

\section{Tabla 1.}

Generalidades sobre la propuesta que vincula la enseñanza de la EDH y la educación emocional en la básica primaria del Liceo Antonia Santos.

\begin{tabular}{|l|l|}
\hline Responsable & $\begin{array}{l}\text { Margareth Lucía López Escandón } \\
\text { Profesora de Preescolar } \\
\text { Directora del curso: }\end{array}$ \\
\hline $\begin{array}{l}\text { Niveles de aplicación de la } \\
\text { propuesta }\end{array}$ & Preescolar y Primaria \\
\hline $\begin{array}{l}\text { Temática de ejecución } \\
\text { propuesta }\end{array}$ & $\begin{array}{l}\text { Educación en derechos Humanos a través de la } \\
\text { educación emocional. }\end{array}$ \\
\hline $\begin{array}{l}\text { Número y formación } \\
\text { involucrados }\end{array}$ & $\begin{array}{l}\text { En total son 30 profesores, Licenciados en } \\
\text { Educación Preescolar y Básica. }\end{array}$ \\
\hline $\begin{array}{l}\text { Áreas curriculares en el cual } \\
\text { se inserta la propuesta }\end{array}$ & $\begin{array}{l}\text { La Propuesta es Transversal a todas las Áreas } \\
\text { de aprendizaje. }\end{array}$ \\
\hline
\end{tabular}

Fuente: Tabla realizada por la investigadora.

En relación con la información anotada, también resulta central el comentar que la propuesta está estructurada para trabajar cinco (5) talleres/actividades durante las cuatro (4) 
semanas que contemplan las conocidas semanas de desarrollo institucional, un espacio de discusión y formación académica en donde los profesores de los colegios públicos organizan, estructuran, modifican, proponen y proyectan ejercicios de sus prácticas educativas institucionales. A saber, este espacio es planteado como un ámbito en el cual son reflexionadas y estructuradas las labores pedagógicas de los maestros teniendo en cuenta los parámetros establecidos por el Ministerio de Educación Nacional, así como de diferentes directrices de orden local y distrital, y se encuentra dividido de la siguiente manera:

\section{Tabla 2.}

Distribución de las semanas de desarrollo institucional

\begin{tabular}{|c|c|}
\hline Semana & Periodo del año \\
\hline 1 & Primera semana laboral del mes de enero \\
\hline 2 & $\begin{array}{c}\text { Semana santa (generalmente en abril o según } \\
\text { corresponda al calendario de cada año) }\end{array}$ \\
\hline 3 & $\begin{array}{c}\text { Semana de receso escolar a mitad de año } \\
\text { (generalmente en junio) }\end{array}$ \\
\hline 4 & Semana de receso escolar en octubre \\
\hline
\end{tabular}

Fuente: Tabla realizada por la investigadora.

Resulta útil mencionar que en cada una de estas semanas no hay estudiantes dentro de la institución, por lo que sólo trabajan profesores evidentemente en las actividades anteriormente señaladas. Es precisamente de esta particularidad que nace el interés por el desarrollo de la propuesta en este periodo de tiempo y no en otro, ya que se tiene en cuenta que la propuesta dirigida a los profesores debe ser llevada a cabo en un momento en el que ellos dispongan del tiempo necesario para tal fin. Añádase a esto que la pretensión de la propuesta es orientar la práctica educativa de los profesores de básica primaria del colegio Antonia Santos de tal manera que vinculen en sus procesos educativos de enseñanza - aprendizaje una EDH basada en la educación emocional, ya que es reconocida la necesidad que tienen los estudiantes de 
transformar sus entornos a partir de nuevas formas de asimilar los DDHH tan fuertemente

promovidos por instituciones de orden nacional e internacional, una afirmación que se basa en la visión crítica que en teoría debería tener todo docente en el marco de las potencialidades que tiene la construcción de una cultura basada en los DDHH, la paz y la democracia.

\subsection{Formulación de la propuesta.}

Conviene afirmar aquí que los profesores de básica primaria del colegio Antonia Santos se caracterizan por tener un alto sentido de compromiso con la formación de los niños y las niñas en tanto evidencian una preocupación genuina por las diferentes problemáticas que rodean el contexto familiar y social de los estudiantes, razón por la cual todos ellos plantean en su práctica pedagógica estrategias encaminadas a intervenir de manera oportuna en la formación de sus educandos. Sin embargo, en el tema específico de la educación en derechos humanos no se ha trabajado con suficiente rigor o profundidad, aun sabiendo que este ámbito de enseñanza debe constituirse como una práctica de la cotidianidad tanto educativa como cultural si el objetivo es edificar una sociedad constituida por sujetos libres, dignos e iguales. Este es, sin duda alguna, uno de los problemas más significativos en este espacio escolar, pues un contexto caracterizado por problemáticas en las familias de los niños (falta de afecto) así como en la zona donde se ubica el colegio (violencia y agresividad) demanda urgentemente un fortalecimiento de la EDH a través de un elemento fundamental en la educación, las emociones.

En este sentido, el crear y presentar una metodología alternativa ante los profesores dentro de la institución educativa con relación a la Educación en Derechos Humanos a través de la educación emocional busca generar un impacto favorable en los estudiantes, en sus familias, en toda la comunidad educativa y, finalmente, en la sociedad colombiana. De igual forma, es decisivo el insistir en que desde la postura que caracteriza este trabajo investigativo la propuesta 
a formular no se centra en el desarrollo de una sola dimensión dentro del proceso enseñanza aprendizaje en los niños, todo lo contrario, de lo que se trata aquí es de incentivar el desarrollo integral y equilibrado de cinco de ellas: Personal-Social, Corporal, Comunicativa, Artística y Cognitiva (Secretaría de Educación de Bogotá, 2010, pág. 52) a partir de un cambio en la práctica pedagógica de los profesores que, como se ha recalcado reiterativamente, socialice los principios constitutivos de la Educación en Derechos Humanos desde de los sentidos, las emociones y las dinámicas innovadoras.

Al respecto, es prudente decir que a pesar del reconocimiento de la inexistencia de metodologías pedagógicas sobre EDH totalmente pertinentes y eficaces dentro del colegio, es imposible desconocer el trabajo sobre enseñanza de DDHH ya hecho en la institución y que, naturalmente, precede a esta investigación. No ahondaremos mucho sobre este aspecto, sin embargo es fundamental dilucidar la presencia de diferentes proyectos de carácter transversal sobre este tema que aportan notablemente a este ejercicio educativo en tanto permiten fortalecer y consolidar ciertas formas y métodos históricos de comprender y vivenciar la EDH en el Liceo, pero que, lamentablemente, no cumplen con las expectativas de enseñanza en la medida en que están permeadas por algunas preconcepciones y estereotipos por parte de los profesores con respecto a la manera tradicional de entender y reproducir los derechos humanos, principalmente por el hecho de asociar a la EDH como una tarea exclusiva de las clases de ética, religión y/o proyecto de vida sin dimensionar la transversalidad de su contenido.

Advertida esta deficiencia sobre los antecedentes e interpretaciones de los profesores en el tema de los derechos humanos, hemos de decir que es momento de hacer comprender a estos la importancia de la EDH en todos los ámbitos educativos, cuestión que implica dejar atrás todas las visiones conservadoras sobre la enseñanza y acoger novedosas maneras de formar a los 
educandos por medio de la educación emocional, he ahí la importancia de la propuesta aquí presentada. Para finalizar estas consideraciones, diremos que en cuanto a la utilización de recursos la propuesta pedagógica no necesita de un gran presupuesto, pues en términos generales la realización de la misma requiere la obtención de materiales fáciles de adquirir y dentro de un precio moderado. Aquí lo realmente importante es contar con la voluntad de profesores que deseen fortalecer y llevar a cabo la propuesta con la finalidad de promover un cambio sustancial en las problemáticas sociales y familiares que acompañan las vidas de los niños y las niñas a impactar.

Teniendo en consideración todo lo anterior, ha llegado la hora de plantear formalmente la propuesta pedagógica, para ello invitamos al lector a conocer los objetivos que sirvieron como guía para tal propósito:

Tabla 3.

Objetivos de la propuesta pedagógica para los profesores del Liceo Antonia Santos.

\begin{tabular}{|l|c|}
\hline \multicolumn{1}{|c|}{ Tipo de objetivo } & \multicolumn{1}{|c|}{ Contenido } \\
\hline General & $\begin{array}{c}\text { Fortalecer la práctica pedagógica de los profesores de Básica } \\
\text { Primaria del Colegio Antonia Santos en el escenario de la Educación } \\
\text { en Derechos Humanos, de tal manera que se apropien de las nuevas } \\
\text { formas de entenderlos y vivenciarlos, tomando como referente para } \\
\text { la puesta en práctica en el aula, la educación emocional. }\end{array}$ \\
\hline Específicos & $\begin{array}{l}\text { Implementar la presente propuesta pedagógica en el } \\
\text { colegio Antonia Santos (Jornada Tarde) de forma que los } \\
\text { profesores vinculen en sus prácticas pedagógicas una } \\
\text { EDH fundamentada en la educación emocional. } \\
\text { Proponer talleres, actividades didácticas y espacios de } \\
\text { discusión académica a los profesores del colegio Antonia } \\
\text { Santos que les permitan vivenciar eficazmente una EDH }\end{array}$ \\
\hline
\end{tabular}




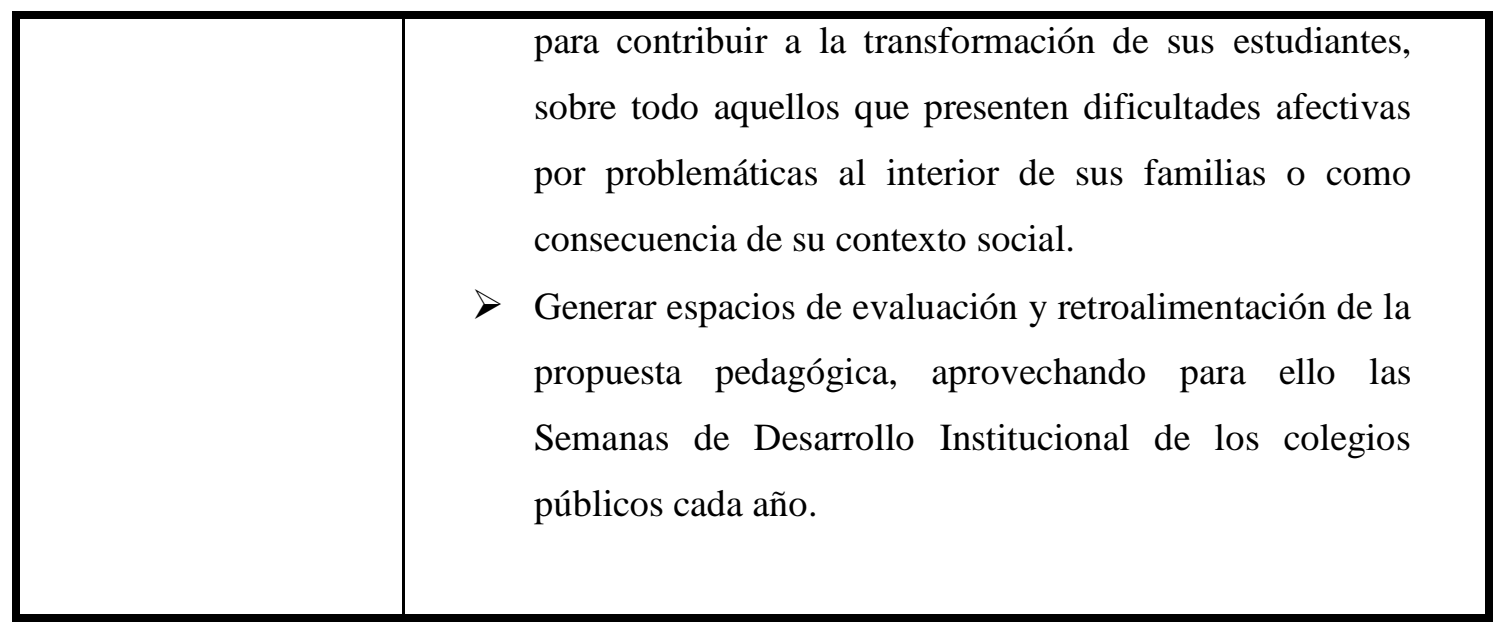

Fuente: Tabla realizada por la investigadora.

Como un segundo aspecto a tener en consideración, hablemos de la metodología usada para fundamentar la propuesta pedagógica. Para ello, empezaremos diciendo que los resultados a futuro de esta propuesta pueden ser obtenidos a partir de la realización de diferentes talleres y discusiones pedagógicas con los profesores en un espacio destinado para tal fin, los cuales serán evaluados permanentemente para identificar dificultades y desaciertos y, posteriormente, mejorarlos cada vez más con la participación de todos los actores que hacen parte de la institución educativa. Estos talleres y discusiones pedagógicas serán descritos con profundidad más adelante, por ahora nos interesa decir que estos no sólo se caracterizarán por un contenido que potencializa la enseñanza de la Educación en Derechos Humanos a partir de la educación emocional, sino que tenderán a ser lúdicos y sensitivos a fin de impulsar la adquisición de nuevas experiencias pedagógicas que fortalezcan la comprensión de los estudiantes y los mismos profesores sobre los derechos humanos y su importancia en la creación de paz.

Así pues, el desarrollo de la propuesta pedagógica implica llevar a cabo un Plan Estratégico estructurado a partir de cuatro ejes temáticos, con sus respectivos objetivos, estrategias y resultados, tal cual es presentado en la siguiente tabla: 


\section{Tabla 4.}

Plan estratégico de la propuesta pedagógica para los profesores del Liceo Antonia Santos.

\begin{tabular}{|c|c|c|c|}
\hline Eje Temático & Objetivo & Estrategia & Resultados \\
\hline $\begin{array}{l}\text { Comprensión del } \\
\text { concepto educación en } \\
\text { derechos humanos a } \\
\text { través de la educación } \\
\text { emocional. }\end{array}$ & $\begin{array}{l}\text { Proponer una nueva } \\
\text { forma de entender la } \\
\text { educación en } \\
\text { derechos humanos } \\
\text { por medio de la } \\
\text { educación } \\
\text { emocional. }\end{array}$ & $\begin{array}{l}\text { Generar un espacio } \\
\text { de discusión } \\
\text { pedagógica entre los } \\
\text { profesores a partir de } \\
\text { la reflexión de las } \\
\text { principales } \\
\text { problemáticas que se } \\
\text { evidencian en el } \\
\text { contexto escolar } \\
\text { sobre derechos } \\
\text { humanos. }\end{array}$ & $\begin{array}{l}\text { Los profesores del } \\
\text { Colegio Antonia Santos } \\
\text { comprenden de forma } \\
\text { novedosa y crítica el } \\
\text { concepto de educación en } \\
\text { derechos humanos a } \\
\text { través de la educación } \\
\text { emocional. }\end{array}$ \\
\hline $\begin{array}{l}\text { Interiorización en las } \\
\text { prácticas pedagógicas } \\
\text { de los profesores } \\
\text { respecto a la EDH y la } \\
\text { educación emocional. }\end{array}$ & $\begin{array}{l}\text { Promover talleres y } \\
\text { actividades que } \\
\text { permitan a los } \\
\text { profesores } \\
\text { incorporar la EDH } \\
\text { en su quehacer } \\
\text { pedagógico. }\end{array}$ & $\begin{array}{l}\text { Realizar talleres } \\
\text { reflexivos con los que } \\
\text { los profesores puedan } \\
\text { interiorizar la } \\
\text { educación emocional } \\
\text { y la EDH a través de } \\
\text { diferentes } \\
\text { sensaciones y estados } \\
\text { anímicos. }\end{array}$ & $\begin{array}{l}\text { Los profesores del } \\
\text { Colegio Antonia Santos } \\
\text { vivencian la EDH usando } \\
\text { la educación emocional, } \\
\text { encontrando un sentido } \\
\text { relevante para su práctica } \\
\text { pedagógica. }\end{array}$ \\
\hline
\end{tabular}




\begin{tabular}{|c|c|c|c|}
\hline $\begin{array}{l}\text { Transformación de las } \\
\text { realidades escolares } \\
\text { tanto por parte de los } \\
\text { profesores como por } \\
\text { parte de los } \\
\text { estudiantes. }\end{array}$ & $\begin{array}{l}\text { Propiciar espacios de } \\
\text { convergencia entre } \\
\text { la EDH y la } \\
\text { educación } \\
\text { emocional, de } \\
\text { manera que los } \\
\text { profesores puedan } \\
\text { aplicarlos en sus } \\
\text { prácticas } \\
\text { pedagógicas. }\end{array}$ & $\begin{array}{l}\text { Juegos de roles y } \\
\text { otras actividades que } \\
\text { posibiliten a los } \\
\text { profesores aplicarlos } \\
\text { con sus estudiantes y } \\
\text { mejorar relaciones } \\
\text { psico-afectivas a } \\
\text { través de las } \\
\text { emociones. }\end{array}$ & $\begin{array}{l}\text { Las prácticas educativas } \\
\text { de los profesores del } \\
\text { colegio Antonia Santos } \\
\text { permiten transformar las } \\
\text { realidades de los niños y } \\
\text { niñas por medio de una } \\
\text { EDH basada en la } \\
\text { educación emocional. }\end{array}$ \\
\hline $\begin{array}{l}\text { Evaluación del } \\
\text { impacto de la } \\
\text { propuesta pedagógica } \\
\text { en el colegio Antonia } \\
\text { Santos I.E.D. }\end{array}$ & $\begin{array}{l}\text { Evaluar el impacto } \\
\text { generado en el } \\
\text { colegio Antonia } \\
\text { Santos con la puesta } \\
\text { en práctica de la } \\
\text { propuesta } \\
\text { pedagógica. }\end{array}$ & $\begin{array}{l}\text { Aplicación de } \\
\text { instrumentos que } \\
\text { permitan evaluar la } \\
\text { propuesta pedagógica } \\
\text { en la práctica } \\
\text { educativa de los } \\
\text { profesores. }\end{array}$ & $\begin{array}{l}\text { La puesta en práctica de } \\
\text { la propuesta pedagógica } \\
\text { en el colegio Antonia } \\
\text { Santos de una EDH } \\
\text { fundamentada en la } \\
\text { educación emocional } \\
\text { tiene un impacto tan } \\
\text { positivo que permite la } \\
\text { transformación y mejora } \\
\text { la calidad de vida de los } \\
\text { estudiantes. }\end{array}$ \\
\hline
\end{tabular}

Fuente: Tabla realizada por la investigadora.

Para dar cumplimiento a los anteriores ejes temáticos, a continuación se presentan una serie de talleres dirigidos a los profesores en donde son planteadas actividades pedagógicas puntuales que facilitan el proceso de formación en el tema anteriormente expuesto.

\section{Tabla 5.}

Actividad 1. Me coloco en los zapatos del estudiante 


\begin{tabular}{|c|c|}
\hline Nombre & Me coloco en los zapatos del estudiante \\
\hline Tema & Empatía en mi labor como profesor \\
\hline Objetivo & $\begin{array}{l}\text { Interiorizar los sentimientos, emociones, estados de ánimo, sensaciones y problemas de los estudiantes y } \\
\text { relacionarlas con la educación en derechos humanos. }\end{array}$ \\
\hline Material & Cuentos cortos o de libro-álbum sobre las emociones, un video ilustrativo, hojas blancas, lápices y esferos. \\
\hline Tiempo & 2 horas \\
\hline Actividad & $\begin{array}{l}\text { 1. Solicitarle al profesor que piense e identifique al estudiante (s) con los que más haya sentido dificultad } \\
\text { recientemente. } \\
\text { 2. Preguntarle ¿por qué considera que le ha costado tanto trabajo?, ¿qué aspectos considera que ha dificultado el } \\
\text { proceso de aprendizaje de ese niño(a)?, ¿es posible que existan otras razones aparte de la aparente pereza e } \\
\text { indisciplina (o cualquier otra razón que usted consideró inicialmente) para que el niño/a tenga esas actitudes? } \\
\text { 3. Leer un cuento corto sobre las emociones, sensaciones y la afectividad infantil. En la biblioteca del colegio } \\
\text { pueden ser encontrados algunos de ellos, la siguiente lista cita a los más relevantes: } \\
\checkmark \text { Llenas, A. (2016). Laberinto del alma. Barcelona, España: Edit. Espasa Infantil. } \\
\checkmark \text { Geis, P. (2010). iSentimientos! Coco y Tula. España: Combel Editorial. } \\
\checkmark \text { Emberly, E y Miranda, A. (2009). Monstruo triste, monstruo feliz. México: Edit. Océano Travesía. }\end{array}$ \\
\hline
\end{tabular}




\begin{tabular}{|c|c|}
\hline & $\begin{array}{l}\checkmark \text { Llenas, A. (2014). Diario de las emociones. Barcelona, España: Edit. Paidós. } \\
\checkmark \text { Roussey, C y Wintek, J. (2014). Así es mi corazón. Madrid, España: Bruño editores. } \\
\checkmark \quad \text { Núñez, C y Romero, R. (2013). Emocionario. Di lo que sientes. España: Edit. Palabras Aladas. } \\
\checkmark \quad \text { Falcón, G (2014). Nube. Barcelona, España: Editorial Alba. } \\
\checkmark \quad \text { Bie, L. (2014). El Pequeño Edu no está enfadado. Barcelona, España: Edit. Juventud. } \\
\checkmark \quad \text { Gutiérrez, M. (2010). Recetas de lluvia y azúcar. España: Thule ediciones. } \\
\checkmark \quad \text { Negley, K (2016). Tipos Duros. También tienen sentimientos. Madrid, España: Editorial Impedimenta. } \\
\text { 4. Proyectar el video Diario de las Emociones de Anna Llenas, disponible en el siguiente link: } \\
\quad \text { https://www.youtube.com/watch?v=groChyApfGs } \\
\text { 5. Cada profesor creará una historia en la que el personaje principal será el estudiante(s) que previamente había } \\
\text { identificado (con el que había tenido dificultades). En la historia deben reflejarse todos los sentimientos y } \\
\text { emociones que considere tiene el niño y la manera como le gustaría resolver sus conflictos. Al finalizar, se } \\
\text { socializarán las historias para compartir la experiencia de cada profesor. }\end{array}$ \\
\hline Evaluación & $\begin{array}{l}\text { En un cuestionario que será entregado a los profesores después de la socialización de las historias deben responder } \\
\text { las siguientes preguntas: } \\
\text { a. ¿Qué sentimientos tuvo al momento de pensar en el estudiante con lo que ha tenido dificultades? }\end{array}$ \\
\hline
\end{tabular}




\begin{tabular}{|l|c|}
\hline b. ¿Qué sentimientos experimentó al crear la historia? \\
c. ¿Cómo es su relación con el estudiante?, ¿considera que su intervención pedagógica es acertada y \\
pertinente? \\
d. ¿Qué sentimientos experimentó al ponerse en los zapatos de un estudiante? \\
e. ¿Considera que la educación emocional es importante en el proceso de aprendizaje de los \\
estudiantes?, ¿por qué? \\
f. ¿La educación en derechos humanos contribuye al mejoramiento de los procesos de aprendizaje? \\
Impacto & $\begin{array}{c}\text { Al finalizar la actividad se espera que los profesores se apropien de elementos conceptuales claves en la propuesta } \\
\text { esperado intervención pedagógica tales como educación en derechos humanos, educación emocional y empatía en la }\end{array}$ \\
labor del profesor para finalmente reflexionar, desde la práctica pedagógica, la importancia de estos elementos en \\
el proceso de aprendizaje de los estudiantes.
\end{tabular}

Tabla 6.

Actividad 2. Carácter transformador del profesor en la educación emocional

\begin{tabular}{|l|l}
\hline Nombre & Carácter transformador del profesor en la educación emocional
\end{tabular}




\begin{tabular}{|c|c|}
\hline Tema & El valor de mi labor como profesor \\
\hline Objetivo & Reflexionar frente a mi labor como profesor en la transformación de la vida de muchos niños y niñas. \\
\hline Material & $\begin{array}{l}\text { Película “estrellas del cielo en la tierra”, hojas blancas, lápices y esferos. } \\
\text { Duración: } 165 \text { minutos } \\
\text { Una breve reseña encontrada en Wikipedia (s.f.) menciona que la película Estrellas del cielo en la tierra : } \\
\text { Es una película de la India dirigida y producida por Aamir Khan y protaganizada por Darsheel Safary y } \\
\text { Aamir Khan. Es la historia de un niño con necesidades especiales y su maestro inspirador. Taare Zameen } \\
\text { Par fue la selección oficial de la India para los Premios Óscar de 2007. (p. 1) }\end{array}$ \\
\hline Tiempo & 3 o 4 horas. \\
\hline Actividad & $\begin{array}{l}\text { 1. Hacer una contextualización al tema incitando a los asistentes a reflexionar sobre el papel transformador que } \\
\text { tienen los profesores a partir de preguntas generadoras, tales como: } \\
\text { a. ¿Cuál considera que es nuestra función como profesor? } \\
\text { b. ¿Qué capacidad de transformar la vida de los niños y niñas tienen los profesores? } \\
\text { c. ¿Qué experiencias de transformación personal tengo en mi experiencia como profesor? } \\
\text { 2. Ver la película completa. }\end{array}$ \\
\hline
\end{tabular}




\begin{tabular}{|c|c|}
\hline & $\begin{array}{l}\text { 3. Se entregará a cada profesor un formato previamente elaborado por la responsable de la actividad que contendrá } \\
\text { las siguientes preguntas: } \\
\text { a. ¿Qué reflexión puedo hacer de la película? } \\
\text { b. ¿Cómo puedo aplicar esta reflexión en mi práctica pedagógica? } \\
\text { c. ¿De qué manera me motivó como profesor?, ¿cómo puedo motivar a los demás? } \\
\text { d. ¿Qué ingrediente adicional le puedo dar a mis estudiantes a parte del lógico/formal? } \\
\text { e. ¿Qué relación puedo establecer entre la educación emocional y el carácter transformador del profesor? } \\
\text { f. ¿Por qué es importante la educación en derechos humanos desde el punto de vista de la película y de mi } \\
\text { contexto escolar? }\end{array}$ \\
\hline Evaluación & $\begin{array}{l}\text { Se dará un tiempo prudencial para que respondan de manera escrita las preguntas y luego se abrirá un debate en el } \\
\text { que se socializarán las respuestas. Con ello la idea es promover y enfatizar en el carácter transformador del } \\
\text { profesor y la importancia de la educación emocional y la educación en derechos humanos en el colegio. }\end{array}$ \\
\hline $\begin{array}{l}\text { Impacto } \\
\text { esperado }\end{array}$ & $\begin{array}{l}\text { Al finalizar la actividad se espera que los profesores reflexionen sobre su práctica pedagógica, afianzando y } \\
\text { vivenciando el carácter transformador que tiene la educación en derechos humanos y la educación emocional en } \\
\text { cada uno de los procesos de aprendizaje de sus estudiantes en la cotidianidad. }\end{array}$ \\
\hline
\end{tabular}

Tabla 7. 
Actividad 3. Un profesor asertivo que vincula la educación emocional

\begin{tabular}{|c|c|}
\hline Nombre & Un profesor asertivo que vincula la educación emocional \\
\hline Tema & La asertividad en la labor pedagógica como fundamento de una educación en derechos humanos. \\
\hline Objetivo & $\begin{array}{l}\text { Promover la comunicación asertiva en los profesores de manera que se tenga “tacto” para decir las cosas y } \\
\text { resolver con eficacia las problemáticas del día a día en las aulas, utilizando para ello la educación emocional. }\end{array}$ \\
\hline Material & Hojas blancas, esferos, vestuario y elementos para dramatizar una situación. \\
\hline Tiempo & 2 horas \\
\hline Actividad & $\begin{array}{l}\text { 1. Describir un caso difícil o controvertido que haya tenido con una persona y en la que haya actuado de forma } \\
\text { pasiva. Al respecto reflexionar sobre lo siguiente: } \\
>\text { ¿Dejamos que los demás violen nuestros derechos? } \\
>\text { ¿Agachamos la mirada y evitamos ver a la cara a quien nos habla? } \\
>\text { ¿Tenemos una voz muy suave (no nos escuchan)? } \\
>\text { ¿Siempre permito que decidan por mí y me dejo manipular con facilidad? } \\
>\text { ¿Tengo una baja autoestima? } \\
\text { 2. Utilizando los recursos para dramatizar, hacer equipos de } 3 \text { o } 5 \text { personas y presentar una pequeña obra de } \\
\text { teatro sobre la situación planteada. }\end{array}$ \\
\hline
\end{tabular}




\begin{tabular}{|c|c|}
\hline & $\begin{array}{l}\text { 3. Analizar lo sucedido a partir de la lectura de aspectos positivos y/o negativos de nuestras acciones y las } \\
\text { consecuencias que estás generan en las demás personas y en mí mismo. Al mismo tiempo, se debe construir } \\
\text { entre todos da una respuesta adecuada a la situación, ¿cómo se debe actuar? y ¿por qué? } \\
\text { 4. Ahora hacemos el ejercicio inverso, describimos una situación con una persona en la que hayamos } \\
\text { reaccionado de forma agresiva. Reflexionar sobre los siguientes puntos: } \\
>\quad \text { ¿Agredimos y ofendemos con nuestras palabras y acciones (humillamos, amenazamos, insultamos...)? } \\
>\quad \text { ¿Nos mostramos con actitudes de grosería, rencor o maldad? } \\
>\quad \text { ¿Nuestro lenguaje no verbal es hostil? } \\
\text { 5. Igualmente, podríamos dramatizar un caso de esta naturaleza, sobretodo en situaciones propias del contexto } \\
\text { escolar. } \\
\text { 6. Analizamos la situación de actuar con violencia y agresividad. } \\
\text { 7. Ahora, en compañía de otros profesores crear una situación escolar donde no se actúe con pasividad, ni } \\
\text { agresividad, sino de manera positiva y asertiva. }\end{array}$ \\
\hline Evaluación & $\begin{array}{l}\text { Aquí se debe analizar el tema de la comunicación asertiva en el ambiente escolar a partir de la respuesta a los } \\
\text { siguientes interrogantes: ¿Cuál es la reflexión final que podemos sacar de todo ello?, ¿Por qué es importante ser }\end{array}$ \\
\hline
\end{tabular}




\begin{tabular}{|l|l|}
\hline & $\begin{array}{l}\text { asertivo como profesores?, ¿Qué incidencia tiene la educación emocional en nuestras acciones?, ¿De qué manera } \\
\text { la asertividad contribuye a una educación en derechos humanos eficaz? }\end{array}$ \\
\hline Impacto & $\begin{array}{l}\text { En esta actividad se espera que los profesores del colegio Antonia Santos comprendan la importancia de } \\
\text { esperado }\end{array}$ \\
& comunicarnos asertivamente entre colegas, estudiantes y demás miembros de la comunidad educativa, siendo uno \\
\hline
\end{tabular}

\section{Tabla 8}

Actividad 4. Una foto de dónde estoy, me dirá ¡cómo estoy!

\begin{tabular}{|l|l|}
\hline Nombre & Una foto de dónde estoy, me dirá icómo estoy! \\
\hline Tema & La vinculación del contexto social y familiar para promover la vivencia de los derechos humanos y las emociones. \\
\hline Objetivo & Aprender a identificar las emociones desde los gestos, los lugares y los contextos sociales y familiares donde me \\
\hline Material & Cámara fotográfica, presentación en prezzi, video beam, registro fotográfico (fotos del colegio, el barrio, las \\
& familias, los profesores), hojas blancas, esferos. \\
\hline Tiempo & 2 horas \\
\hline Actividad & Esta actividad se desarrolla en tres (3) momentos: \\
\hline
\end{tabular}




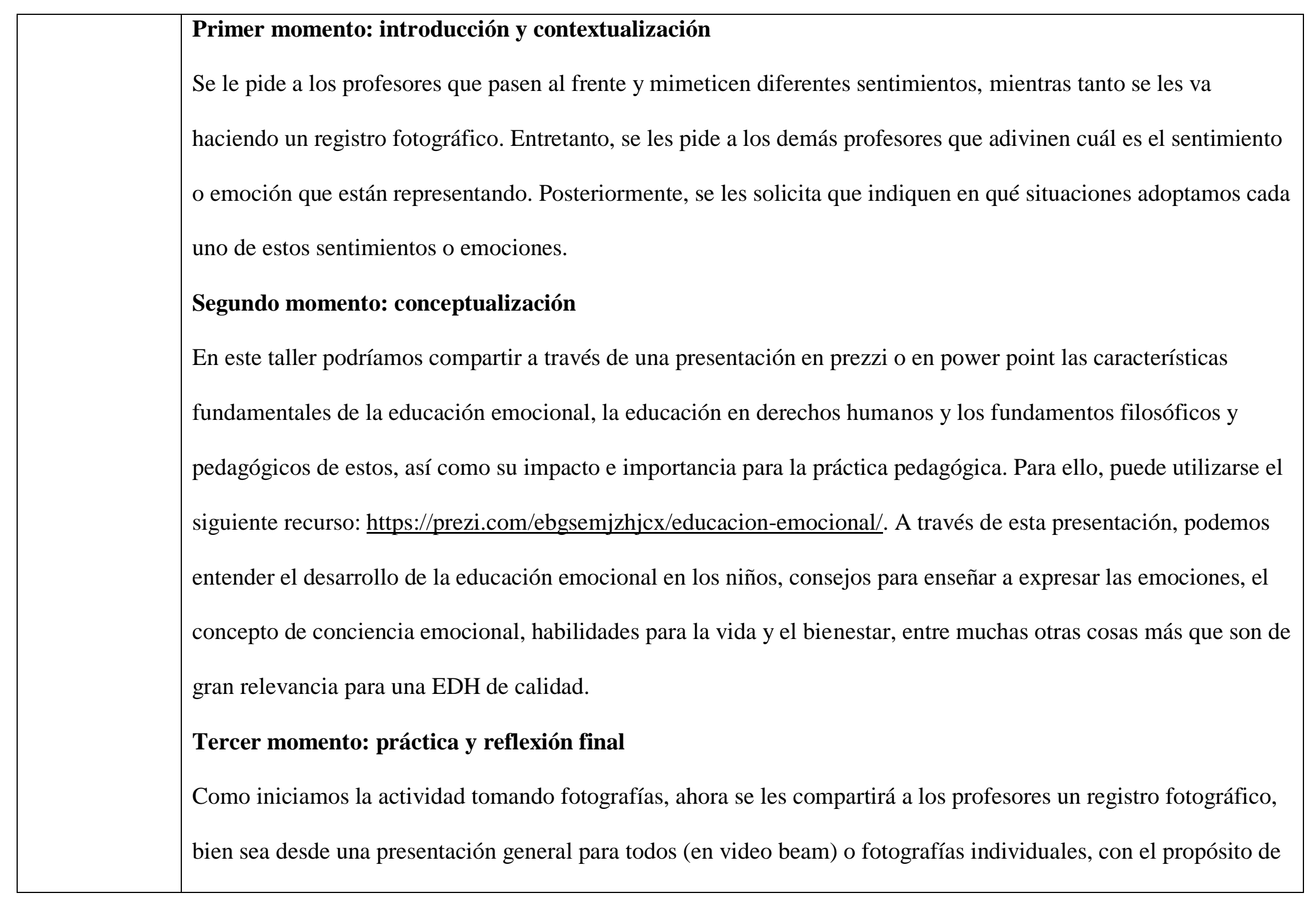




\begin{tabular}{|l|l|}
\hline \multirow{2}{*}{$\begin{array}{l}\text { compilar un álbum de fotografías sobre los directivos de la institución, los estudiantes, sus familias, el interior del } \\
\text { colegio y todos los escenarios que vinculen el contexto social, familiar y educativo de los profesores (el interior del } \\
\text { colegio) y los alumnos. La idea es mostrar estas fotografías a los profesores para que ellos puedan identificar e } \\
\text { inferir las emociones que sienten los niños en cada uno de estos lugares y con aquellas personas, de ahí que sea } \\
\text { muy relevante que exista una variedad en fotografías pues en últimas se debe hacer referencia a distintos } \\
\text { escenarios y emociones. }\end{array}$} \\
\hline Impacto & $\begin{array}{l}\text { Con esta actividad se pretende que los profesores no sólo afiancen los conceptos que son claves para la educación } \\
\text { en derechos humanos y la educación emocional sino que también reconozcan las necesidades y problemáticas del } \\
\text { contexto para su posterior transformación de tal manera que direccionen sus prácticas pedagógicas a la }\end{array}$ \\
\hline
\end{tabular}

Tabla 9

Actividad 5. Aprendiendo derechos humanos a través de una feria de juegos tradicionales

\begin{tabular}{|l|l|}
\hline Nombre & Aprendiendo derechos humanos a través de una feria de juegos tradicionales \\
\hline Tema & Los juegos tradiciones como excusa para el fortalecimiento de una educación en derechos humanos. \\
\hline
\end{tabular}




\begin{tabular}{|c|c|}
\hline Objetivo & $\begin{array}{l}\text { Vivenciar los derechos humanos jugando. Se trata entonces de recordar los mejores momentos de la vida cuando } \\
\text { se es un niño. }\end{array}$ \\
\hline Material & $\begin{array}{l}\text { Lazos, pelotas, tizas, bombas de agua, tablas, costales, tapas de gaseosa, retazos y todos los materiales y/o recursos } \\
\text { que se utilizan en los juegos tradicionales. }\end{array}$ \\
\hline Tiempo & 2 horas \\
\hline Actividad & $\begin{array}{l}\text { Aquí el propósito es realizar una feria de juegos tradicionales. Para preparar esta actividad se debe contar con un } \\
\text { equipo que previamente realice la logística de la feria. Es necesario contar con un espacio amplio y abierto en el } \\
\text { colegio, como por ejemplo, el patio. Allí han de ser ubicados aleatoriamente diversos juegos liderados por el grupo } \\
\text { organizador (podría pedírsele a un grupo de estudiantes de grado undécimo que ayuden con esta actividad). } \\
\text { Deben ser seleccionadas } 10 \text { bases o puntos en los que se ubican los siguientes juegos tradicionales: } \\
\text { 1. Carrera de costales } \\
\text { 2. Yermis } \\
\text { 3. Goloza } \\
\text { 4. Brincar la cuerda (o halarla) } \\
\text { 5. Trompo } \\
\text { 6. Canicas }\end{array}$ \\
\hline
\end{tabular}




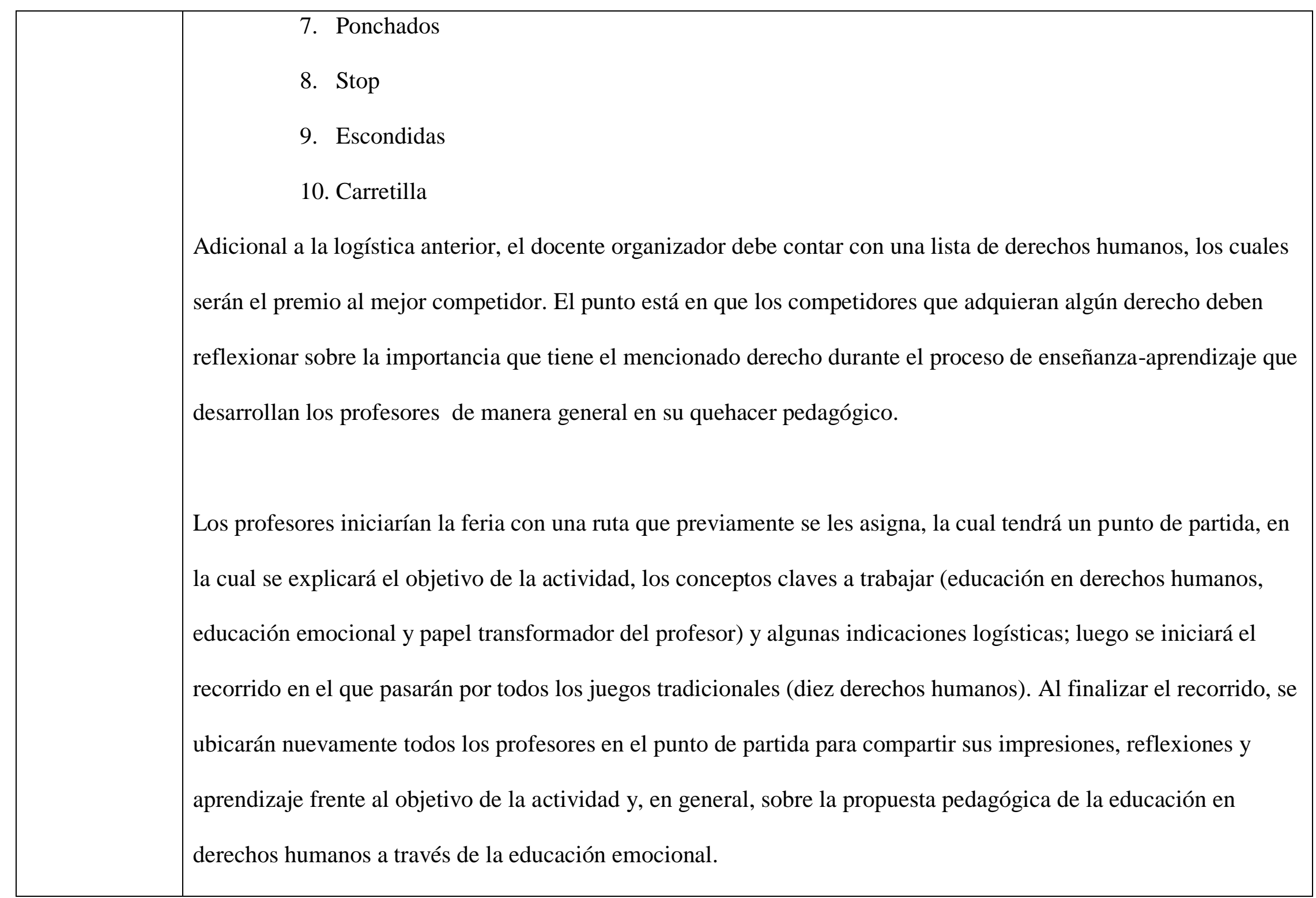




\begin{tabular}{|l|l|}
\hline Impacto & $\begin{array}{l}\text { Con esta actividad de cierre, se espera que los profesores se apropien y apliquen en sus prácticas pedagógicas los } \\
\text { esperado }\end{array}$ \\
& $\begin{array}{l}\text { estrategia para fomentar valores, competencias y saberes en sus estudiantes. } \\
\end{array}$ \\
\hline
\end{tabular}

\section{Tabla 10}

Actividad 6. Coloquio del Antonia Santos: experiencias exitosas en EDH

\begin{tabular}{|l|l|}
\hline Nombre & Coloquio del Antonia Santos: experiencias exitosas en EDH \\
\hline Tema & Experiencias exitosas en EDH. \\
\hline Objetivo & Compartir experiencias exitosas en EDH entre los profesores del colegio Antonia Santos I.E.D. \\
\hline Material & Libre (depende de los aportes de cada profesor) \\
\hline Tiempo & 2 horas \\
\hline Actividad & Esta actividad de cierre pretende dar la palabra a los profesores y permitir que ellos tengan una espacio para \\
& socializar algunas de sus experiencias, para ello la propuesta es: \\
\hline
\end{tabular}




\begin{tabular}{|c|c|}
\hline & $\begin{array}{l}\text { 1. Organizar en mesa redonda a los profesores y pedirles que piensen e identifiquen las mejores experiencias que } \\
\text { hayan tenido o aprendido durante su formación académica, en el transcurso de su experiencia profesional o en la } \\
\text { implementación de esta propuesta pedagógica para que ser socializadas. } \\
\text { 2. Ambientarlos con preguntas como: ¿por qué considera que la experiencia fue exitosa?, ¿cómo logró transformar } \\
\text { la vida de uno o varios estudiantes?, ¿es posible impactar positivamente en los niños? } \\
\text { 3. Ceder la palabra y permitir que los que deseen intervenir lo hagan con comodidad y tranquilidad, resaltando la } \\
\text { importancia de su labor y el impacto positivo generado en la comunidad. }\end{array}$ \\
\hline Evaluación & La evaluación la harán entre todos a través de los aportes de cada uno. \\
\hline $\begin{array}{l}\text { Impacto } \\
\text { esperado }\end{array}$ & $\begin{array}{l}\text { Al finalizar la actividad se espera que los profesores se apropien de la propuesta pedagógica incluyendo los } \\
\text { elementos conceptuales como: educación en derechos humanos, educación emocional, empatía en la labor del } \\
\text { profesor y sientan el gran papel que cumplen en este proceso formativo para los estudiantes. }\end{array}$ \\
\hline
\end{tabular}


Visto lo anterior sólo nos queda anexar tres comentarios más. El primero de ellos hace referencia a la necesidad de resaltar ante la comunidad educativa que cada taller de esta propuesta pedagógica cuenta con una actividad de cierre y/o reflexión cuyo propósito es evaluar el impacto, la pertinencia, la gestión e innovación de cada uno de los conceptos a tratar, cuestión que permitirá valorar la estructura de la propuesta, la metodología y la efectividad en el cumplimiento del objetivo para la cual fue implementada, a su vez, servirá para mejorar aquellos aspectos que se consideren débiles a partir de la ayuda de todos los profesores (quienes tienen mucha experiencia y vivencias por compartir). La mención de este aspecto de hace oportuna en el sentido en que se quiere consolidar una propuesta que no sólo responda a la coyuntura del colegio Liceo Antonia Santos como tal, sino que también sea constantemente perfeccionada para su acogimiento y posterior aplicación en otros contextos académicos.

El segundo y el tercero de ellos tienen que ver con la previsión de dos dificultades. La primera es que muy posiblemente exista un problema con la puesta en práctica de la propuesta pedagógica en el tiempo dispuesto para ello (las Semanas de Desarrollo Institucional) ya que el Consejo Académico o Directivo de la Institución - quienes planean las temáticas a trabajar en cada una de aquellas semanas - puede dar una negativa ante el permiso de su realización, no obstante esta situación puede ser superada si se solicita con tiempo de antelación los espacios para llevar acabo la mencionada propuesta de forma que el Consejo pueda tenerlos en cuenta e incluirlos como un método relevante en el propósito de mejorar la calidad educativa dentro de la institución. La segunda tiene que ver con una eventual predisposición por parte de los profesores ante la propuesta como consecuencia de la sobrecarga de trabajo y/o la falta de tiempo, así que para su superación se pretende recrear talleres dinámicos que logren captar el interés de los profesores y, a su vez, les genere un gran impacto. 


\section{Conclusiones}

Llegados a este punto es necesario enumerar ante el lector, algunas conclusiones frente los objetivos planteados en esta investigación. La primera es que efectivamente es posible estructurar y llevar a cabo una propuesta pedagógica teniendo en cuenta la esencia tanto de la educación en derechos humanos como de la educación emocional; a su vez, es tenida en consideración el papel transformador del profesor en la vida de los estudiantes, la escuela y la sociedad. Para ello, fue necesario el aporte personal de la experiencia educativa y académica de la autora de este trabajo investigativo, así como el apoyo de otras autoridades en este tema, compañeros del colegio y de otras instituciones educativas, con los que se estableció un diálogo teórico-práctico permanente en discusiones y debates acerca de la educación en derechos humanos y la educación emocional.

La segunda, tiene que ver con la fundamentación filosófica de los derechos humanos, en donde los debates presentados por autoridades como Pollmann y Menke con respecto a Pogge, fueron posicionados como una herramienta necesaria a la hora del debido reconocimiento de los DDHH en las prácticas pedagógicas de todos los profesores tanto en el colegio Liceo Antonia Santos, como a nivel distrital y nacional.

La tercera es que sin duda alguna nuestra intención fue que el debate de los derechos humanos y la educación en derechos humanos se dirigiera al desarrollo de un pensamiento crítico en los profesores partícipes de la propuesta pedagógica con el propósito de incentivar la transformación de las realidades de los estudiantes a partir del análisis de sus dificultades; este objetivo hizo posible darle a los profesores algunas herramientas para estudiar las posibilidades reales de cambio teniendo en cuenta las particularidades del contexto del ámbito educativo y, con ello, las problemáticas familiares, sociales y pedagógicas en las que se encuentran inmersos sus 
estudiantes a fin de contribuir con el disfrute de valores como la vida, la libertad y la dignidad, cuestión que al final ha de hacer reconocer públicamente la importancia los derechos humanos en la escuela.

La cuarta es que, en efecto, existe una relación -necesaria- entre la EDH y la educación emocional dentro de las prácticas pedagógicas de los profesores, ya que tanto ellos como los estudiantes son seres cargados de emociones que transitan entre la felicidad, el disgusto o la sorpresa, fenómeno que hace imposible concebir un ambiente escolar sin tener en cuenta todas y cada una de las emociones que son experimentadas.

La quinta, es que no cabe duda que el profesor posee un papel transformador e inspirador en sus estudiantes lo que significa que a través de su práctica pedagógica contribuye a la transformación y mejoramiento no sólo en la escuela, sino también en la sociedad. Por ello, es considerado como la figura clave en el proceso de enseñanza - aprendizaje, entre otras razones porque motiva, transforma e inspira. Este estatus le permite, además, construir de manera autónoma las herramientas, modelos y estrategias pedagógicas más acertadas para su práctica.

Así pues, la propuesta sugerida a través de este trabajo constituye una ayuda valiosísima para la puesta en práctica de una educación en derechos humanos tal cual es requerida por las políticas públicas, programas y organismos del orden nacional e internacional (es decir, como un derecho en sí mismo ya que reconoce a todos los miembros de la comunidad educativa como sujetos de derechos), ya que establece una relación directa con la educación emocional, una dimensión no muy tenida en cuenta dentro de los esquemas pedagógicos y prácticas de la institución estudio de caso.

Teniendo en cuenta lo anterior, se sabe que el rol del docente va más allá de la misión encomendada, pues no es un mero transmisor, sino que debe ser entendido como un ser que 
emana sensibilidad en su trato con los niños y los hace sentir importantes, respetados y valorados, en últimas logra vivenciar todo aquello que enseña y además involucra a toda la comunidad educativa: padres, estudiantes, directivos y otros profesores.

Finalmente, hemos de decir que la propuesta de intervención pedagógica constituye una herramienta de un valor significativo para los profesores del colegio Antonia Santos (primaria jornada tarde) ya que brinda estrategias adecuadas para llevar a cabo una educación en derechos humanos fundamentada en la educación emocional, con pertinencia y eficacia. Además la propuesta tiene un gran impacto y puede ser aplicada por cualquier otro profesor o institución educativa del país, debido a que las actividades planteadas son generalizadas y aplicables a cualquier contexto social del país. 


\section{Referencias Bibliográficas}

Arias, C. (2003). La educación emocional como facilitadora de procesos de paz en el contexto educativo. Recuperado de http://rlcu.org.ar/recursos/ponencias_IX_encuentro/Arias_Ortiz.pdf

Arias, F (2010). La emergencia del hombre en la formación de maestros en Colombia: segunda mitad del siglo $X X$ (Tesis de doctorado). Recuperado de http://bibliotecavirtual.clacso.org.ar/Colombia/alianza-cinde-umz/20110407012757/tesis$\underline{\text { arias-m.pdf }}$

Bisquerra, R. (2003). Educación emocional y competencias básicas para la vida. En Revista de Investigación Educativa. 21(1). P.p. 7-43. Recuperado de http://revistas.um.es/rie/article/viewFile/99071/94661

Buganza, J. (2006). La Otredad o Alteridad en el Descubrimiento de America y la Vigencia de la Utopia Lascasiana. En Razón y Palabra, 11 (54). Recuperado de http://www.redalyc.org/articulo.oa?id=199520736014

Comisión Nacional de los Derechos Humanos México. (2012). Pacto Internacional de Derechos Económicos, Sociales y Culturales, y su Protocolo Facultativo. Recuperado de https://transparencia.info.jalisco.gob.mx/sites/default/files/Pacto\%20Internacional\%20de\% 20Derechos $\% 20$ Econ $\%$ C $3 \%$ B 3micos $\% 2$ C $\% 20$ sociales $\% 20 \mathrm{y} \% 20$ Culturales.pdf

Delgado, R y Luque, P. (s.f.). Educación política. En Delgado, R (2005). Educación para el conocimiento social y político. (pp. 67 -81). Recuperado de https://books.google.com.co/books?id=6KGqsRLmEjsC\&pg=PA89\&lpg=PA89\&dq=Adol 
fo+\%C3\%81lvarez+\%E2\%80\%9CDemocracia+y+conflicto+en+la+escuela\%E2\%80\%9D $\underline{\text { ssource=bl\&ots=rwQ31c8Vl7\&sig=k7kZ1_IGtJ2pjkIHWfBfZhlx3pc\&hl=es- }}$ 419\&sa=X\&ved=0ahUKEwjZkOKPnJ7XAhXKMSYKHcSVCfUQ6AEIJTAA\#v=onepag e\&q=ecosistema\%20democr\%C3\%A1tico\&f=false

Domínguez et al. (2009). Inteligencia emocional: beneficios educativos de su estimulación y desarrollo. Actas do X Congresso Internacional Galego-Português de Psicopedagogia. Universidade do Minho. Braga, Portugal. Recuperado de http://www.educacion.udc.es/grupos/gipdae/documentos/congreso/Xcongreso/pdfs/t9/t9c3 $\underline{32 . p d f}$

Espinel, O. O. (2010). Pedagogías críticas y educación en derechos humanos Una mirada desde escenarios escolares y no escolares. En Rollos Nacionales. Recuperado de http://revistas.pedagogica.edu.co/index.php/NYN/article/viewFile/905/934

Fernández, M. R., Palomero, J.E. y Teruel, M. (2009). El desarrollo socioafectivo en la formación inicial de los maestros. En REIFOP, 12 (1). P.p. 33-50. Recuperado de http://w.aufop.com/aufop/uploaded_files/articulos/1240872524.pdf

Fernández, P (2009). Inteligencia emocional y el estudio de la felicidad. En Revista Interuniversitaria de formación del profesorado. 66 (23). P.p. 85 - 108. Recuperado de http://emotional.intelligence.uma.es/documentos/PDF35estudio_felicidad.pdf

Flórez, R., y Vivas, M. (2007). La formación como principio y fin de la acción pedagógica. Revista Educación y Pedagogía. Vol. XIX. Núm. 47. Enero - Abril de 2007 
Fondo de las Naciones Unidas para la Infancia - UNICEF-. (2002). Unicef va a la escuela para promover los derechos de los niños, las niñas y los adolescentes. Recuperado de https://www.unicef.org/argentina/spanish/ar_insumos_educvaescuela1.PDF

Goleman, Daniel. (2009). La inteligencia emocional. Por qué es más importante que el cociente intelectual. El libro que revoluciona el concepto de inteligencia. Editorial Kairós.

Hoyos, G. (2001). Formación ética, valores y democracia, tomado de Estados del Arte de la Investigación en Educación y Pedagogía en Colombia. Recuperado de http://www.socolpe.org/data/public/libros/InvestigacionPedagogia/14Etica\%20y\%20valores\%20-EstadodelArte.pdf

Hoyos, G. (2001). Formación ética, valores y democracia. Recuperado de http://www.socolpe.org/data/public/libros/InvestigacionPedagogia/14Etica\%20y\%20valores\%20-EstadodelArte.pdf

Ley 115 de 1994. Ley General de Educación. Publicada en Diario Oficial 41.214 del 8 de febrero de 1994. Recuperado de http://www.alcaldiabogota.gov.co/sisjur/normas/Norma1.jsp?i=292

Ley 1620 de 2013. Diario Oficial 48910 de septiembre 11 de 2013. Recuperado de http://www.alcaldiabogota.gov.co/sisjur/normas/Norma1.jsp?i=54537

Liceo Nacional Antonia Santos (s.f.). Historia. Recuperado de http://www.redacademica.edu.co/webcolegios/14/antoniasantos/Historia.html

Magendzo, A (2006). Educación en derechos humanos: un desafío para los docentes de hoy. Recuperado de 
https://books.google.com.co/books?id=rknenIwfcHYC\&printsec=frontcover\&dq=Educaci \%C3\%B3n+en+derechos+humanos:+un+desaf\%C3\%ADo+para+los+docentes+de+hoy\&h $\underline{\text { less- }}$

419\&sa=X\&ved=0ahUKEwjhhNufoMLXAhVEySYKHVbhBuYQ6AEIJTAA\#v=onepage \&q=Educaci\%C3\%B3n\%20en\%20derechos\%20humanos\%3A\%20un\%20desaf\%C3\%AD o\%20para $\% 201$ os $\% 20$ docentes $\% 20 \mathrm{de} \% 20 \mathrm{hoy} \& \mathrm{f}=$ false

Magendzo, A y Toledo, M. (2009). Educación en derechos humanos: curriculum historia y ciencias sociales del $2^{\circ}$ año de enseñanza media. Subunidad "régimen militar y transición a la democracia. En Estudios pedagógicos, 1 (1). Pp. 139 - 154. Recuperado de http://www.scielo.cl/pdf/estped/v35n1/art08.pdf

Magendzo, A. (2005). Educación en derechos humanos: Un desafío y una misión irrenunciable. Cooperativa Editorial Magisterio: Bogotá, Colombia.

Magendzo, A. (2008). Ideas-fuerza y pensamiento de la educación en derechos humanos en Iberoamérica. Recuperado de http://unescopaz.uprrp.edu/documentos/ideasfuerza.pdf

Magendzo, A. (2008). La escuela y los Derechos Humanos. Recuperado de https://es.scribd.com/document/137088329/Abraham-Magendzo-La-Escuela-y-LosDerechos-Humanos

Malagón, Y. (2015). Problemas, contenidos y acciones relacionados con los derechos humanos en la escuela. El caso de cinco instituciones educativas y una fundación social. En Revista Aletheia, 7 (2). Recuperado de http://www.scielo.org.co/pdf/aleth/v7n2/v7n2a04.pdf 
Menke, C. y Pollman, A. (2010). Filosofía de los Derechos Humanos. Herder. Barcelona: España.

Ministerio de Educación Nacional República de Colombia - MEN -. (2009). Programa de Educación para el Ejercicio de los Derechos Humanos - EDUDERECHOS -, La educación para e l ejercicio de los derechos humanos en la escuela: un compromiso de todos. Módulo 1. Recuperado de http://www.mineducacion.gov.co/1621/articles$\underline{241325 \_ \text {archivo_pdf.pdf }}$

Mujica, R (2002). La metodología de la educación en derechos humanos. Recuperado de http://www.dhnet.org.br/educar/mundo/a_pdf/mujica_metodologia_educacion.pdf

Mujica, R. (2007). ¿Qué es educar en derechos humanos? Recuperado de http://www.corteidh.or.cr/tablas/r24456.pdf

Olguín, J. (s.f.). Inteligencia emocional. Recuperado de http://www.grupoelron.org/autoconocimientoysalud/inteligenciaemocional.htm

Parra, R y Vásquez, P. (2017). De la teoría de la alteridad a la reflexión crítica de educación en derechos humanos: una propuesta para maestros y maestras de las instituciones educativas distritales castilla y general Santander de la ciudad de Bogotá (Tesis de maestría). Recuperado de http://repository.usta.edu.co/bitstream/handle/11634/3954/Parrarosa2017.pdf?sequence=1

Peluffo, M y Roig, P. (2005). Los derechos humanos y la enseñanza de una lengua: Experiencia áulica en escuela secundaria. Puertas abiertas. En Memoria Académica, 11 (3). Pp. 1 - 7. Recuperado de http://www.memoria.fahce.unlp.edu.ar/art_revistas/pr.6963/pr.6963.pdf 
Pico, I. (s.f.). Componentes de la inteligencia emocional. Recuperado de https://psicopico.com/componentes-la-inteligencia-emocional/

Pogge, T. (2005). La pobreza en el mundo y los Derechos Humanos. Ediciones Paidós. Barcelona: España.

Proyecto Educativo Institucional. (2013). Institución Educativa Distrital Liceo Nacional Antonia Santos. Educación de calidad para una sana convivencia. Bogotá, Colombia

Real Academia Española de la Lengua (s.f.). Emoción. Recuperado de http://dle.rae.es/?id=EjXP0mU

Rodríguez, C. (2012). La constitución de sujetos maestros en las tensiones escolares. (Tesis de maestría). Universidad Nacional de Colombia Facultad de Ciencias Humanas. Bogotá, Colombia.

Rodríguez, D (2015). Tres experiencias para pensar la educación en derechos humanos en Colombia. (Tesis de maestría). Universidad del Rosario, Bogotá. Recuperado de http://repository.urosario.edu.co/bitstream/handle/10336/11809/TRES\%20EXPERIENCIA S\%20PARA\%20PENSAR\%20LA\%20EDUCACION\%20EN\%20DERECHOS\%20HUM ANOS\%20EN\%20COLOMBIA.pdf?sequence $=1$

Secretaría de Educación Distrital. (2010). Lineamiento pedagógico y curricular para la educación inicial en el Distrito. Recuperado de http://old.integracionsocial.gov.co/anexos/documentos/lineamientopedagogico.pdf 
Teruel, M. P. (2000). La inteligencia emocional en el currículo de la formación inicial de los maestros. Revista Interuniversitaria de formación del profesorado. 38 (12). pp. 141 - 152. Recuperado de https://dialnet.unirioja.es/servlet/articulo?codigo=118075

Torquemada, A. (2007). La práctica educativa de derechos humanos en educación primaria. En Eikasia. Revista de Filosofía, 2 (3). Recuperado de http://www.revistadefilosofia.org/13$\underline{13 . p d f}$

United States InterAmerican Community Affairs (s.f.) Inteligencia emocional. Recuperado de http://interamerican-usa.com/articulos/Ger-Talen-hum/Int-emoc-2.htm

Wikipedia. (s.f.). Taare Zameen Par. Recuperado de: https://es.wikipedia.org/wiki/Taare_Zameen_Par 


\begin{abstract}
Anexos
Anexo No. 1. Encuesta a los profesores de Básica Primaria del colegio Antonia Santos

I.E.D.

Tema: la Educación en Derechos Humanos fundamentada en la educación emocional

La presente encuesta tiene como objetivo conocer algunas apreciaciones de los profesores que laboran en la Básica Primaria del Colegio Antonia Santos I.E.D.; con el tema de la Educación en Derechos Humanos fundamentada en la educación emocional y el papel transformador del maestro en esta labor, para trabajar la Tesis de investigación de la Maestría en Defensa de los Derechos Humanos que realizo en la Universidad Santo Tomás.
\end{abstract}

Se trata de preguntas cerradas a las cuales solamente tiene que marcar con una equis $(\mathrm{X})$. Muchas gracias por su colaboración.

1. ¿qué importancia tiene una educación en derechos humanos (EDH) en el contexto escolar? Es relevante Muy relevante Poco relevante Insignificante

2. ¿qué significado tiene para el maestro en su labor diaria contar con herramientas pedagógicas adecuadas para una EDH?

Es relevante __ Muy relevante ___ Poco relevante ___ Insignificante

3. ¿qué relevancia tiene para el colegio Antonia Santos I.E.D. el fortalecimiento de una educación en derechos humanos dentro del aula de clase?

Es relevante Muy relevante

Poco relevante Insignificante

4. ¿qué importancia tiene que las prácticas pedagógicas de los profesores se encuentren basadas en una educación en derechos humanos para transformar significativamente la vida de sus estudiantes?

Es relevante Muy relevante Poco relevante Insignificante

5. La educación en derechos humanos y la educación emocional tienen algunos elementos en común, entre ellos un interés particular en la persona ¿qué importancia tiene involucrar las emociones en un proceso de EDH al interior del aula de clase?

Es relevante Muy relevante

Poco relevante

Insignificante

6. ¿qué importancia tiene en su labor como maestro una educación basada en las emociones? Es relevante Muy relevante Poco relevante Insignificante

7. ¿qué pertinencia tiene vincular en el trabajo pedagógico del profesor la educación de los derechos humanos fundamentado en la educación emocional?

Es relevante Muy relevante Poco relevante Insignificante 
8. ¿considera relevante para esta institución educativa el fortalecimiento de la EDH basada en la educación emocional, teniendo en cuenta las características propias de los estudiantes?

Es relevante Muy relevante

Poco relevante

Insignificante

9. La EDH y la educación emocional son apuestas pedagógicas que le apuntan a mejorar la calidad de vida de los estudiantes, ¿qué importancia tiene el profesor en la transformación social de sus estudiantes?

Es relevante Muy relevante Poco relevante Insignificante

10. ¿el tipo de estrategia pedagógica que pone en práctica el profesor en el aula de clase, incide en el impacto que genera en la vida de sus estudiantes?

Es relevante Muy relevante Poco relevante Insignificante

11. ¿qué importancia tiene en el colegio Antonia Santos los profesores para transformar la vida de sus estudiantes?

Es relevante __ Muy relevante ___ Poco relevante ___ Insignificante

12. Como profesor de Primaria del colegio Antonia Santos ¿considera pertinente poner en práctica una apuesta pedagógica en la que se vincule la Educación en Derechos Humanos fundamentada en la educación emocional en su aula de clase?

Es relevante Muy relevante

Poco relevante

Insignificante

Muchas gracias por su colaboración.

\author{
Margareth Lucía López \\ Candidata a Magister en Defensa de los derechos Humanos \\ Universidad Santo Tomás
}

Anexo No. 2. Proyecto Educativo Institucional del colegio Liceo Antonia Santos.

HIMNO DE LA IED LICEO NACIONAL ANTONIA SANTOS

CORO

Con trinos comienzan las aves el día,

que el nuestro comience con cantos también;

un coro que exprese labor y alegría, 
un ritmo en que alterne el rosal y el laurel (bis).

I

El hoy es promesa feliz del mañana,

la palma conquista constancia y afán;

para esa cosecha feliz el Liceo

sembró la simiente y el fruto vendrá.

II

La virgen doncella patriota y altiva

que al hosco cadalso serena subió,

nos dio con su muerte la norma de vida

y el nombre que amamos

con el corazón, con el corazón.

(Coro)

Autor: Gustavo Gómez Ardila

Arreglo: Luis Lizcano

\section{PATRIMONIO CULTURAL DE LA CIUDAD}

La Alcaldìa Mayor de Bogotà y el Departamento administrativo de Planeación Distrital -DAPD- con carta fechada el 18 de febrero de 2002 informó a la I.E.D. Liceo Nacional Antonia Santos que el inmueble de su locativa ha sido declarado "Bien de interés cultural" por el decreto 606 de julio 26 de 2001 firmado por el entonces alcalde mayor de Bogotá Antanas Mockus y publicado en la Gaceta de urbanismo y 
construcción de obra No. 196 de junio 30 de 2001 (fuente documento técnico de soporte Plan de ordenamiento territorial decreto 619 de 2000 y el 606 de 2001). Esto implica que como bien cultural está cobijado por normas que buscan la preservación de sus valores y características originales.

Segùn lo concebido por planeación distrital, "la ciudad es producto de un largo acontecer. En su estructura física se reflejan acciones de las sociedades que la han habitado en las diferentes épocas de la historia, que han dejado huellas y sus deseos plasmados en espacios, edificios y lugares"; asimismo, el DAPD afirma que "como vestigios de las formas de crecimiento de la Bogotà construida hasta la primera mitad del siglo, los bienes de interès cultural estàn cobijados por normas que buscan la preservaciòn de sus valores y características originales".

Este recorrido histórico evidencia que nuestra instituciòn, como todo lo grande y trascendental, tuvo un inicio discreto, se trataba de cimentar profundamente las bases de una obra que debìa perpetuarse a travès de muchos años como se ha logrado hasta ahora (2009); las directrices fijadas por quienes orientaron a los jòvenes hicieron que en las aulas cultivaran su inteligencia y formaran su corazòn, responsabilidad social que se mantiene en el tiempo y es asì como sus exalumnos y egresados se sienten fieles a una tradiciòn llena de valores que se constituyen en paradigma de vida, verdad y amor y testimonian el esfuerzo y la entrega de educadores que supieron dejar un mensaje de vida, ciencia y humanidad.

\section{EXPRESIONES ARTÍSTICAS}

En el año 2010 la Secretaría de Educación D.C en convenio con la Fundación BOGOTA ARTE CONEXIÓN-BAC- el arte independiente, y en el marco del programa de CONVIVENCIA Y PROTECCION ESCOLAR a través del componente manejo saludable y creativo del tiempo libre, abre espacios de convivencia a los estudiantes mediante la participación en actividades lúdicas, recreativas, deportivas y artísticas, al mismo tiempo que promueve el desarrollo de talentos forjados desde acciones pedagógicas y formativas de los eventos que llevan a cabo.

Con esta perspectiva, el programa "Buscando Talentos" se ejecuta en el colegio Liceo Nacional Antonia Santos como proyecto educativo y pedagógico para brindar a la comunidad educativa, especialmente a los estudiantes, la creación artística, el conocimiento e interpretación de la imagen y la apreciación estética mediante la elaboración de obras de arte.

En este sentido, es de reconocer, en nuestra experiencia institucional, que la mediación de las artes plásticas en la educación establece una serie de condiciones en la persona dando oportunidad para su desarrollo integral en sus dimensiones intelectual, espiritual, cultural y social desde la expresión 
simbólica, la imaginación, la creatividad, el sentido estético, la sensibilidad, la percepción y el conocimiento, todos ellos factores integradores de la educación artística, de lo cual emerge la relación armónica entre el individuo y el mundo exterior conducente a su transformación individual y colectiva.

De lo desarrollado en el entorno cultural del colegio, como creación y producción de obras pictóricas de gran formato, tipo mural, con la técnica acrílico sobre lienzo en 8 módulos de 1,30 x1,30 metros y el trabajo profesional del artista Edwin Pinzón instalado en el colegio durante 45 días con su taller de pintura, estrategia denominada Artista en Residencia, provocó la interacción permanente de estudiantes, docentes, funcionarios administrativos y padres de familia alrededor de la elaboración de la obra pictórica dando acceso a los diferentes momentos como inducción del artista, socialización de técnicas y conceptos, elaboración de producciones de pintura de los estudiantes.

Así avanzó el proceso y en la medida que el artista avanzaba en su obra titulada “ EL ABRAZO”, los estudiantes por cursos asistieron a su taller por períodos de tiempo de una hora para intercambiar ideas, compartir conocimientos, provocar la sensibilidad por el arte, elaborar pequeñas obras individuales y así descubrir talento. También el artista los involucra en su obra y ellos se sienten metidos en el cuadro, lo cual les crea sentido de pertenencia, los configura como guardianes del producto.

Como uno de los resultados del proceso, se hizo una exposición con sus propias elaboraciones y a manera de concurso institucional se eligieron cinco de ellas, a quienes se les otorgó reconocimiento y con el jurado, constituido a nivel institucional, se eligió una sola pintura premiada con un de Kit de pintor; de este modo, el estudiante elabora su propia obra asesorado por el artista para concursar a nivel distrital con exposición en las bibliotecas públicas de Bogotá.

Con estas ejecuciones, el proyecto resultó ser tan impactante a nivel convivencial, educativo y cultural que se vislumbró la necesidad de desarrollarlo también con los niños de Primaria, solicitud que fue aceptada por la Fundación y la SED y como producto de esta gestión, también en primaria se realiza una obra de otros ocho módulos tipo mural.

Bajo este horizonte, el programa de CONVIVENCIA Y PROTECCION ESCOLAR de la Secretaría de Educación D.C y lo vivido en el Liceo permite afirmar que el proyecto "BUSCANDO TALENTOS" contribuyó efectivamente a formar en el respeto por la diferencia y las relaciones dialógicas en los conflictos, a disminuir los índices de violencia, a apreciar el arte como sensibilidad humana, para construir una nueva visión de mundo acorde con los principios de sana convivencia. 
En este mismo sentido en el año 2016 la SED en convenio con Idartes y en el marco del programa de mejorar ambientes de aprendizaje, se asigna al artista Jairo Tabares para que en un proceso pedagógico indague con los niños de primaria intereses, creaciones, fantasías, imaginarios para plasmar en un mural dentro de las instalaciones del colegio.

\section{DIRECTIVOS DOCENTES RECTORES}

JORNADA DE LA MAÑANA:

$\begin{array}{ll}1967-1992 & \text { ANA MARIA VARGAS GUERRA } \\ 1992-1994 & \text { MARIOLA CUERVO DE BRICEÑO } \\ 1994-2000 & \text { LUCILA GUTIERREZ MENDEZ } \\ 2001-2004 & \text { GUILLERMO GUEVARA RIVEROS } \\ 2004-2005 & \text { MARIA DEL CARMEN HERNANDEZ } \\ 2005 \text { a la fecha } & \text { IRMA TORO CASTAÑO }\end{array}$

JORNADA DE LA TARDE:

$1967-1972$

1973

$1974-1978$

$1979-1983$

$1984-1987$

$1988-1990$

$1991-1999$

$2000-2001$

$2002-2004$

$2004-2005$

2005 a la fecha
ANA MARIA VARGAS GUERRA

ANA JULIA DE RAMOS

FANNY DE CORDOBA

CARMEN ROSA RODRIGUEZ

TERESA TOVAR CASTELLANOS

EDILBERTO CASTELLANOS

INES VANEGAS DE V $\{$ ASQUEZ

REINALDO CABALLERO FARFAN

GUILLERMO GUEVARA RIVEROS

MARIA DEL CARMEN HERNANDEZ

IRMA TORO CASTAÑO 


\section{REGISTRO HISTÓRICO DE INDICADORES DE DESEMPEÑO INSTITUCIONAL}

El colegio ha tomado siempre como referencias de calidad los resultados de las pruebas externas y el índice sintético de calidad, cifras sobre las cuales analiza y propone planes de mejoramiento institucional.Los siguientes cuadros dan cuenta de ello.

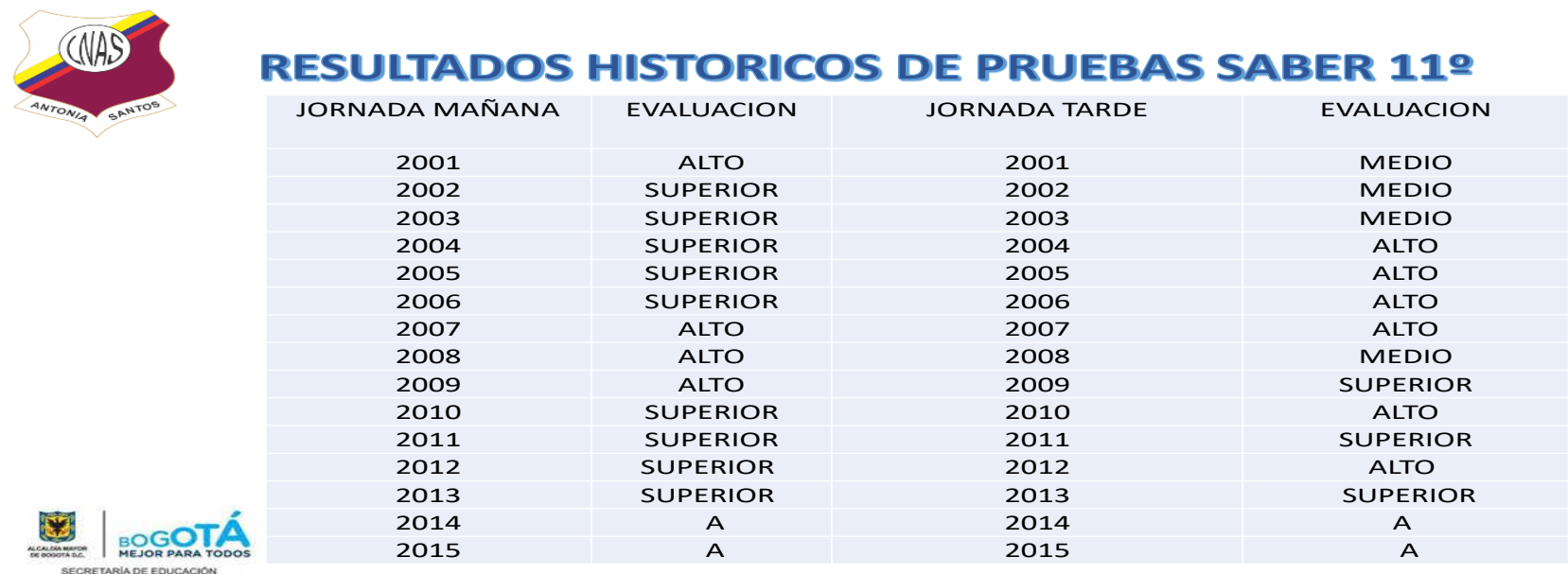

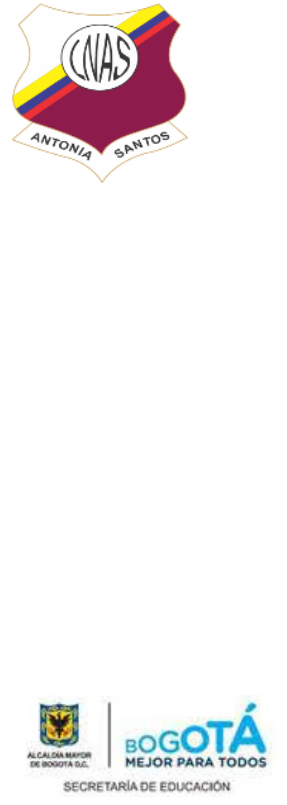

\begin{tabular}{|c|c|c|c|c|c|c|c|c|c|}
\hline \multirow[b]{2}{*}{ INSTITUCION } & \multicolumn{2}{|c|}{ ISCE Primaria } & \multirow{2}{*}{$\begin{array}{l}2015 \\
\text { Promedi } \\
\text { o } \\
\text { Nacional }\end{array}$} & \multicolumn{2}{|c|}{ ISCE Secundari } & \multirow{2}{*}{$\begin{array}{l}\text { a } 2015 \\
\text { i Promedi } \\
\text { o } \\
\text { Naciona } \\
\text { I }\end{array}$} & \multicolumn{3}{|c|}{ ISCE Media 2015} \\
\hline & ISCE & $\begin{array}{l}\text { Promedio } \\
\text { Distrital } \\
\text { SED }\end{array}$ & & ISCE & $\begin{array}{l}\text { Promedi } \\
\text { o } \\
\text { Distrital } \\
\text { SED }\end{array}$ & & ISCE & $\begin{array}{l}\text { Promedi } \\
\text { o } \\
\text { Distrital } \\
\text { SED }\end{array}$ & $\begin{array}{l}\text { i Promedi } \\
0 \\
\text { Naciona } \\
1\end{array}$ \\
\hline EGIO EDUARDO SANTOS IED & 6,55 & 5,82 & 5,07 & 5,41 & 5,74 & 4,93 & 7,04 & 6,48 & 5,57 \\
\hline $\begin{array}{l}\text { OOLEGIO REPUBLICA BOLIVARIANA DE } \\
\text { ENEZUELA IED }\end{array}$ & 4,07 & 5,82 & 5,07 & 4,56 & 5,74 & 4,93 & 4,64 & 6,48 & 5,57 \\
\hline $\begin{array}{l}\text { EOLEGIO LICEO NACIONAL ANTONIA SANTOS } \\
\text { ED }\end{array}$ & 4,99 & 5,82 & 5,07 & 5,63 & 5,74 & 4,93 & 7,14 & 6,48 & 5,57 \\
\hline $\begin{array}{l}\text { COLEGIO LICEO NACIONAL AGUSTIN NIETO } \\
\text { ABBALERO IED }\end{array}$ & 6,93 & 5,82 & 5,07 & 6,92 & 5,74 & 4,93 & 3,85 & 6,48 & 5,57 \\
\hline COLEGIOTECNICO MENORAH IED & 6,95 & 5,82 & 5,07 & 7,49 & 5,74 & 4,93 & 7,5 & 6,48 & 5,57 \\
\hline COLEGIO PANAMERICANO IED & 4,22 & 5,82 & 5,07 & 3,73 & 5,74 & 4,93 & 6,8 & 6,48 & 5,57 \\
\hline COLEGIO RICAURTE IED & 6,69 & 5,82 & 5,07 & 3,96 & 5,74 & 4,93 & 7,2 & 6,48 & 5,57 \\
\hline COLEGIO SAN FRANCISCO DE ASIS IED & 1 & 5,82 & 5,07 & 1 & 5,74 & 4,93 & 5,5 & 6,48 & 5,57 \\
\hline nstituto Técnico Central & NA & 5,82 & 5,07 & 8,78 & 5,74 & 4,93 & 8,31 & 6,48 & 5,57 \\
\hline
\end{tabular}




\section{RESULTADOS HISTORICOS DE INDICE SINTETICO DE CALIDAD}

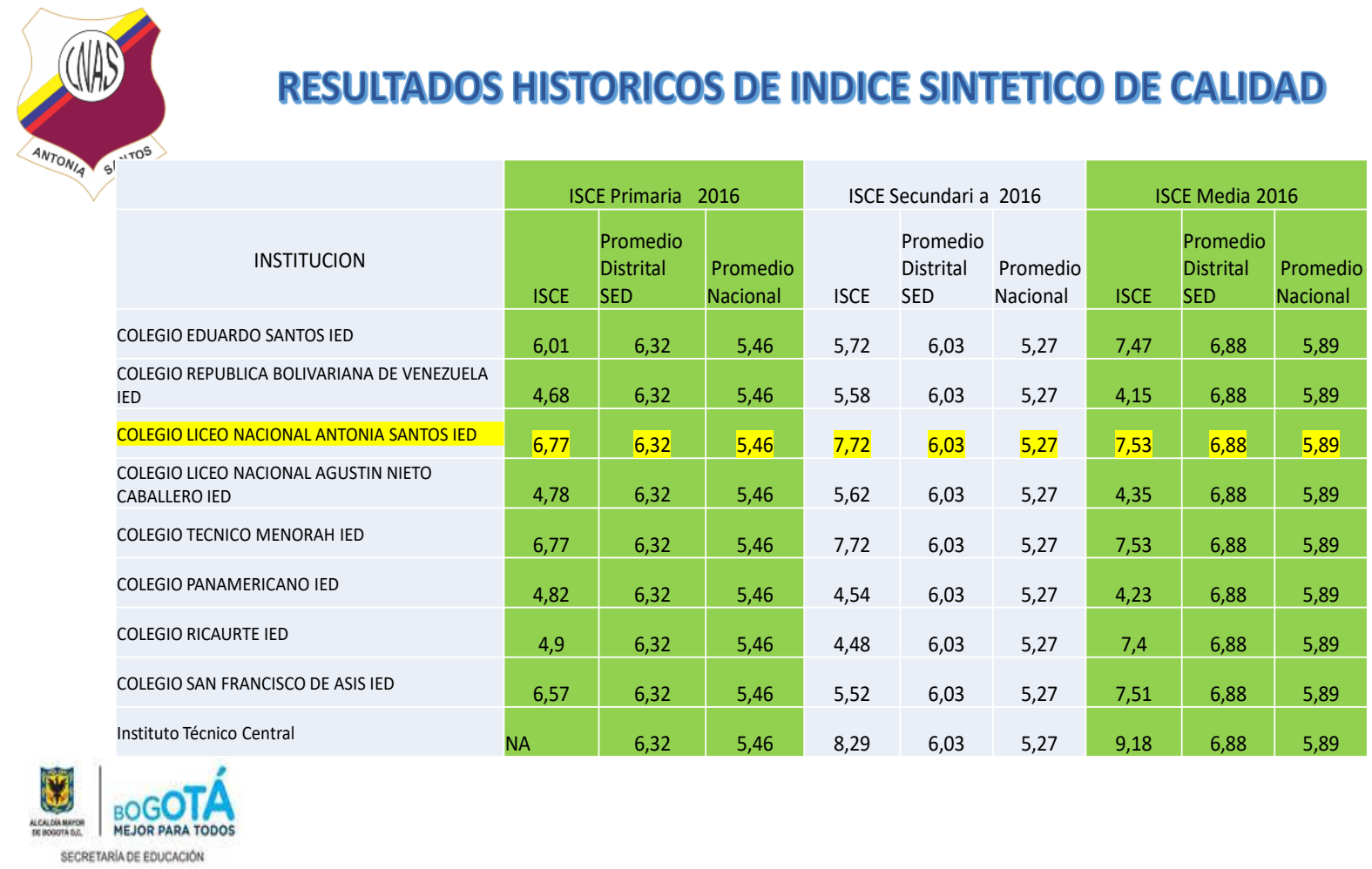

\section{PROCESOS PEDAGOGICOS ESPECIALES}

\section{ALIADOS 10.}

En 2016, por iniciativa del Ministerio de Educación Nacional- MEN-, y la OEI-Organización de Estados Iberoamericanos para la Educación, la Ciencia y la Cultura, y la ONG Corpoeducación, se celebró el Convenio de Cooperación, con el fin de aunar esfuerzos académicos, técnicos, administrativos y financieros para estructurar, acompañar y ejecutar el proyecto de acompañamiento "Colegios líderes por la excelencia-Aliados 10", entre establecimientos educativos cuyo interés es el de fomentar el trabajo conjunto hacia el mejoramiento de la calidad educativa, aprovechando las capacidades, las experiencias y las buenas prácticas entre pares académicos institucionales, que en este caso son dos colegios de carácter oficial del Distrito Capital.

La dinámica del acompañamiento llevo a que, como parte de la planeación del proyecto, se establecieron los roles de la institución educativa mentora, al Colegio Morisco I.E.D, quien con el ejercicio voluntario y motivada por el compromiso social y educativo apoya a la institución educativa acompañada, Colegio Liceo Nacional Antonia Santos I.E.D. a partir de su realidad y desde sus prácticas pedagógicas. Así, los dos colegios se han dispuesto en participar y aprovechar la oportunidad 
que se presenta para mejorar el desempeño en varios aspectos, que se denominan para el proyecto, componentes básicos: el liderazgo pedagógico, el uso inteligente de datos, el ambiente escolar, la gestión pedagógica y las prácticas de aula, liderado por un equipo de cada colegio llamado equipo de enlace.

Con los componentes así definidos, los equipos de enlace expresaron el interés común de focalizar las acciones, inicialmente, hacia los componentes de liderazgo y gestión pedagógica y prácticas de aula en virtud de las necesidades institucionales priorizadas por los consejos académicos: evaluación de aprendizajes y la formación docente.

Desde esta perspectiva, se concertó realizar un trabajo pedagógico conjunto sobre evaluación de aprendizajes por competencias y diseño de preguntas tipo SABER como eje temático de la formación docente y con miras a mejorar tanto el desempeño de los estudiantes en pruebas externas como el Índice Sintético de Calidad Educativa, -ISCE-, en cada uno de los colegios.

Los efectos de este proceso y el trabajo colectivo, se evidenciaron a través de la integración y el liderazgo pedagógico de los directivos y docentes con el trabajo por áreas y jornadas; la apropiación de técnicas educativas para la gestión pedagógica y de calidad con el diseño de preguntas, y la utilización de recursos didácticos para las prácticas de aula como guías para la elaboración de pruebas tipo SABER.

De este modo, se considera que la estrategia de alianza con intercambio e interlocución entre pares, configura una forma particular de ejercer la docencia y el oficio de maestro, de tal manera, que se debe proyectar la continuidad de dicho proceso con base en los cuestionamientos sobre la práctica cotidiana y lo que debería ser, y con ellos determinar los nuevos ejes de trabajo conjunto.

\section{RECONOCIMIENTOS Y PREMIOS ALCANZADOS}

La labor educativa y de formación realizada por el colegio Liceo Nacional Antonia Santos ha sido objeto de reconocimientos y distinciones como se relaciona a continuación:

Inclusión de la planta física en el inventario distrital de los inmuebles, Bienes de Interés Cultural, para su conservación integral, tipológica y restitución. Resolución No. 606 del 26 de julio de 2001 expedida por la Alcaldía Mayor de Bogotá y el Departamento Administrativo de Planeación Distrital. 
Premio a la Excelente Gestión Escolar 2010 en la modalidad Bronce categoría Oficial otorgado por la Alcaldía Mayor de Bogotá y la Secretaría de Educación con fecha noviembre 26 de 2010.

Premio por Rendimiento Académico al obtener los mejores resultados de Inglés en la prueba de estado ICFES-SABER $11^{\circ}$ en el 2010 otorgado por la Alcaldía Mayor de Bogotá y la Secretaría de Educación con fecha noviembre 30 de 2010.

Premio por Rendimiento Académico al obtener los mejores resultados en la prueba de Estado ICFESSABER $11^{\circ}$ en el 2010 otorgado por la Alcaldía Mayor de Bogotá y la Secretaría de Educación con fecha noviembre 30 de 2010.

Reconocimiento por contribuir al desarrollo de las acciones del programa Salud al colegio. otorgado por el Hospital Centro oriente y el Programa Salud al Colegio con fecha noviembre de 2010.

Reconocimiento por haber sido merecedores del premio a la Excelente gestión escolar 2010 otorgado por la Casa de Justicia de la localidad Los Mártires

Certificación por la participación con una muestra de estudiantes en la Prueba Piloto "Estudio Internacional sobre progreso en competencia lectora- PIRLS-“ expedida por el ICFES y la organización nacional de PIRLS Colombia en abril de 2010.

Reconocimiento por los mejores puntajes a nivel de ciudad en el examen de estado para el ingreso a la educación superior 2009 y quedar clasificados en categoría SUPERIOR. Otorgado por la Alcaldía Mayor de Bogotá y la Secretaría de Educación

Distinción Orden Civil al Mérito "Localidad de Los Mártires” en el grado Gran Oficial. Resolución No. 735 del 15 de diciembre de 2009, expedida por la Alcaldía Local de Los Mártires.

Reconocimiento del Concejo de Bogotá a la labor de colegio en sus 80 años en agosto 22 de 2016

\section{MEDIA FORTALECIDA.}

Con la implementación de las políticas públicas en educación en el distrito capital con el plan de desarrollo Bogotá Humana de Gustavo Petro se implementan programas que se orientan hacia el fortalecimiento de ciudadanía y convivencia, la educación entendida como derecho, el acceso a educación superior, la promoción de una lengua extranjera y por ello, el colegio entra en una dinámica de gestión alrededor de: implementación de las aulas de inmersión en inglés con los docentes extranjeros desde el año 2013; la media fortalecida haciendo su diseño en 2015 para iniciar se aplicación en el 2016 con los grados décimos y undécimos en los énfasis de Lenguas y Humanidades y matemáticas ingenierías y tecnologías de la información y respectivamente en líneas de comunicación y medios alternativos y cultura matemática acompañados por las universidades Minuto de Dios para la primera y Sergio Arboleda par la segunda. 


\section{CONSTRUCCION, RESTAURACION Y REFORZAMIENTO SEDE A}

La sede de primaria fue reforzada y con nueva construcción se dio al servicio en el año 2006; el paso de los años se evidencia en la planta física del Liceo en la sede A y desde el año 2005 se vinieron observando situaciones de completo deterioro hasta cuando ocurre el desalojo de las instalaciones por evaluación de alto riesgo evaluado por la DPAE; es entonces cuando los estudiantes de bachillerato en marzo del año 2008 se trasladan a la localidad Antonio Nariño ocupando una edificación en arriendo hasta finalizar el año 2015.

La obra en la sede A, incluyó reforzamiento del edificio biblioteca, teatro y capilla, restauración de aulas y construcción nueva de laboratorios, aulas, comedor.

El traslado de la sede de bachillerato se planifica para que en enero de 2016 se inicie el año escolar en dicha sede pero con ciertas modificaciones: 18 grupos en cada una de las jornadas ( con reducción de grupos), parámetros de estudiantes por aula de 32, la media fortalecida para los décimos y undécimos, el aula de inmersión y la realización de algunos proyectos específicos como la orquesta sinfónica juvenil que inicia su conformación en el año 2006, las escuelas deportivas en futbol sala masculino femenino y voleibol, grupos de danzas. La preocupación del momento es que la cobertura tiene una tendencia a la baja de tal manera que a 2015 se registran 900 jóvenes en secundaria y 850 en primaria en ambas jornadas.

\section{CARACTERIZACIÓN DE LA INSTITUCIÓN}

Nombre

Liceo Nacional Antonia Santos Institución Educativa Distrital

Dirección

Sede A: Carrera 21 No 12 -49 Barrio Ricaurte

Teléfono $2473421 / 3706599$

Sede B: Calle 12 N$^{\circ}$ 21-14. Barrio Ricaurte.

Teléfono 2473421 / 3706599

Jornadas Mañana y Tarde.

Género Mixto

Sector Urbano

Localidad 14 - Los Mártires

Establecimiento Oficial - Distrital 
Modalidad

Niveles de Educación

Código Dane

NIT

E- mail

FAX

Resolución No
Académica

Preescolar, Educación Básica y Media.

111001019526

830.015.079-8

lnalantoniasantos14@redp.edu.co

2473421/ 3726691

7457 de Noviembre 13 /1998 y 2582 de Agosto

TITULO I

CAPÍTULO 1

Proyecto Educativo Institucional

"EDUCACIÓN DE CALIDAD PARA UNA SANA CONVIVENCIA"

ARTÍCULO1. Legalidad. El Colegio Liceo Nacional Antonia Santos I.E.D.es una Institución Educativa de carácter público aprobado legalmente por el MEN, Resolución 4500 de agosto 22 de 1972 y

Resolución 3288 de septiembre 18 de 2000, Decreto 2582 del 28 de agosto de 2002 emanada de la SED, para impartir enseñanza formal en los niveles de Preescolar, Básica Primaria, Básica Secundaria, Media Académica, y Media Fortalecida jornadas Mañana y Tarde, calendario A

ARTÍCULO 2. Misión. El Liceo Nacional Antonia Santos garantiza una educación integral al educando en los niveles de EDUCACION INICIAL ( jardín y transición) Educación Básica Primaria $\left(\right.$ de $1^{\circ}$ a $5^{\circ}$ ), Educación Básica Secundaria ( $6^{\circ}$ a $9^{\circ}$ ) y Educación media $\left(10^{\circ}\right.$ y $\left.11^{\circ}\right)$ desde el fortalecimiento de los procesos de desarrollo biofísico, competencia comunicativa, ética y cognitiva, dentro del marco de la dignificación humana, que le permita un crecimiento y desarrollo social adecuado, para posibilitar su acceso y permanencia a la educación superior. 
ARTÍCULO 3. Visión. El colegio Liceo Nacional Antonia Santos será una institución líder en la formación de educandos en aspectos académicos, de desarrollo humano, tecnológicos, científicos, democráticos y productivos, con compromiso comunitario y una visión crítica, aportando a su desarrollo personal, de su contexto y a la continuidad en su formación académica superior con una adecuada gestión administrativa y la continua capacitación de los docentes y orientada, sus acciones de formación, hacia lineamientos emergentes de políticas y programas educativos establecidos por la secretaría de educación.

ARTÍCULO 4. Filosofía. La I.E.D. Liceo Nacional Antonia Santos, educa a todos los integrantes de la comunidad educativa, según las exigencias del momento y, hace parte de su filosofía, la educación fundamentada en valores, con sólidos principios religiosos, éticos y morales que se reflejan en todas sus actividades.

La Institución parte del principio de educar y desarrollar plenamente la personalidad, dentro de un proceso de formación integral en y para la libertad, a través de valores tales como: respeto a la vida, derechos humanos, cumplimiento de deberes, justicia y convivencia, tolerancia, solidaridad, equidad, paz, autoridad y cultura; asimismo, promueve la adquisición y generación de conocimientos científico-técnicos y humanísticos (históricos, sociológicos, matemáticos, lingüísticos), para el desarrollo de la capacidad crítica, analítica, reflexiva y creativa orienta hacia la concientización de la conservación del medio ambiente, a la práctica del trabajo, en pro de mejorar la calidad de vida y la solución de los problemas familiares escolares y sociales.

La vivencia diaria de la filosofía Institucional debe generar actitudes de respeto, hacia las personas, la autoridad, la ley, los símbolos patrios, las creencias, y las tradiciones; en todo el proceso educativo dentro de un ambiente de honestidad, respeto y responsabilidad que promueva la identidad personal y cultural de sus miembros, y se concrete en un auténtico compromiso social en la conservación de los bienes del colegio y del medio ambiente.

Asimismo, propicia la participación activa en la auténtica libertad y el respeto a la individualidad, promueve el desarrollo de la personalidad juvenil, el espíritu investigativo y la experiencia en el proceso de aprendizaje.

\section{ARTÍCULO 5. Principios básicos de la formación educativa.}

Toda acción pedagógica en el Liceo Nacional Antonia Santos I.E.D., se rige por el Enfoque Pedagógico Crítico Social, con principios de:

FORMACIÓN HUMANÍSTICA. Centrada en valores con proyección práctica y estrechos vínculos con la problemática de la vida real, donde se combine lo aprendido en el aula de clase con la práctica laboral y social. 
PERSONALIZACIÓN DEL/LA ESTUDIANTE. Entendida como la toma de conciencia de su dignidad humana, apoyo a su autodeterminación, integrada a la vida comunitaria y comprometida frente a su futuro.

EDUCACIÓN PARA LA VIDA. Educar para hoy y para mañana, orientando el desarrollo de habilidades que le permitan involucrarse y competir en un campo específico de trabajo para satisfacer las necesidades básicas. Correlacionar el quehacer pedagógico con la cotidianidad, de manera que los conocimientos resulten útiles y prácticos en función de un estudiante libre, autónomo, responsable, crítico y solidario.

COMPETENCIA COMUNICATIVA. Fomentar la competencia comunicativa a nivel individual y social, con actitudes renovadoras de diálogo, concertación y conciliación que busquen la adecuación del trabajo docente a la necesidad de cambios que exige la sociedad moderna.

DESARROLLO DEL SENTIDO CRÍTICO. Desarrollar la capacidad de análisis y de crítica frente a la realidad del mundo circundante en los niveles económico, político, social, científico, religioso, etc. con el fin de promover cambios que en el inmediato futuro trasciendan al interior y al exterior del Colegio.

CREATIVIDAD Y DESARROLLO DE CAPACIDADES LÚDICAS. Precisar procesos investigativos en los que el profesor es Orientador y facilitador, y el estudiante un investigador creativo. El docente propiciará espacios agradables y motivantes que desarrollen el sentido lúdico de todas las personas involucradas en el proceso educativo.

PARTICIPACIÓN ACTIVA. Involucrar a la comunidad, desde la formulación de problemas, hasta la interpretación de los datos y la discusión de soluciones frente a unos intereses comunes.

LIBERTAD DE CÁTEDRA. Libertad de cátedra y de aprendizaje (Constitución Nacional) con sujeción a los criterios fijados en el plan de estudios; el educador puede presentar a consideración sus propuestas sobre organización de contenidos, enfoque pedagógico y disponer de los métodos de enseñanza que crea más convenientes para efectivizar su labor. Al mismo tiempo los estudiantes pueden controvertir y exponer libremente sus opiniones.

IDONEIDAD: desarrollar capacidades y características que faculten a los estudiantes para desempeñarse en forma eficiente en la vida cotidiana y universitaria.

RESPETO A LA DIVERSIDAD: Entendido como la comprensión de las diferentes expresiones culturales, emocionales, cognitivas y sociales, que permitan a través de la tolerancia y el respeto entender la diferencia como un factor de desarrollo personal.

ARTÍCULO 6. Objetivo General. 
Promover la formación integral de cada uno de los estudiantes liceístas, mediante el desarrollo de su integralidad, que le permita enfrentar y resolver los problemas cotidianos y pueda dar continuidad a su proyecto académico y laboral con proyección a mejorar su calidad de vida.

\section{ARTÍCULO 7. Objetivo Específicos.}

Promover el respeto a los derechos humanos, mediante la participación en la sociedad,

dentro de las normas de convivencia, pluralismo, justicia, solidaridad y equidad, así como el ejercicio de la tolerancia y la libertad.

Propiciar la participación de todos los estamentos en la elaboración de los lineamientos conceptuales y metodológicos que permitan implementar en forma progresiva los cambios que se requieran.

Crear mecanismos de autodisciplina que faciliten el cumplimiento de los deberes propios del medio en que se encuentre.

Inculcar la honestidad como valor fundamental del comportamiento para lograr una sociedad más justa y equilibrada.

Propiciar en la Comunidad Educativa la autoestima dentro de un ambiente de valoración personal, en los aspectos intelectual, moral, físico, con miras al mejoramiento de la calidad de vida. Propiciar oportunidades y espacios de tiempo para desarrollar las capacidades de liderazgo y la participación en trabajos comunitarios, dentro del ámbito de convivencia y mutua tolerancia.

Crear espacios para la realización de actividades que permitan a los estudiantes descubrir sus habilidades y destrezas en el campo artístico y deportivo.

Estimular el desarrollo del pensamiento mediante la capacidad crítica, reflexiva y analítica, que fortalezcan el avance científico y tecnológico, perfeccionando métodos de estudio y de investigación que conviertan al estudiante en artífice de su propio aprendizaje.

Formular procesos de autovaloración y optimizar los recursos materiales, humanos, técnicos, ambientales y económicos existentes dentro de la Comunidad Educativa y de su entorno acordes con el concepto fundamental de desarrollo.

Desarrollar habilidades que permitan leer, comprender, escribir, escuchar y expresarse 
correctamente.

Desarrollar y fortalecer capacidades intelectuales y académicas en los énfasis de Matemáticas y Comunicación en Medios Alternativos, que faculten a los estudiantes para un buen desempeño en la vida productiva y universitaria..

Generar espacios de inclusión hacia la diversidad étnica, de gènero y trastornos transitorios de aprendizaje, con el fin de formar un ser humano integral que propenda por el desarrollo social de su entorno

. Promover el sentido de pertenencia, cuidado y preservación del medio ambiente

ARTÍCULO 8. Organización y Gobierno Escolar. El organigrama define el ordenamiento administrativo del Colegio Liceo Nacional Antonia Santos I.E.D. con sus cuadros directivos y líneas jerárquicas de asesoría y coordinación.

El Gobierno Escolar. De acuerdo con el artículo 68 de la Constitución Nacional de 1991 y la Ley 115/94, artículo 142 y Decreto 1860/ 97, artículos 19 y 20, las instituciones educativas establecerán en su reglamento un Gobierno Escolar, con la participación de la Comunidad Educativa. Está conformado por:

a) Consejo Directivo

b) El Rector

c) El Consejo Académico

PARÁGRAFO. Además del Gobierno Escolar, el Colegio tiene los siguientes organismos de participación:

1. Por el Colegio.

El Comité de Convivencia (Acuerdo Nº4 de 2000, del Concejo de Bogotá)

2. Por los estudiantes.

a) El Consejo de Estudiantes. (Decreto 1860/94, artículo 29).

b) El Representante de estudiantes al Consejo Directivo (Ley 115/94, artículo 93).

c) El Personero de estudiantes (Ley 115/94, artículo 94; Decreto 1860/94, artículo 28).

d) El Contralor y Vice contralor (Acuerdo del Concejo de Bogotá No 401 de 2009)

f) La Asociación de ex alumnos (Decreto. 1860/ 94 Artículo 21 numeral 5). (Ver Título III, capítulo 2, artículo 71, de la agenda escolar.)

g) El Cabildante estudiantil. Acuerdo del Consejo de Bogotá D.C. No 116 de 29 de Diciembre de 2003. 
h) Vigías ambientales escolares (Acuerdo Nº 166 de 2005, del Concejo de Bogotá)

i) Estudiantes que hacen parte del comité institucional de presupuestos participativo. (Resolución $\mathrm{N}^{\circ}$ 181, 27 Enero de 2009 de la secretaría de Educación del Distrito).

j) Estudiantes en el comité consultivo para el relacionamiento de la educación media con el sector empresarial. (Decreto 400 de 2001 "Por el cual se reglamenta el artículo 32 de la Ley 590 de 2000).

3. Por los padres de familia.

a) La Asociación de Padres de Familia ( Corte Constitucional, Sentencia 041 febrero 3/94 - Decreto 1625/72, artículo 10; Ley 115/94, artículos 4,7; Decreto 1860/94, artículo 30).

b) El Consejo de Padres de Familia (Decreto 1860, artículo 31)

ARTÍCULO 9. El Consejo Directivo. Es la máxima instancia de participación de la Comunidad Educativa y el responsable de la orientación de las políticas académicas y administrativas de la Institución, después de haber agotado los procedimientos previstos en el Manual de Convivencia. (Ver Título III, capítulo 2, artículo 62, de la agenda escolar.)

El Consejo Directivo está conformado por:

El Rector, quien lo presidirá y convocará ordinariamente 1 (una) vez por mes y

Extraordinariamente cuando lo considere necesario.

b) Dos docentes elegidos por la Asamblea de Profesores.

c) Un representante de los estudiantes elegido por sus compañeros del Consejo Estudiantil.

d) Dos padres de familia uno de la Junta Directiva de la Asociación uno del Consejo de Padres.

e) Un representante de los ex alumnos elegido por el Consejo Directivo de ternas

Presentadas por las organizaciones que aglutinen la mayoría de ellas o, en su defecto, por quien haya ejercido el año inmediatamente anterior el cargo de representante de los estudiantes.

f) Un representante de los sectores productivos organizados en el ámbito local o subsidiariamente de las entidades que auspicien o patrocinen el funcionamiento del establecimiento educativo. El representante será escogido por el Consejo Directivo, de 
candidatos propuestos por las respectivas organizaciones.

ARTÍCULO 10. El Rector(a). Es el orientador del proceso educativo. En tal calidad, además de las actividades que le corresponde realizar de acuerdo con lo previsto en el reglamento interno de trabajo o manual de funciones de la Institución, en el Manual de Convivencia o en otras normas vigentes.

ARTÍCULO 11. El Consejo Académico. (Ley 115/94, artículo 145 y Decreto 1860/94, artículo 24). Instancia superior para participar en la orientación pedagógica del establecimiento y está integrado por: (Ver Título III, capítulo 2, artículo 63, de la agenda escolar.)

a) El Rector quien lo convoca y preside y/o el coordinador académico.

b) Los Directivos Docentes de la Institución.

c) Un Docente de cada área definido en el plan de estudios.

ARTÍCULO 12. El Comité de Convivencia. (Acuerdo 04 de 2000, Concejo de Bogotá). Harán parte integral de los Comités de Convivencia: (Ver funciones Título III, capítulo 2, artículo 64, de la agenda escolar.)

a) Los representantes del personal docente ante el Consejo Directivo u otro elegido por los profesores.

b) EL representante de los estudiantes ante el Consejo directivo u otro elegido por los estudiantes.

c) El representante del Consejo Estudiantil.

d) El Personero de los estudiantes.

e) Dos (2) representantes de los padres de familia y dos (2) representantes de otras instituciones.

f) El Coordinador de disciplina o de convivencia o quien haga sus vences, quien lo presidirá.

g) Un representante del personal administrativo y/o operativo del plantel, elegido por estos mismo.

ARTÍCULO 13. La representación de los/las estudiantes. Existen en el Colegio las siguientes instancias de representación de los estudiantes: 
a) El Consejo de Estudiantes (Decreto 1860/94, artículo 29).

b) El Personero de Estudiantes (Ley 115/94, artículo 94 y Decreto 1860/94, artículo 28)

c) El Representante de los estudiantes al Consejo Directivo (Ley 115, artículo 93)

d) El Contralor.

e) El Cabildante estudiantil. Acuerdo del Consejo de Bogotá D.C. No 116 de 29 de Diciembre de 2003. (Ver Título III, capítulo 2, artículo 76, de la agenda escolar.)

f) El Consejo Electoral. (Ver Título III, capítulo 2, artículo 66, de la agenda escolar.)

g) Los vigías ambientales escolares. (Acuerdo $\mathrm{N}^{\circ} 166$ de 2005, del Concejo de Bogotá)

h) Estudiantes que hacen parte del comité institucional de presupuestos participativo.

(Resolución N 181, 27 Enero de 2009 de la secretaría de Educación del Distrito).

i) Estudiantes en el comité consultivo para el relacionamiento de la educación media con el sector empresarial. (Decreto 400 de 2001 "Por el cual se reglamenta el artículo 32 de la

Ley 590 de 2000).

ARTÍCULO 14. Consejo de estudiantes. De conformidad con el artículo 29 del Decreto 1860 de 1994, el Liceo tendrá un Consejo Estudiantil que será el máximo organismo colegiado para asegurar y garantizar el continuo ejercicio de la participación estudiantil. Está integrado por un representante de cada uno de los grados. (Ver Título III, capítulo 2, artículo 69, de la agenda escolar.)

ARTÍCULO 15. El Personero de Estudiantes. El Colegio tendrá un(a) personero(a) de los estudiantes perteneciente al grado once, y debe ser elegido democráticamente de conformidad con el artículo 28 del Decreto 1860 de 1994. (Ver Título III, capítulo 2, artículo 71, de la agenda escolar.)

ARTÍCULO 16. El Representante de los Estudiantes ante el Consejo Directivo. El representante de los estudiantes es un(a) estudiante del grado $11^{\circ}$, perteneciente al Consejo de Estudiantes y delegado por este ante el Consejo Directivo.

ARTÍCULO 17. El Contralor estudiantil. Acuerdo del Consejo de Bogotá D.C. No 071 de 2008. (Ver Título III, capítulo 2, artículo 72, de la agenda escolar).

ARTÍCULO 18. Los vigías ambientales escolares. Acuerdo № 166 de 2005, del Concejo de Bogotá. (Ver Título III, capítulo 2, artículo 73, de la agenda escolar).

ARTÍCULO 19. Estudiantes que hacen parte del comité institucional de presupuestos participativo. Resolución Nº 181, 27 Enero de 2009 de la secretaría de Educación del Distrito. (Ver Título III, capítulo 2, artículo 74, de la agenda escolar). 
ARTÍCULO 20. Estudiantes en el comité consultivo para el relacionamiento de la educación media con el sector empresarial. Decreto 400 de 2001 "Por el cual se reglamenta el artículo 32 de la Ley 590 de 2000. (Ver Título III, capítulo 2, artículo 75, de la agenda escolar).

\section{ARTÍCULO 21. La representación de los padres de familia.}

El Consejo de Padres de Familia. El Consejo de Padres es un órgano representativo de los padres de familia que se encarga de garantizar la participación de los padres y acudientes en el proceso pedagógico del establecimiento. Está integrado por el vocero de los padres de los estudiantes que cursen cada uno de los diferentes grados que ofrece el Liceo. La elección se efectúa por mayoría de votos de los miembros presentes en la Asamblea de Padres.

La Asociación de Padres de Familia. ( Corte Constitucional, Sentencia 041 de febrero 3 de 1994; Decreto 1625/72, artículo 1 Ley 115, artículo 4 y 7 y Decreto 1860/94, artículo 30) y demás normas reglamentarias. (Ver Título III, capítulo 2, artículo 78, de la agenda escolar.)

\section{CAPITULO 2}

\section{Del Proceso Académico}

ARTíCULO 22. Plan de Estudios. (Ley 115/94, artículos 78 y 79). El plan de estudios es el esquema estructurado de las áreas obligatorias y fundamentales y de áreas optativas con sus respectivas asignaturas, que forman parte del currículo de la Institución. Se entiende como una propuesta dinámica del quehacer educativo, nacidas de los procesos curriculares que incorpora y promueve las dimensiones y procesos del desarrollo humano.

Las competencias, estándares y los logros por niveles, grados, áreas, y ciclos; la metodología, la distribución del tiempo, los criterios de evaluación y la administración y demás aspectos del currículo y del plan de '-estudios, son determinados y desarrollados en el Proyecto Educativo Institucional.

Niveles y Modalidad. (Ley 115/94, artículos 10 y 11 y Decreto 1860/94, artículos 9). El Colegio Liceo Nacional Antonia Santos I.E.D ofrece los niveles de educación Inicial , básica primaria, básica secundaria, media y media fortalecida.

Evaluación y Promoción del/la estudiante. (Decreto 1290/09 el Sistema de evaluación del colegio Liceo Nacional Antonia Santos es coherente con lo establecido en el Decreto 1290 de Abril 26 de 2009, por el cual se reglamenta la evaluación de aprendizajes y promoción de los estudiantes de los niveles de educación preescolar, , básica secundaria , media y media fortalecida.

El estudiante del Liceo Nacional Antonia Santos de la Media Fortalecida se acoge como Liceísta a los direccionamientos contemplados en el SIEE, y adicionalmente a los contemplados en el presente documento 
Áreas de formación en educación Preescolar formación integral por dimensiones : cognitiva, comunicativa, corporal, socio afectiva y artística

Áreas de formación en educación Básica y Media. (Ley 115/94, artículos 14-23-21

y 32 y Decreto 1860/94, artículos 34,35,36 y 41). Para el logro de los objetivos de la educación básica y media, se establecen áreas obligatorias y fundamentales, y áreas optativas con sus respectivas asignaturas.

Son áreas obligatorias y fundamentales para la educación básica, las siguientes:

a) Ciencias naturales y educación ambiental.

b) Ciencias sociales, historia, geografía, Constitución Política y democracia, derechos humanos y cátedra afro colombiana.

c) Educación artística.

d) Educación ética y en valores humanos.

e) Educación física, recreación y deporte.

f) Educación religiosa.

g) Humanidades: lengua castellana e idioma extranjero.

h) Matemáticas.

i) Tecnología e Informática.

Para la educación Media: Todas las anteriores, más Filosofía y Ciencias económicas y políticas.

Articulo 23 ORGANIZACIÓN DE LOS PLANES DE ESTUDIO DE LA EDUCACION MEDIA FORTALECIDA( EMF)

Para el énfasis de matemáticas, ingeniería y tecnologías de la información se ha determinado el plan de estudios con una caracterización fuerte hacia la cultura Matemática, con asignaturas semestrales propias de carreras universitarias que algunas de ellas otorgan certificación de asistencia y otras créditos homologables a instituciones de educación superior con una jornada adicional del ciclo de profundización en media fortalecida es de 10 horas semanales,

En cuanto al énfasis de Humanidades, la caracterización especial se orienta hacia un plan de estudios en Comunicación y Medios Alternativos, con asignaturas semestrales que posibilitan el manejo de diferentes medios y que permiten la integración de asignaturas de carreras del área humanística; algunas de ellas con certificación de asistencia y otras con créditos homologables con Instituciones de Educación Superior, con una jornada adicional en el ciclo de educación media de 10 (diez) horas semanales. 
Estas profundizaciones sustentan el ajuste en la malla curricular de todos los niveles de enseñanza en el colegio para ser coherentes con este nivel de desarrollo

Para la evaluación de los educandos se definen criterios y condiciones en el Sistema Institucional de Evaluación.

PARÁGRAFO 1. La educación sexual, la enseñanza de la protección del ambiente, de la ecología y de los recursos naturales, así como la educación para la justicia, la paz, la democracia, la solidaridad, la confraternidad, el cooperativismo, la prevención de desastres y riesgos y en general la formación en valores humanos, se hacen mediante Proyectos pedagógicos, seminarios, talleres, etc.

PARÁGRAFO 2. El estudio de estos temas y la formación en tales valores, salvo los numerales a) y b), no exige asignatura específica. Esta formación debe incorporarse al currículo y desarrollarse a través de todo el plan de estudios

Enseñanza obligatoria. Artículo 14 de la Ley 115 de 1994. En todos los establecimientos oficiales o privados que ofrezcan educación formal es obligatorio en los niveles de la educación preescolar, básica y media, cumplir con:

El estudio, la comprensión y la práctica de la Constitución y la instrucción cívica, de conformidad con el artículo 41 de la Constitución Política;

El aprovechamiento del tiempo libre, el fomento de las diversas culturas, la práctica de

la educación física, la recreación y el deporte formativo, por lo cual el Gobierno promoverá y estimulará la difusión y desarrollo;

La enseñanza de la protección el ambiente, la ecología y la preservación de los recursos

naturales, de conformidad con lo establecido en el artículo 67 de la Constitución Política;

La educación para la justicia, la paz, la democracia, la solidaridad, la confraternidad, el

cooperativismo y, en general, la formación en los valores humanos, y

La educación sexual, impartida en cada caso de acuerdo con las necesidades psíquicas,

físicas y afectivas de los educandos según su edad.

\section{Articulo 24 SISTEMA INTEGRAL DE EVALUACION ( SIEE)}

\section{ARTICULO 20. NATURALEZA}


El sistema de evaluación del Colegio LICEO NACIONAL ANTONIA SANTOS es coherente con lo establecido en el Decreto 1290 de abril 26 d 2009 por el cual se reglamenta la evaluación del aprendizaje y promoción de los estudiantes de los niveles de educación: EDUCACIÓN INICIAL, BÁSICA, MEDIA. Y MEDIA FORTALECIDA

Dentro de sus lineamientos generales en términos de evaluación.

\section{ARTICULO 3․ PROPOSITOS Y OBJETIVOS}

El SIEE tiene propósitos y objetivos como se describen a continuación:

Propósitos

Identificar las características personales, intereses, ritmos de desarrollo y estilos de aprendizaje del estudiante para valorar sus avances.

Proporcionar información básica para consolidar o reorientar los procesos educativos relacionados con el desarrollo integral del estudiante.

Suministrar información que permita implementar estrategias pedagógicas para apoyar a los estudiantes que presenten debilidades y desempeños superiores en su proceso formativo.

Determinar la promoción de estudiantes.

Aportar información para el ajuste e implementación del plan de mejoramiento institucional

Servir de herramienta para determinar los niveles de desempeño de los estudiantes en los campos de saber según la línea de énfasis seleccionada que permitan potencializar sus habilidades y capacidades en la educación superior

Objetivos:

Fortalecer la responsabilidad institucional para el diseño de estrategias de calidad, evaluación y promoción en el proceso educativo que desarrolla.

Establecer estrategias de evaluación, diferenciadas, acordes con los procesos y grupos de edad de los estudiantes.

Determinar pautas que orienten la solución a problemas y necesidades pedagógicas, de pertinencia y participación de la comunidad educativa en relación con la evaluación

\section{ARTICULO 4 . AMBITOS DE APLICACIÓN}


Los ámbitos de aplicación de este SIEE son los estudiantes, los docentes, directivos y padres de familia de la comunidad educativa liceísta en relación con los diversos procesos que se desarrollan en el marco del proyecto educativo.

\section{ARTICULO 5․ COMPONENTES}

El SIEE, queda constituido por los siguientes componentes:

Los criterios de evaluación y promoción.

La escala de valoración institucional y su respectiva equivalencia con la escala nacional.

Las estrategias de valoración integral de los desempeños de los estudiantes.

Las acciones de seguimiento para el mejoramiento de los desempeños de los estudiantes durante el año escolar.

Los procesos de auto-evaluación de los estudiantes.

Las estrategias de apoyo necesarias para resolver situaciones pedagógicas pendientes de los estudiantes.

Las acciones para garantizar que los directivos docentes y docentes cumplan con los procesos evaluativos estipulados en el sistema institucional de evaluación.

La periodicidad de entrega de informes a los padres de familia.

La estructura de los informes de los estudiantes, para que sean claros, comprensibles y den información integral del avance en la formación.

Las instancias, procedimientos y mecanismos de atención y resolución de reclamaciones sobre la evaluación y promoción.

Los mecanismos de participación de la comunidad educativa en la construcción del sistema institucional de evaluación de los estudiantes

\section{ARTICULO $6^{\circ}$. USO DE RESULTADOS DE EVALUACIÓN}

Los resultados de las pruebas de evaluación externas a la institución, SABER, examen de estado e internacionales y las internas, se constituyen en referentes orientadores para los procesos pedagógicos y de mejoramiento dentro de la institución. El análisis y la interpretación de sus resultados orientan a la comunidad educativa para explicar y comprender las distintas razones de las situaciones relacionadas con debilidades y fortalezas evidenciadas en los estudiantes evaluados y son parámetro de Medida del índice sintético de calidad que determinan el presupuesto asignado a la institución.

\section{ARTICULO $7^{\circ}$. CRITERIOS}


Los criterios de evaluación de los aprendizajes de los educandos en el colegio Liceo Nacional Antonia Santos en cada una de las áreas de su plan estudios y durante el año escolar, son los que determinan el perfil académico y del estudiante liceísta en cada uno de los grados.

La valoración integrada de dichos perfiles (académico y del estudiante liceísta) se expresa en una sola nota por área y también en los casos de las asignaturas establecidas, sobre la base de las 5 dimensiones del desarrollo humano:

Cognitiva: abarca todos los procesos de desarrollo de pensamiento que implica una serie de operaciones racionales como representación, análisis, síntesis, comparación, generalización, razonamiento lógico y abstracción expresados a través innovaciones, juicios críticos y formulación y resolución de problemas

Comunicativa: a nivel individual y social está vinculada estrechamente con actitudes de diálogo, concertación, conciliación y da cuenta de la habilidad para interactuar con sus pares y con ello socializar conocimientos, conceptos, expresar ideas, emociones y sentimientos y también desarrollar lenguaje oral, escrito, gráfico, gestual y capacidad de escucha, y el procesamiento de información, entre otros procesos.

Socioafectiva: procesos relacionados con la promoción de la sana convivencia, asumiendo responsablemente los derechos y deberes en su ejercicio de estudiante, identificando su propio desarrollo de manera crítica y consciente para solucionar los problemas familiares, escolares y sociales; así también los procesos que permiten reafirmar la identidad de los estudiantes, respetando las diferencias que se establecen en el grupo, para el desarrollo del sentido de justicia y tolerancia, valorando la importancia de conservar la naturaleza y el medio ambiente,

Corporal: relacionado con procesos que desarrollan el sentido lúdico, motricidad, esquema corporal, fuerza y destreza en los desplazamientos y manipulación de objetos y equilibrio

Artística: trabaja los aspectos del ámbito valorativo, creatividad, cultiva y orienta aptitudes artísticas, sentido de lo bello y armónico, posibilita captar la belleza en manifestaciones de armonía entre lo que se hace y se dice

La evaluación de cada una de las dimensiones estará determinada por escalas de desempeños asi:

\begin{tabular}{|l|l|l|l|}
\hline SUPERIOR & ALTO & BASICO & BAJO \\
de 4,6 a 5,0 & de $\mathbf{4 , 0}$ a 4,5 & de 1,0 a $\mathbf{~ 2 , 9}$ \\
\hline $\begin{array}{l}\text { Asume con alto grado de } \\
\text { responsabilidad y } \\
\text { dedicación sus } \\
\text { compromisos }\end{array}$ & $\begin{array}{l}\text { Asume con } \\
\text { responsabilidad sus } \\
\text { compromisos } \\
\text { académicos y }\end{array}$ & $\begin{array}{l}\text { En ocasiones asume } \\
\text { sus compromisos } \\
\text { académicos y } \\
\text { convivencia les de }\end{array}$ & $\begin{array}{l}\text { Asume sin mayor } \\
\text { responsabilidad y } \\
\text { dedicación sus } \\
\text { compromisos académicos }\end{array}$ \\
\hline
\end{tabular}




\begin{tabular}{|c|c|c|c|}
\hline $\begin{array}{l}\text { SUPERIOR } \\
\text { de } 4,6 \text { a } 5,0\end{array}$ & $\begin{array}{l}\text { ALTO } \\
\text { de } \mathbf{4 , 0} \text { a } 4,5\end{array}$ & $\begin{array}{l}\text { BASICO } \\
\text { de } 3,0 \text { a } 3,9\end{array}$ & $\begin{array}{l}\text { BAJO } \\
\text { de } 1,0 \text { a } 2,9\end{array}$ \\
\hline $\begin{array}{l}\text { académicos y } \\
\text { convivenciales de } \\
\text { acuerdo con su edad y } \\
\text { nivel de desarrollo }\end{array}$ & $\begin{array}{l}\text { convivencia les. de } \\
\text { acuerdo con su edad y } \\
\text { nivel de desarrollo }\end{array}$ & $\begin{array}{l}\text { acuerdo con su edad } \\
\text { y nivel de desarrollo }\end{array}$ & $\begin{array}{l}\text { y convivencia les de } \\
\text { acuerdo con su edad y } \\
\text { nivel de desarrollo }\end{array}$ \\
\hline $\begin{array}{l}\text { Presenta a tiempo sus } \\
\text { trabajos, consultas, } \\
\text { tareas y las argumenta } \\
\text { con propiedad, } \\
\text { presentando las } \\
\text { diferentes fuentes de } \\
\text { información. }\end{array}$ & $\begin{array}{l}\text { Presenta a tiempo sus } \\
\text { trabajos, consultas y } \\
\text { tareas con } \\
\text { argumentación. }\end{array}$ & $\begin{array}{l}\text { Presenta algunos de } \\
\text { sus trabajos, } \\
\text { consultas y tareas }\end{array}$ & $\begin{array}{l}\text { Pocas veces presenta sus } \\
\text { trabajos, consultas y } \\
\text { tareas }\end{array}$ \\
\hline $\begin{array}{l}\text { Alcanza todos los logros } \\
\text { sin actividades } \\
\text { complementarías y } \\
\text { aporta ideas que ayuden } \\
\text { en el proceso de su } \\
\text { mejoramiento académico }\end{array}$ & $\begin{array}{l}\text { Alcanza todos los } \\
\text { logros propuestos } \\
\text { realizando alguna } \\
\text { actividad de } \\
\text { mejoramiento y } \\
\text { complementarias . }\end{array}$ & $\begin{array}{l}\text { Alcanza los logros } \\
\text { propuestos, } \\
\text { realizando } \\
\text { actividades de } \\
\text { mejoramiento }\end{array}$ & $\begin{array}{l}\text { Presentando actividades } \\
\text { de mejoramiento no } \\
\text { alcanza los logros } \\
\text { propuestos. }\end{array}$ \\
\hline $\begin{array}{l}\text { Manifiesta un alto } \\
\text { sentido de pertenencia } \\
\text { institucional. }\end{array}$ & $\begin{array}{l}\text { Manifiesta sentido de } \\
\text { pertenencia con la } \\
\text { institución }\end{array}$ & $\begin{array}{l}\text { Algunas veces } \\
\text { manifiesta sentido } \\
\text { de pertenencia } \\
\text { institucional. }\end{array}$ & $\begin{array}{l}\text { Manifiesta bajo sentido de } \\
\text { pertenencia Institucional. }\end{array}$ \\
\hline $\begin{array}{l}\text { Asiste puntualmente a la } \\
\text { Institución y en caso de } \\
\text { inasistencia la justifica. }\end{array}$ & $\begin{array}{l}\text { Asiste a la institución, } \\
\text { pero presenta fallas } \\
\text { justificadas }\end{array}$ & $\begin{array}{l}\text { Asiste a la } \\
\text { institución, presenta } \\
\text { fallas justificadas e } \\
\text { injustificadas. }\end{array}$ & $\begin{array}{l}\text { Asiste a la institución } \\
\text { presentando fallas } \\
\text { justificadas, injustificadas } \\
\text { y retardos. }\end{array}$ \\
\hline $\begin{array}{l}\text { Manifiesta autocontrol } \\
\text { en su comportamiento y } \\
\text { en su relación con todas } \\
\text { las personas de la } \\
\text { comunidad educativa }\end{array}$ & $\begin{array}{l}\text { Manifiesta autocontrol } \\
\text { de su comportamiento } \\
\text { la mayoría de las veces } \\
\text { con todas las personas } \\
\text { de la comunidad. }\end{array}$ & $\begin{array}{l}\text { Ocasionalmente } \\
\text { manifiesta } \\
\text { autocontrol de su } \\
\text { comportamiento con } \\
\text { las personas de la } \\
\text { comunidad. }\end{array}$ & $\begin{array}{l}\text { Casi nunca manifiesta } \\
\text { autocontrol en su } \\
\text { comportamiento con las } \\
\text { personas de la comunidad. }\end{array}$ \\
\hline $\begin{array}{l}\text { Lidera procesos } \\
\text { culturales, privilegiando } \\
\text { lo democrático y } \\
\text { ambiental que estimula }\end{array}$ & $\begin{array}{l}\text { Participa en los } \\
\text { procesos culturales, } \\
\text { privilegiando lo }\end{array}$ & $\begin{array}{l}\text { Ocasionalmente } \\
\text { participa en los } \\
\text { procesos culturales, } \\
\text { privilegiando lo }\end{array}$ & $\begin{array}{l}\text { Es indiferente e interfiere } \\
\text { en los procesos culturales, } \\
\text { que privilegian lo }\end{array}$ \\
\hline
\end{tabular}




\begin{tabular}{|l|l|l|l|}
\hline SUPERIOR & ALTO & BASICO & BAJO \\
de 4,6 a 5,0 & de 4,0 a 4,5 & de $\mathbf{1 , 0}$ a 2,9 \\
\hline $\begin{array}{l}\text { la participación del } \\
\text { grupo }\end{array}$ & $\begin{array}{l}\text { democrático y lo } \\
\text { ambiental }\end{array}$ & $\begin{array}{l}\text { democrático y } \\
\text { ambiental. }\end{array}$ & $\begin{array}{l}\text { democrático y lo } \\
\text { ambiental. }\end{array}$ \\
\hline
\end{tabular}

\section{ARTICULO 8. ESCALA DE EVALUACIÓN}

La escala de valoración institucional en el colegio Liceo Nacional Antonia Santos y su respectiva equivalencia con la escala nacional queda determinada así:

En Educacion Inicial la valoración es de orden cualitativo sin escala ya que no se repueba el grado y se ve el estudiante en su proceso de aprendizaje y desarrollo hacia la escolaridad.

En Preescolar la escala de valoración es simbólica con carita feliz de 2 a 5 de ellas asì:

\begin{tabular}{|l|l|}
\hline $\begin{array}{l}\text { NO. CARITAS } \\
\text { FELICES }\end{array}$ & $\begin{array}{l}\text { DESEMPEÑO EN ESCALA } \\
\text { NACIONAL }\end{array}$ \\
\hline 5 & Superior \\
\hline 4 & Alto \\
\hline 3 & Básico \\
\hline 2 & Bajo \\
\hline
\end{tabular}

En educación básica y Media la escala de valoración es de 1.0 a 5.0 con una cifra decimal sin aproximaciones.

\begin{tabular}{|l|l|}
\hline RANGO & $\begin{array}{l}\text { DESEMPEÑO EN ESCALA } \\
\text { NACIONAL }\end{array}$ \\
\hline 4,6 a 5,0 & Superior \\
\hline 4,0 a 4,5 & Alto \\
\hline
\end{tabular}




\begin{tabular}{|l|l|}
\hline 3,0 a 3,9 & Básico \\
\hline 1,0 a 2,9 & Bajo \\
\hline & \\
\hline
\end{tabular}

\begin{tabular}{|l|l|}
\hline $\begin{array}{l}\text { Escala de valoración Colegio Liceo Nacional Antonia } \\
\text { Santos }\end{array}$ & $\begin{array}{l}\text { Equivalente de desempeño en Escala } \\
\text { Nacional }\end{array}$ \\
\hline 4,6 A 5,0 & SUPERIOR \\
\hline 4,0 A 4,5 & ALTO \\
\hline 3,0 A 3,9 & BÁSICO \\
\hline 1,0 A 2,9 & BAJO \\
\hline
\end{tabular}

Parágrafo 1: la valoración de cada área o asignatura se calculará con el promedio aritmético simple de las notas generadas en cada una de las dimensiones evaluadas y descritas en el artículo $7^{\circ}$ de este acuerdo.

Parágrafo 2. La valoración de una área conformada por varias asignaturas, estará determinada por el promedio aritmético simple de las notas generadas en cada una de ellas.

\section{ARTICULO 9. PROMOCIÓN ESCOLAR}

Un estudiante será promovido de un grado al grado siguiente en uno de los siguientes casos:

Cuando en todas y cada una de las áreas del plan de estudio ha alcanzado una valoración en el rango de 3.0 a 5.0 y ha asistido mínimo al 75\% de las horas de clases asignadas en el año escolar y de acuerdo con la intensidad horaria establecida.

Cuando en las áreas del plan de estudio ha alcanzado una valoración en el rango de 3.0 a 5.0, excepto en una de ellas y ha asistido mínimo al $75 \%$ de las horas de clases asignadas en el año escolar y de acuerdo con la intensidad horaria establecida. 
Cuando la comisión de evaluación y promoción del respectivo grado haya aprobado la promoción anticipada de acuerdo con lo establecido en el artículo $11^{\circ}$ de este acuerdo.

Cuando la Comisión de evaluación y promoción del respectivo grado haya determinado la promoción en los casos especiales.

Parágrafo 1: la promoción determinada en este SIEE se aplicará en los grados de $2^{\circ}$ a $11^{\circ}$; los grados de educación inicial tendrán evaluación y se les aplicará promoción automática.

Parágrafo 2: La comisión de evaluación y promoción (establecida por el consejo académico) de cada grado, tendrá la competencia para decidir sobre la promoción de estudiantes en los casos especiales presentados por coordinación académica y orientación.

Parágrafo 3. Los estudiantes diagnosticados con necesidades educativas especiales serán considerados casos especiales para evaluar su promoción en la comisión de evaluación y promoción del respectivo grado.

\section{ARTÍCULO 10. PERDIDA DE AREAS/ASIGNATURAS}

La pérdida de la(s) 1 área(s) o asignatura(s) se da cuando:

La nota de valoración está en el rango de 1,0 a 2,9

El estudiante deja de asistir sin justificación al 25\% o más del número total anual de horas de su intensidad horaria asignadas en el plan de estudios.

En los casos de estudiantes que al finalizar el año reprueben una o dos áreas, tendrán el derecho de presentar una prueba de suficiencia en las áreas no aprobadas, que contemplaran los contenidos del año. La nota mínima aprobatoria, de esta prueba será de 3.0.

El que pierda dos áreas y presente sus respectivas pruebas de suficiencia, y pase una de ellas será PROMOVIDO, y se modifica la nota del área aprobada.

El que pierda un área y pase la prueba de suficiencia. se modificara la nota, para efectos de su boletín y certificado del año escolar cursado.

La prueba de suficiencia la realizara el mismo docente de la asignatura o área y en caso de reclamo, la Coordinación Académica analizara la situación y asignara si es pertinente, un segundo evaluador. 
Parágrafo 1. La ceremonia de proclamación es un acto protocolario en el cual se gradúan públicamente los respectivos bachilleres, para lo cual se debe cumplir los siguientes requisitos:

Promoción del grado $11^{\circ}$

Cumplimiento de las horas establecidas para el servicio social.

Demostrar buen comportamiento durante el año escolar

Estar a paz y salvo con la institución por todo concepto.

Aprobar el área Media Fortalecida con una nota definitiva mínima promedio de 3,0 (tres coma cero), una vez termine todo el proceso académico, es decir en el segundo semestre de grado Undécimo.

Todo estudiante de grado once debe tener legalizado los documentos a 30 de Octubre del año en curso, de lo contrario NO será proclamado

\section{ARTÍCULO 11. PROMOCION ANTICIPADA.}

Es la promoción de un estudiante de un grado al siguiente cuando alcance las metas de calidad educativa con un desempeño Superior (con notas 4.0 a 5.0) en todas las áreas del plan de estudios; ocurre solamente en el transcurso del primer período del año escolar y estará determinada por la comisión de evaluación y promoción del respectivo grado. Esta planteada para estudiantes que se consideren con suficiencia académica para la promoción y los estudiantes que reprobaron el grado anterior.

Para ser promovido deben presentar pruebas de suficiencia en las todas áreas del plan de estudios y aprobarlas.

Parágrafo 1: El procedimiento para hacer solicitud de promoción anticipada es el siguiente:

Presentación de carta de solicitud dirigida a la comisión de evaluación y promoción del respectivo grado del estudiante y firmada por el padre de familia o acudiente y estudiante.

La comisión de evaluación y promoción decide sobre la promoción anticipada con comunicación escrita a coordinación y padres de familia.

El padre de familia o acudiente realiza nueva matrícula en los casos de aprobación.

Se adjunta acta a los libros de registros.

Un estudiante que obtenga promoción anticipada en grado $10^{\circ}$ desarrollará la malla de media fortalecida propuesta para grado $10^{\circ}$ en el énfasis de su elección.

\section{ARTICULO 12. ESTRATEGIAS DE VALORACIÓN INTEGRAL DE LOS DESEMPEÑOS DE LOS ESTUDIANTES}


Las estrategias con las cuales se realiza la valoración integral de los desempeños de los estudiantes son auto evaluación, coevaluacion y heteroevaluación

PARÁGRAFO 1. Competencia. La capacidad que tiene el sujeto para hacer uso de lo aprendido de manera adecuada y creativa en la solución de problemas y en la construcción situaciones nuevas en un contexto con sentido. El nivel de desarrollo de las mismas solo se percibe a través de desempeños y acciones bien sea en el campo social, cognitivo, cultural, estético o físico o artístico.

PARÁGRAFO 2. Logros. Los avances que se consideran deseables, valiosos, necesarios en los procesos de desarrollo de los estudiantes. Comprenden los conocimientos, las habilidades, los comportamientos, las actitudes y demás capacidades que deben alcanzar los estudiantes de un nivel o grado en un área determinada en su proceso de formación.

PARAGRAFO 3. Acciones de seguimiento: Actividad continua que provee información sobre el progreso del estudiante mediante la comparación de avances periódicos y objetivos definidos con anterioridad; muestra el estado actual del estudiante, identifica sus avances, logros y dificultades y sobre esta información se llevan a cabo acciones acordes con proceso que desarrolla el estudiante y a las cuales se debe hacer monitoreo para orientarles progresivamente hacia el objetivo propuesto.

PARAGRAFO 4. Autoevaluación : Es las evaluación que realiza el mismo estudiante con la cual conoce el desarrollo y alcance de su proceso de aprendizaje en relación con los objetivos trazados previamente; le permite al estudiante verificar su situación de aprendizaje y desde ellos elaborar o proponer actividades para mejorar y superar sus propias dificultades. Con ello se pretende que el estudiante sea consciente de sus propias responsabilidades, que monitoree sus aprendizajes, los juzgue, los critique y los mejore progresivamente, con lo cual desarrolla la autonomía, la autodisciplina y el autocontrol.

PARAGRAFO 5. Heteroevaluación: Evaluación que realiza el profesor o grupo de profesores y los padres sobre el estudiante con relación a su trabajo, su actuación, su rendimiento, etc.

PARAGRAFO 6. Coevaluación: Es la evaluación con responsabilidad compartida entre el docente, el grupo y los educandos sobre el proceso humano de la intercomunicación; es la retroalimentación continua que todo proceso de enseñanza aprendizaje contiene.

\section{ARTICULO $13^{\circ}$ ACCIONES DE SEGUMIENTO PARA EL MEJORAMIENTO DE LOS DESEMPEÑOS DE LOS ESTUDIANTES DURANTE EL AÑO ESCOLAR}

Con el propósito de garantizar el mejoramiento efectivo de los estudiantes en los casos que presentan dificultades para alcanzar logros establecidos, se implementarán acciones como:

Dinamizar el uso de la agenda escolar como instrumento de comunicación permanente entre los docentes y los padres de familia.

Implementar formato de plan de mejoramiento individual (diseñado por consejo académico) para que los docentes de las áreas asignen al estudiante, procesos y estrategias que serán desarrollados en la primera semana del periodo siguiente. Este instrumento se aplica a los estudiantes que hayan quedado con desempeño bajo en el transcurso de un periodo y se entrega al padre de familia 0 acudiente para que acompañe el proceso. 


\section{Las áreas serán garantes de dinamizar procesos que contribuyan a la disminución de los índices de} reprobación.

Desarrollar la escuela de padres, como estrategia de fortalecimiento del proceso educativo desde las familias.

Llevar a cabo direcciones de curso para orientar procesos de formación individual y grupal.

Dinamizar el uso de la página web del colegio para publicaciones institucionales relacionadas con los procesos de formación de los estudiantes .

Participación del padre de familia o acudiente en el proceso de formación de los estudiantes.

Compartir con el padre de familia o acudiente, período a período, la responsabilidad del plan de mejoramiento individual de los estudiantes.

La Comisión de Evaluación y Promoción respectiva revisará el cumplimiento de los compromisos inscritos entre la familia y el colegio. El eventual incumplimiento será causal para estudiar el caso sin perjuicio del derecho al debido proceso.

\section{ARTICULO 14º. PROCESO DE EVALUACIÓN}

Desde el marco que establece el PEI, el docente formulará período a período los criterios de evaluación del área/asignatura que el estudiante recibirá al inicio de cada uno de ellos para conocer oportunamente las directrices del proceso de EVALUACIÓN, permitiendo que el estudiante emita un concepto reflexivo acerca del nivel de desempeño que logró alcanzar durante el período evaluado.

El proceso de EVALUACIÓN se aplicará sobre TODAS las dimensiones definidas en este SIEE, artículo $7^{\circ}$ y en cada una de las áreas/asignaturas

\section{ARTICULO $15^{\circ}$. ESTRATEGIAS DE APOYO NECESARIAS PARA RESOLVER SITUACIONES PENDIENTES DE LOS ESTUDIANTES.}

Citación a padres de familia en todos los casos que a criterio de los docentes se consideren con méritos para ello.

Seguimiento a los procesos por parte de las coordinaciones con base en el plan de mejoramiento individual 
El plan de mejoramiento Individual de los estudiantes se desarrollara en la primera semana del periodo siguiente y la nota obtenida reemplazará la del periodo, siempre y cuando no sea inferior a la obtenida en el periodo correspondiente

4) Los alumnos que presenten necesidades especiales, serán presentados al departamento de Orientación y tendrán prioridad en los programas de apoyo que ofrezcan al colegio.

\section{ARTICULO $16^{\circ}$ ACCIONES PARA GARANTIZAR QUE LOS DIRECTIVOS DOCENTE Y DOCENTES CUMPLAN CON LOS PROCESOS EVALUATIVOS ESTIPULADOS EN EL SISTEMA INSTITUCIONAL DE EVALUACIÓN .}

Seguimiento de los procesos por parte de coordinación académica y/o de convivencia. Mantener diálogo con docentes, estudiantes y padres de familia sobre el proceso en las diferentes áreas/asignaturas.

Verificación, por parte de coordinación académica y/o de convivencia, de los instrumentos a aplicar por el docente para los procesos de evaluación,

Diligenciamiento de los formatos de seguimiento por parte de los docentes.

Entrega de informes en presencia de: estudiante, padre de familia o acudiente y docente para propiciar el diálogo y establecer compromisos sobre el proceso desarrollado y establecer acciones de mejoramiento.

Comunicación constante entre los docentes y el Comité de Evaluación y Promoción para el seguimiento de los casos en procura de alcanzar los desempeños.

Publicar y divulgar a toda la comunidad educativa el cronograma del proceso evaluativo

Documentar y registrar evidencias del proceso de evaluación en cada una de las áreas y grados

Revisión continua y seguimiento al proceso evaluativo, permitiendo ajustes y cambios

: $\quad$ 9) Entrega de plantación de áreas o asignaturas a coordinación en las fechas preestablecidas en el cronograma-

\section{ARTICULO $17^{\circ} .$. PERIODICIDAD DE ENTREGA DE INFORMES A LOS PADRES DE FAMILIA}

Los informes a los padres de familia se entregarán cada uno de los cuatro periodos y al final zar el año escolar también recibirán un informe final que incluirá una evaluación integral del rendimiento anual del estudiante en cada una de las áreas.

Parágrafo: los padres podrán recibir informes de forma personalizada de acuerdo al seguimiento realizado por cada uno de los docentes, en los horarios establecidos

ARTICULO 18 ${ }^{\circ}$. LA ESTRUCTURA DE LOS INFORMES DE LOS ESTUDIANTES PARA QUE SEAN CLAROS , COMPRENSIBLES Y DEN INFORMACIÓN INTEGRAL DEL AVANCE EN LA FORMACIÓN 


\section{TENDRAN EN CUENTA:}

Los desempeños del estudiante en las diferentes asignaturas con la descripción de las fortalezas, debilidades, acciones de mejoramiento, recomendaciones y/o observaciones.

Valoración, del desempeño según escala.

Descripción y valoración del aspecto convivencial del estudiante donde se evidencie el compromiso con la filosofía de la Institución.

Logros alcanzados, fallas y acumulados.

En básica primaria Desempeños del Padre de familia o acudiente con respecto al acompañamiento en el proceso de formación del estudiante y la descripción de las fortalezas y debilidades. Esta evaluación se realiza con la participación del Estudiante y los Docentes.

\section{ARTICULO 19. LAS INSTANCIAS, PROCEDIMIENTOS Y MECANISMOS DE ATENCIÓN Y RESOLUCIÓN DE RECLAMACIONES DE PADRES DE FAMILIA Y ESTUDIANTES SOBRE LA EVALUACIÓN Y PROMOCIÓN}

Para el estudio de circunstancias académicas es necesario establecer unos canales y unos procedimientos a través de los cuales se actúa y se toman decisiones. Se requiere en todos los casos que haya una comunicación permanente y respetuosa entre el colegio y la familia del estudiante con el fin de garantizar un adecuado seguimiento y acompañamiento de la situación presentada .

Con los estudiantes que presentan dificultades académicas y/o de convivencia se procederá de la siguiente manera:

\section{INSTANCIAS}

Docente de área/asignatura: de manera directa con el profesor de área/asignatura y en forma verbal, cada estudiante o padre de familia o acudiente tiene derecho a presentar respetuosamente reclamaciones sobre su evaluación..

Director de curso: de manera directa al director de curso y en forma verbal y escrita, cada estudiante o padre de familia tiene derecho a presentar respetuosamente reclamaciones sobre su evaluación de cualquiera de las áreas/asignaturas del plan de estudio cuando no tenga respuesta del respectivo profesor. El director de curso será un mediador entre el estudiante y el docente de área/asignatura

Coordinación académica: de manera escrita cada estudiante, padre de familia o acudiente tiene derecho a presentar respetuosamente reclamaciones sobre su evaluación de cualquiera de las áreas/asignaturas del plan de estudio cuando no tenga respuesta del profesor de la asignatura, ni con la intervención del director 
de curso. La coordinación indagará personalmente el caso con las personas involucradas y tomará decisiones para la siguiente acción

Comisión de Evaluación y Promoción: esta comisión intervendrá el caso y tomará decisiones cuando no se hayan dado soluciones en las anteriores instancias.

Consejo Directivo: como órgano de gobierno escolar es quien determina la solución final para los casos que allí se remitan

Con los estudiantes de la Media Fortalecida que presentan dificultades académicas y/o de convivencia se procederá de la siguiente manera:

Instancias:

Docente de área/asignatura.

Docente de enlace.

Coordinador académico y/o Coordinador de convivencia.

Comisión de evaluación

Consejo directivo

\section{EL DEBIDO PROCESO}

CITACIÓN A PADRES DE FAMILIA: Para informar sobre el programa de recuperación, actividades de refuerzo y plan de mejoramiento a la que haya lugar en área/asignatura en la que se presenta bajo desempeño. Esta citación es realizada por el profesor encargado del área/asignatura con presencia del estudiante para firmar seguimiento académico.

Cuando un estudiante presente desempeño bajo en una o mas asignaturas y/o esta en posibilidad de reprobar el grado el director de curso lo remitirá al departamento de orientación...

COMPROMISO CON COORDINACIÓN ACADÉMICA: cuando el plan de mejoramiento asignado por el docente no se logra a satisfacción, la coordinación académica cita a los padres con presencia del estudiante para firmar compromiso académico .

REMISIÓN A LA COMISIÓN DE EVALUACIÓN Y PROMOCIÓN: de no superar el plan dado en el caso anterior, el docente de área/asignatura presenta el caso del estudiante a la comisión de evaluación y promoción del respectivo grado/ciclo y se siguen las recomendaciones asignadas por esta comisión.

CITACIÓN A CONSEJO DIRECTIVO. agotadas todas las instancias se citará a padres de familia y estudiante para tomar decisiones al no cumplir los compromisos pactados. 


\section{ARTICULO 20․ LOS MECANISMOS DE PARTICIPACIÓN DE LA COMUNIDAD EDUCATIVA EN LA CONSTRUCCIÓN DEL SISTEMA INSTITUCIONAL DE EVALUACIÓN DE LOS ESTUDIANTES}

a) Aportes en mesas de trabajo de las instancias del gobierno escolar y otros mecanismos de participación como equipo de gestión, contraloría y personería estudiantil, consejo estudiantil, asamblea de docentes, funcionarios administrativos, consejo de padres y asociación de padres de familia.

b) Estudio, análisis y aprobación de las propuestas en jornadas pedagógicas con la participación de todos los miembros de la comunidad.

\section{Articulo 25. MEDIA FORTALECIDA}

El estudiante del Liceo Nacional Antonia Santos de la Media Fortalecida se acoge como Liceísta a los direccionamientos contemplados en el SIEE, y adicionalmente a los contemplados en el presente documento.

1.Áreas de formación en Educación Media

La Educación Media Fortalecida se considera como un área más de la formación integral de los estudiantes Liceísta que promueve el desarrollo de las dimensiones y procesos del ser humano y que será impartida a los estudiantes del nivel de educación media.

El área Educación Media fortalecida está conformada por las asignaturas de cada semestre, según la malla curricular de cada uno de los énfasis.

2.Vinculación a la Media Fortalecida

Se considera de carácter obligatorio la vinculación a una de las líneas de formación ofrecidas por la Institución en la Educación Media Fortalecida.

Parágrafo \#1: Un estudiante nuevo en grado $11^{\circ}$ que se vincule a la institución tendrá la opción de escoger uno de los énfasis ofrecidos por la institución para la media fortalecida y debe ingresar al primer semestre si no certifica estudios de media en las líneas aprobadas por el Liceo Nacional Antonia Santos .

Parágrafo \#2: Para formalizar la vinculación a cualquiera de las líneas de formación, el estudiante deberá anexar la siguiente documentación:

Diligenciar el formulario respectivo.

Fotocopia ampliada al 150\% del documento de identificación.

Fotocopia de la EPS o SISBEN. 
Fotocopia de un servicio público del lugar de domicilio.

Legajar en carpeta tamaño carta.

3.Criterios de evaluación Media Fortalecida.

\subsection{Periodos de Evaluación- Semanas de cortes:}

Cada una de las asignaturas del plan de estudios de la Educación Media Fortalecida será evaluada semestralmente en tres (3) periodos llamados cortes. Cada corte proporcionara una nota parcial cuyo valor se debe consolidar durante las semanas: sexta $\left(6^{\mathrm{a}}\right)$; décima segunda $\left(12^{\mathrm{a}}\right)$ y décima sexta $\left(16^{\mathrm{a}}\right)$

\subsection{Porcentajes de notas en cada corte de evaluación:}

Para obtener el $100 \%$ de la nota definitiva de cada asignatura al finalizar el semestre, se realizará la sumatoria de las notas parciales correspondientes a los porcentajes de cada uno de los tres cortes, los cuales están asignados de la siguiente forma: primer corte $30 \%$, segundo corte $30 \%$ y tercer corte $40 \%$.

\subsection{Procesos de evaluación:}

Los procesos de evaluación de cada una de las asignaturas, serán dados a conocer por parte del maestro al inicio del semestre y serán explícitos en los Syllabus respectivos. Los criterios de evaluación planteados dependen de las características particulares de la asignatura dados por el plan de estudio.

4.Tiempo de cambio de énfasis

El tiempo para tomar la decisión de cambio de la vinculación a uno de los énfasis de la Educación Media Fortalecida será de 2 (dos) semanas contadas a partir del inicio del programa (primer semestre del año) y se podrá realizar únicamente en el grado décimo $\left(10^{\circ}\right)$.

El estudiante deberá hacer la solicitud escrita, avalada por el acudiente, argumentando los motivos y dirigirla a la rectoría para su correspondiente estudio.

Parágrafo1 : De ser aceptado el cambio, el estudiante adquiere el compromiso de realizar de manera autónoma e independiente los procesos de nivelación con el nuevo énfasis elegido.

La escala para asignar calificaciones en las áreas del plan de estudios de la Educación Media Fortalecida está determinada desde 1,0 (uno coma cero) hasta 5,0 (cinco coma cero). 
5.Tiempo de desarrollo de asignaturas

Cada una de las asignaturas del plan de estudios de la media fortalecida tendrá un tiempo de desarrollo de dieciséis (16) semanas por semestre, contemplando dos semanas adicionales al finalizar cada uno para realizar procesos de reflexión a manera de mejoramiento frente a resultados y proyección en la Educación Media Fortalecida.

6.Aprobación de asignaturas

Para considerarse como aprobada cada una de las asignaturas del plan de estudios correspondiente a la Educación Media Fortalecida en la institución deberán cumplir con los siguientes requisitos:

Parágrafo \#1: Para las asignaturas que son susceptibles del reconocimiento de créditos académicos, por parte de la Institución de Educación Superior, la nota mínima final aprobatoria deberá ser de 3,5 (tres coma cinco).

Parágrafo \#2: Para las asignaturas de la Educación Media Fortalecida, del énfasis de Matemáticas, que configuran un mismo campo de saber y cuyo contenido se desarrolla en dos semestres académicos; tales como Algebra Lineal 1 y 2, Estadística y Probabilidad 1 y 2; la nota final será el resultado del promedio aritmético de la nota obtenida durante los dos semestres cursados.

Para la acreditación de estas asignaturas, por lo tanto, dicho promedio debe cumplir las condiciones expuestas en el parágrafo 1 del presente artículo.

Parágrafo \#3: Las asignaturas que no cumplan con lo planteado en el presente numeral, se considerarán reprobadas.

7.Aprobación del Área Media Fortalecida

Para considerarse como aprobada el área Media Fortalecida al finalizar el semestre se deberá obtener una nota definitiva mínima promedio de 3,0 (tres coma cero).

Parágrafo: La nota definitiva del área MEDIA FORTALECIDA corresponderá al promedio aritmético de la nota final de todas las asignaturas vistas en cada semestre y se reflejará en el informe académico del segundo y cuarto periodo académicos del año escolar. 


\section{PLANES DE MEJORAMIENTO}

1. Entrega a los acudientes de informes de desempeño según los cortes y al finalizar el semestre.

2. Seguimiento del proceso de cada estudiante por parte del docente de enlace líder de enlace.

3. Semana de reflexión pedagógica cuyo propósito es fortalecer los aprendizajes y mejorara los procesos formativos.

4. En todos los casos no se contempla la realización de planes de mejoramiento, nivelaciones y/o pruebas de suficiencia debido a que las Instituciones de Educación Superior no lo tienen previsto en sus políticas internas y el Liceo busca que la Educación Media Fortalecida sea lo más cercana a la formación universitaria.

\section{Periodicidad de informes}

Entrega a los acudientes de informes de desempeño según los cortes y al finalizar el semestre.

Seguimiento del proceso de cada estudiante por parte del docente de enlace líder de enlace.

Semana de reflexión pedagógica cuyo propósito es fortalecer los aprendizajes y mejorara los procesos formativos.

En todos los casos no se contempla la realización de planes de mejoramiento, nivelaciones y/o pruebas de suficiencia debido a que las Instituciones de Educación Superior no lo tienen previsto en sus políticas internas y el Liceo busca que la Educación Media Fortalecida sea lo más cercana a la formación universitaria.

10.Expedición de certificaciones Media Fortalecida

Se expedirán al finalizar el proceso de la media fortalecida, es decir, una vez culminado el proceso académico del segundo semestre de grado undécimo y una vez verificados los requisitos del proceso de cada estudiante.

Parágrafo \# 1: Cuando un estudiante de la media fortalecida se retira del colegio, el Liceo Nacional Antonia Santos le expedirá una certificación de lo cursado en la Educación Media Fortalecida. 
Parágrafo \# 2: La certificación de reconocimiento de créditos académicos de las asignaturas del plan de estudio de la media fortalecida será otorgado, por parte de la institución de Educación Superior correspondiente, una vez verificado el cumplimiento de los requisitos correspondientes.

Parágrafo \# 3: Para las asignaturas que sean aprobadas pero su nota no amerite reconocimiento de Créditos Académicos, por parte de la Institución de Educación Superior correspondiente, el Liceo Nacional Antonia Santos otorgará un certificado de asistencia.

Parágrafo \#4: Para las asignaturas que no son susceptibles de otorgamiento de créditos por parte de la Institución de Educación Superior, como aparece en las correspondientes mallas, el Liceo expedirá una Constancia de Asistencia con la correspondiente nota final obtenida.

Parágrafo \#5: Cuando el estudiante termina su proceso de formación en la Educación Media Fortalecida, el Liceo le expedirá una constancia en donde se especifican la línea de formación y el total de horas de asistencia.

\section{Conceptos}

Crédito académico: El Decreto 1295 de 2010 define el crédito académico como una unidad de medida de trabajo académico que incluyen actividades académicas propias del plan de estudio que deben ser desarrolladas por los estudiantes para aprobar un espacio académico. Un crédito académico equivale a 48 horas de trabajo académico del estudiante que incluyen trabajo dirigido por el docente, trabajo independiente, actividades de estudio, prácticas, etc

Articulo 26 Servicio Social.

El servicio social estudiantil obligatorio se llevará a cabo teniendo en cuenta lo establecido en el artículo $39^{\circ}$ del decreto 1860 del 3 de agosto de 1994 y el proyecto establecido en el P.E.I de la Institución que determinan el propósito principal y los mecanismos generales para la prestación del servicio social del estudiante, dispuesto, también lo expresado en los artículos $66^{\circ}$ y $97^{\circ}$ de la ley 115 de 1994 determina la prestación del servicio social obligatorio por los estudiantes de educación media y la resolución 4210 del 
12 de septiembre de 1996 del ministerio de educación nacional. Que establece reglas generales para su organización y funcionamiento. Por otra parte, el decreto 1743 de 1994 artículo $7^{\circ}$ expresa que los estudiantes de educación media de los establecimientos de educación formal, estatales y privados, podrán prestar el servicio social obligatorio previsto en los artículos $66^{\circ}$ y $97^{\circ}$ de la ley 115 de 1994 , en Educación Ambiental, participando directamente en los proyectos ambientales escolares, apoyando la formación o consolidación de grupos ecológicos escolares para la resolución de problemas ambientales específicos o participando en actividades comunitarias de educación ecológica o ambiental.

El servicio social estudiantil obligatorio y sus proyectos pedagógicos en el colegio Liceo Nacional Antonia Santos deberán:

Permitir la relación y correlación del desempeño académico de los educandos en las áreas del conocimiento y de la formación con su desarrollo personal y social.

Ser integrales y continuos, para que brinden una sistemática y efectiva atención a los diversos grupos poblacionales, beneficiarias de este servicio.

Constituir un medio para articular las acciones educativas del establecimiento con las expresiones culturales locales, satisfacer necesidades de desarrollo comunitario e integrar acciones adelantadas por otras organizaciones sociales, en favor de la comunidad

Atender prioritariamente, necesidades educativas, culturales, sociales y de aprovechamiento de tiempo libre, identificadas en la comunidad del área de influencia del establecimiento educativo, tales como la alfabetización, la promoción y preservación de la salud, la educación ambiental, la educación ciudadana, la organización de grupos juveniles y de prevención de factores socialmente relevantes, la recreación dirigida y el fomento de actividades físicas, prácticas e intelectuales.

El número de horas de prestación del servicio social obligatorio será de 120 ciento veinte durante el tiempo de su formación en los grados $9^{\circ}, 10^{\circ}$ y $11^{\circ}$ como requisito indispensable para la obtención del título de bachiller.

El colegio Liceo Nacional Antonia Santos asigna a los orientadores de secundaria la responsabilidad del diseño, planeación, ejecución, acompañamiento, seguimiento y control de la prestación de este servicio por parte de los estudiantes liceístas.

En el colegio Liceo Nacional Antonia Santos se concibe el servicio social estudiantil obligatorio como un componente curricular para la formación integral del estudiante, por cuanto aporta a la construcción de su identidad cultural, nacional, regional, local e institucional, así también en el contexto familiar y en la sociedad a través de la participación ciudadana. 
Los proyectos pedagógicos en los cuales el estudiante participa para cumplir este requerimiento, tienen como propósito integrarlo a la vida comunitaria, desarrollarle valores especialmente la solidaridad, la participación la protección, conservación y mejoramiento del medio ambiente, la dignidad y sentido del trabajo y del tiempo libre. 